\title{
Evaluation of surface mechanical properties of pot hardware materials in continuous galvanizing lines
}

Anand Krishnaswamy

West Virginia University

Follow this and additional works at: https://researchrepository.wvu.edu/etd

\section{Recommended Citation}

Krishnaswamy, Anand, "Evaluation of surface mechanical properties of pot hardware materials in continuous galvanizing lines" (2005). Graduate Theses, Dissertations, and Problem Reports. 4163. https://researchrepository.wvu.edu/etd/4163

This Thesis is protected by copyright and/or related rights. It has been brought to you by the The Research Repository @ WVU with permission from the rights-holder(s). You are free to use this Thesis in any way that is permitted by the copyright and related rights legislation that applies to your use. For other uses you must obtain permission from the rights-holder(s) directly, unless additional rights are indicated by a Creative Commons license in the record and/ or on the work itself. This Thesis has been accepted for inclusion in WVU Graduate Theses, Dissertations, and Problem Reports collection by an authorized administrator of The Research Repository @ WVU. For more information, please contact researchrepository@mail.wvu.edu. 


\title{
Evaluation of Surface Mechanical Properties of Pot Hardware materials in Continuous Galvanizing Lines
}

\author{
Anand Krishnaswamy \\ Thesis submitted to the College of Engineering and Mineral Resources \\ at West Virginia University in partial fulfillment of the \\ requirements for the degree of
}

\author{
Master of Science \\ In \\ Mechanical Engineering \\ Bruce. S. Kang, Ph.D., Chair \\ Thomas M. Damiani, Ph.D. \\ Kenneth H. Means, Ph.D. \\ Shalini Rangarajan, Ph.D. Candidate \\ Department of Mechanical and Aerospace Engineering
}

Morgantown, West Virginia

2005

Keywords: Hardness, Elastic modulus, Ultrasonic frequency shift, microstructure 


\title{
ABSTRACT \\ Evaluation of Surface Mechanical Properties of Pot Hardware materials in Continuous Galvanizing Lines
}

\begin{abstract}
Anand Krishnaswamy
Pot hardware in continuous galvanizing lines is subjected to harsh and corrosive environment. The application of pot hardware in such conditions can cause surface degradation of the pot hardware materials thereby decreasing their life. The surface degradation can be due to wear, decrease in hardness or change in surface elastic modulus. The 500-lb lab scale test set-up at WVU was used to simulate the conditions existing in the actual continuous galvanizing line.

Ultrasonic equipment has gained immense importance in the field of non-destructive testing. One such instrument that measures surface hardness based on the shift of an ultrasonic frequency was used for measuring the on-site hardness of pot hardware materials. The hardness measured by the instrument is also a function of the elastic modulus of the material. The change in surface elastic modulus was determined theoretically based on the governing equation for the instrument.

The change in surface hardness and elastic modulus was explained and correlated to the corresponding microstructural analyses.
\end{abstract}




\section{ACKNOWLEDGEMENTS}

I would like to thank Dr. Bruce Kang for giving me the opportunity to work under him as a research assistant and guiding me throughout the course of my thesis. His knowledge in the field of materials testing and metallurgy has inspired me a lot. I thank Dr. Thomas M. Damiani and Dr. Kenneth H. Means for serving on my committee and providing me valuable advice which led to the successful completion of this thesis.

I am thankful to Chuck Coleman and David Estep for their help in maintaining the laboratory test equipment. I would like to acknowledge the Department of Energy and WV-IOF program for providing the financial support under the grant DE-FCO7-01-ID14042.

I would like to express my deepest thanks to Venkatesh Parthasarathy, Kian Huat Tan, Ridha Kamil and Adam Ensminger for all their help and contribution during the course of this research work. I would like to thank my friends Shalini Rangarajan and Mohan Krishnamurthy for their constant support and encouragement.

I wish to thank my roommates Gopalan Arun Prasaad, Sankara Mahalingam Kannan, Satish Sridharan, Rohin Kumar Govindarajan and Srinivasan Chandrasekharan for their help and support. I am thankful to all my friends who directly or indirectly helped me in the successful completion of this thesis.

I would like to express my gratitude to my parents and sister for their love and constant encouragement, inspiring me to go after my goals and sacrificing so much for me. I dedicate my thesis to them.

Finally I would like to express my gratitude to God for providing me this opportunity to pursue higher education. 
Dedicated to my Parents and my Sister 


\section{TABLE OF CONTENTS}

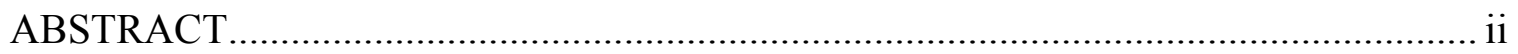

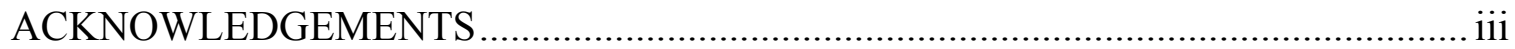

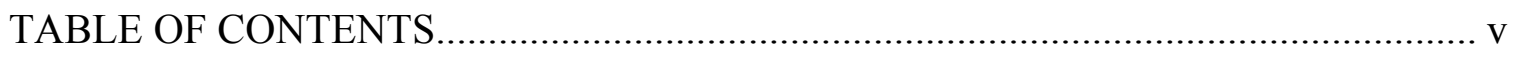

LIST OF FIGURES ….................................................................................. viii

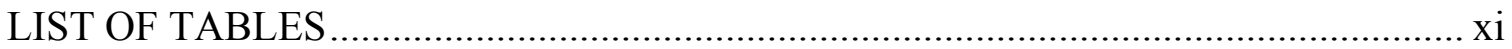

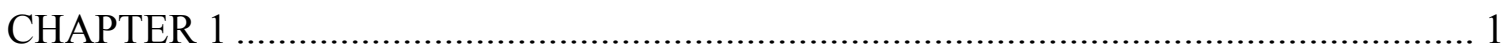

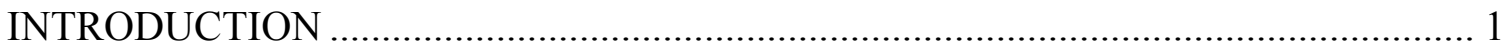

1.1 Problems Faced by Galvanizing Industries.......................................... 1

1.2 Ultrasonic Technique for Hardness Measurement.................................. 2

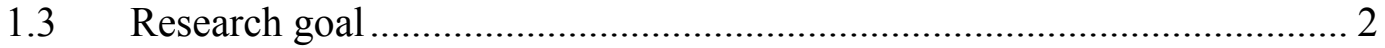

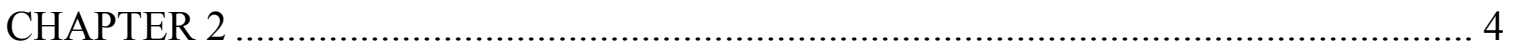

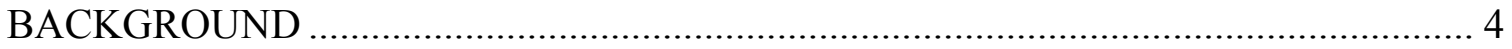

2.1 Friction and Wear Characteristics of Materials in Molten Zinc ...................... 4

2.1.1 Continuous Galvanizing Process ............................................. 4

2.1.2 Pot Hardware ...................................................................... 5

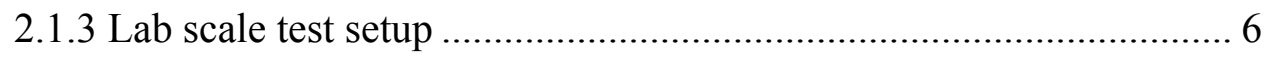

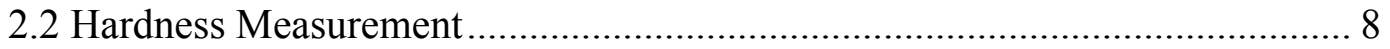


2.2.1 Conventional Methods of Hardness Measurement ............................ 10

2.2.2 Portable Hardness Testing ………………………........................ 14

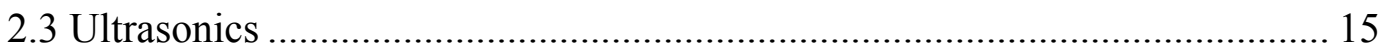

2.3.1 Ultrasonics and Non Destructive Testing ...................................... 15

2.4 Operating principle of Krautkramer MIC-10DL Portable Hardness Tester-.. 17

Ultrasonic Contact Impedance Method .......................................................... 17

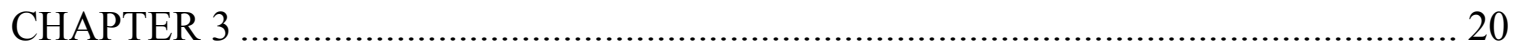

RESEARCH OBJECTIVE AND PROCEDURE ..................................................... 20

3.1 Hardness Measurement by Portable Hardness Tester (KrautkramerMIC-10

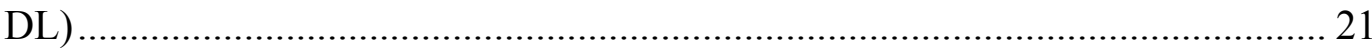

3.2 Hardness Measurement Using Newage Standard Vickers Hardness Tester... 22

3.3 Microstructure Analysis Using 'Infiniti’ Long Distance Microscope ............. 23

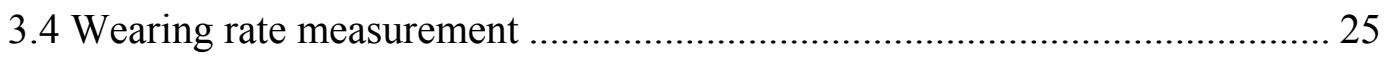

3. 5 Procedure for Examining the Degradation of Surface.................................. 26

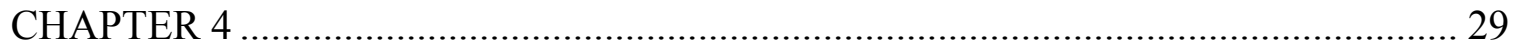

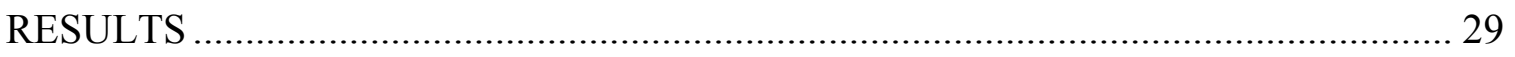

4.1 CF3M with Tungsten Carbide Coating against Vesuvius ACD Ceramics ..... 29

4.1.1 Correlation between Surface Hardness and Elastic Modulus .......... 29

4.2 Stellite 6 against Tribaloy T-400 …............................................................. 40

4.2.1 Correlation between Surface Hardness and Elastic Modulus .......... 40 


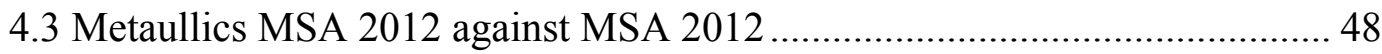

4.3.1 Correlation between surface hardness and elastic modulus........................ 48

4.4 CF3M with Tungsten Carbide ASB coating against low carbon steel ........... 54

4.4.1 Correlation between surface hardness and elastic modulus.............. 54

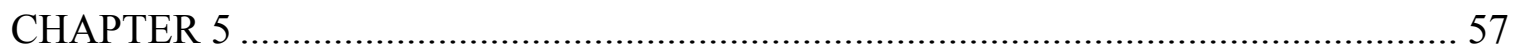

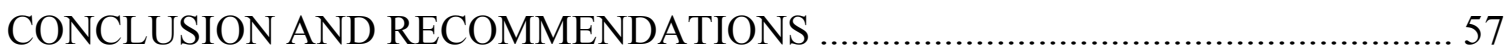

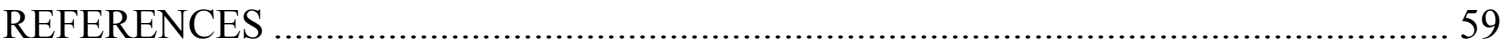

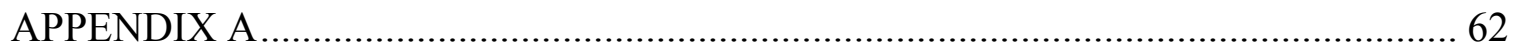

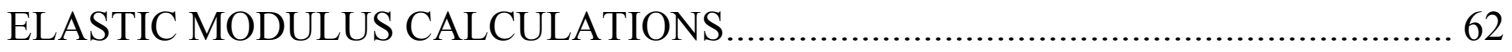

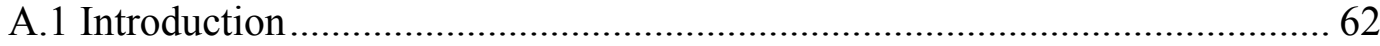

A.2 Material: 316 LS Coated with WC Laser Clad Coating ................................. 63

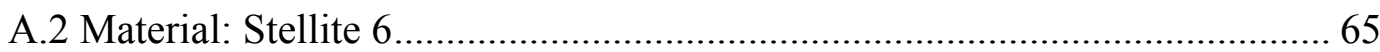

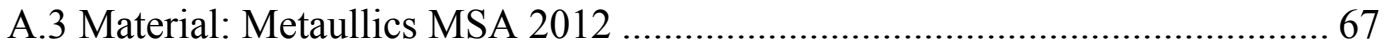

A.4 Material: CF3M with Tungsten Carbide ASB Coating ……………….......... 69 


\section{LIST OF FIGURES}

Figure 1 Schematic of Continuous Galvanizing line [1] .................................................. 4

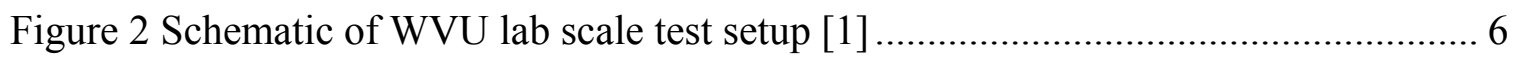

Figure 3 Wearguard test setup [1].......................................................................... 7

Figure 4 Bearing sleeve setup for stellite 6 sleeve against T-400 bushing [1] .................. 7

Figure 5 Complete test setup [1] .................................................................. 8

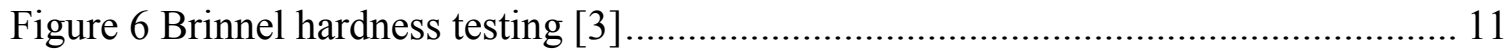

Figure 7 Standard Vickers Indentation [3] ......................................................... 13

Figure 8 Portable hardness testing using motorized probe ............................................ 15

Figure 9 Ultrasonic hardness testing [7] .............................................................. 16

Figure 10 Ultrasonic Contact Impedance principle [6]................................................ 19

Figure 11 Microstructure analysis using long distance microscope ................................ 24

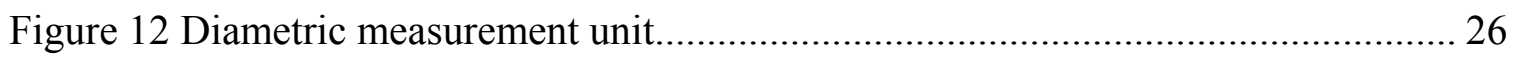

Figure 13 Hardness variation on the wearing sleeve surface......................................... 31

Figure 14 Microstructure of Tungsten carbide laser clad sleeve before the test .............. 32

Figure 15 Cracks on the wearing sleeve surface [1] .................................................. 33

Figure 16 Corrosion crack on the wearing sleeve cross section [1] …......................... 33

Figure 17 Microstructure of wearing sleeve surface showing voids left behind by WC

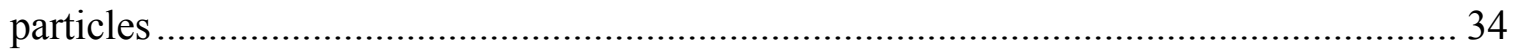

Figure 18 Density of tungsten carbide particles before polishing …………………...... 35

Figure 19 Density of WC particles after polishing ........................................................... 35

Figure 20 Ratio of elastic modulus after the test to the elastic modulus before the test as a

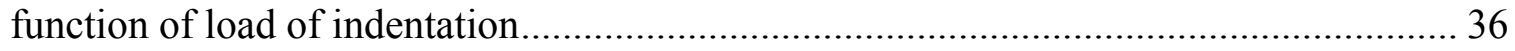


Figure 21 Density of tungsten carbide particles in the non wearing region 37

Figure 22 Indentation in the matrix region of the non wearing part of the sleeve. 38

Figure 23 Indentation on WC particle in the non wearing region ............................... 38

Figure 24 Indentation in the matrix region of the wearing part of the sleeve.................. 39

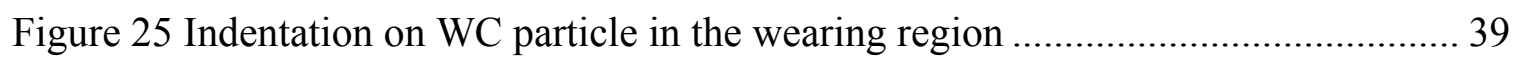

Figure 26 Hardness variation on the wearing sleeve surface..................................... 42

Figure 27 Grooves seen on Stellite 6 surface due to plowing by intermetallic particles.. 42

Figure 28 Grooves seen on Stellite 6 surface due to plowing by intermetallic particles.. 43

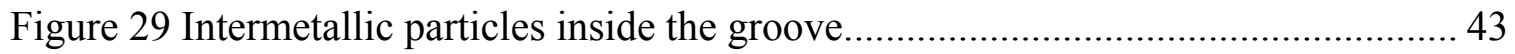

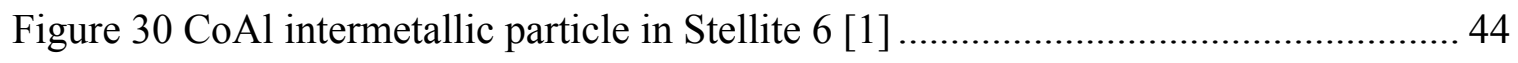

Figure 31 Cross sectional view showing depletion of cobalt near the wear surface [1]... 45

Figure 32 Cross sectional view showing an increase of cobalt further away from the

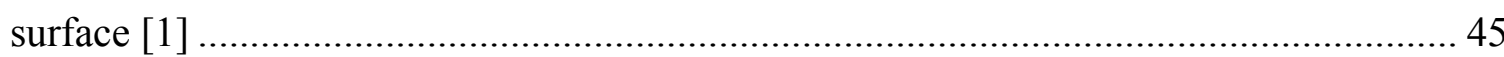

Figure 33 Cross sectional view showing actual Stellite 6 composition away from the

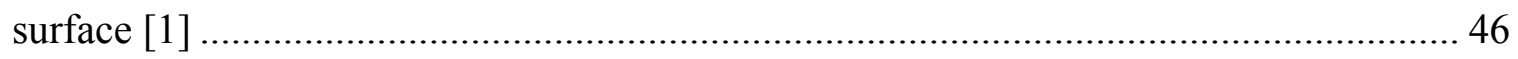

Figure 34 Ratio of elastic modulus after the test to the elastic modulus before the test as a

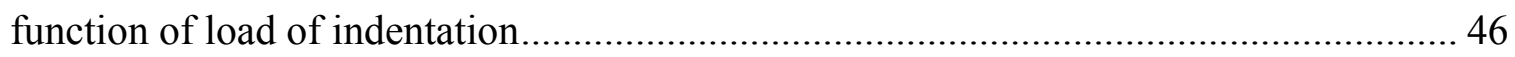

Figure 35 Hardness variation on the wearing sleeve surface...................................... 50

Figure 36 SEM cross section view of MSA 2012 sleeve.......................................... 51

Figure 37 Elemental mapping of MSA 2012 sleeve cross section ............................... 52

Figure 38 Ratio of elastic modulus after the test to the elastic modulus before the test as a

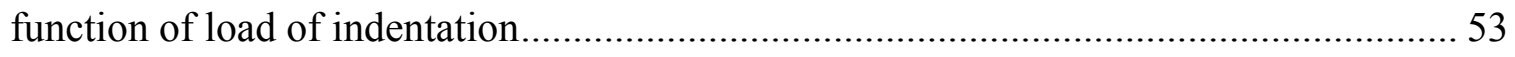

Figure 39 Hardness variation on the roll sleeve surface .......................................... 54 
Figure 40 Surface microstructure of the WC coated ASB roll surface before the test..... 55

Figure 41 Surface microstructure of WC coated ASB roll surface after the 6th cycle..... 55

Figure 42 Ratio of elastic modulus after the test to the elastic modulus before the test as a

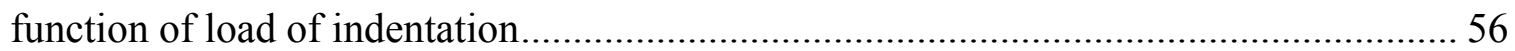




\section{LIST OF TABLES}

Table 1 Chemical composition of tungsten carbide laser clad coating........................... 29

Table 2 Lab scale test conditions for WC laser clad coating against Vesuvius ACD

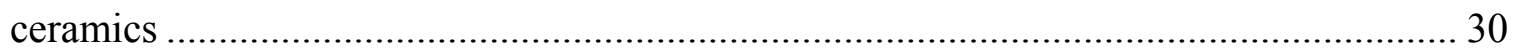

Table 3 Wearing rate on the tungsten carbide laser clad sleeve .................................. 30

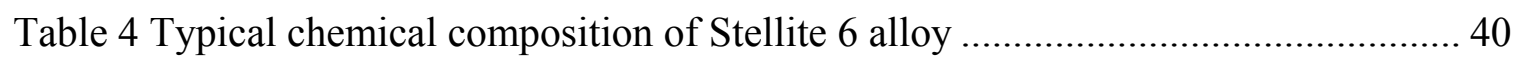

Table 5 Typical chemical composition of Tribaloy T-400 alloy .................................. 40

Table 6 Lab scale test conditions for Stellite 6 against Tribaloy T-400 ...................... 41

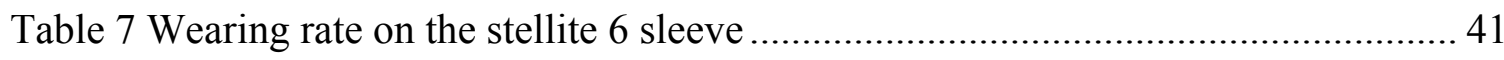

Table 8 Hardness value comparison of stellite 6 from AK steel and lab scale test ......... 47

Table 9 Typical chemical composition of MSA 2012 alloy ....................................... 48

Table 10 Lab scale test conditions for Metaullics 2012 against MSA 2012 .................. 49

Table 11 Wearing rate on the Metaullics MSA 2012 sleeve ........................................ 49

Table 12 Typical chemical composition of tungsten carbide coated ASB roll................ 54

Table 13 Hardness and frequency shift values for WC laser clad coating before the test 63

Table 14 Hardness and frequency shift values for WC laser clad coating after the test... 64

Table 15 Change of elastic modulus for WC laser clad sleeve................................... 65

Table 16 Hardness and frequency shift values for Stellite 6 sleeve before the test......... 65

Table 17 Hardness and frequency shift values for Stellite 6 sleeve after the test............ 66

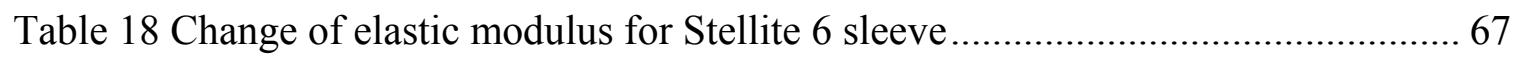

Table 19 Hardness and frequency shift values for MSA 2012 sleeve before the test ...... 67

Table 20 Hardness and frequency shift values for MSA 2012 sleeve after the test ......... 68

Table 21 Change of elastic modulus for Metaullics MSA 2012 sleeve.......................... 69 
Table 22 Hardness and frequency shift values for WC ASB coating before the test ....... 69

Table 23 Hardness and frequency shift values for WC ASB coating after the test......... 70

Table 24 Change of elastic modulus for ASB roll surface ...................................... 71 


\section{CHAPTER 1}

\section{INTRODUCTION}

\subsection{Problems Faced by Galvanizing Industries}

Most galvanizing industries in the U.S are faced with the problem of frequent line stoppage. Reliable performance of galvanizing pot hardware is critical to the productivity and quality of the coating produced. The frequent reason for line stoppage in galvanizing lines is problem related to pot hardware. This problem can occur due to

1. Performance of sink roll, stabilizer roll and deflector roll. The rolls and the supporting bearings are used to guide incoming steel strips through the zinc bath during coating process.

2. Corrosion of pot hardware materials

3. Nucleation and growth of intermetallic particles (dross) on pot hardware especially roll surfaces causing poor surface finish in strip coating.

All the above reasons can lead to a degradation of surface of pot hardware materials which can be characterized based on the wear rate, hardness change and change in elastic modulus.

A two pronged approach of improving the life of pot hardware materials is underway. The first approach focuses on the improvement of existing pot hardware materials and design. The second focuses on creating entirely new classes of pot hardware materials. 


\subsection{Ultrasonic Technique for Hardness Measurement}

Hardness is a measure of a material's resistance to local deformation caused by an indentation from a hard body. Hardness is not a fundamental property of a material, but a response to a particular test method. Hardness measurements serve as an important tool in the hands of metallurgists to research the characteristics of a material.

Conventional hardness requires the test specimen to be brought to the test device. With the advent of mobile hardness testing, this is no longer required as the hardness can now be tested on site itself. One of the main reasons for the development of mobile hardness testing is the technological strides made in the field of ultrasonic testing.

Krautkramer MIC 10 DL is one such instrument that uses the ultrasonic principles to measure hardness. Ultrasonic Contact Impedance (UCI) principle is the governing principle for the MIC 10DL hardness tester. The instrument measures the frequency shift of a resonating rod and electronically converts it to the hardness value. By doing so, the instrument not only permits in-situ hardness measurement but also removes errors in the optical measurement of indent present in standard bench hardness testers. This is because the area of indentation is no longer measured optically, but electronically by measuring the ultrasonic frequency shift. The hardness value also depends on the elastic modulus of the material. Therefore a correlation of hardness and elastic modulus is possible.

\subsection{Research goal}

The pot hardware materials used in hot dip galvanizing industries suffer surface degradation due to exposure to harsh and corrosive environments. The surface degradation can be in the form of wear, drop in surface hardness, and change in surface stiffness or a combination of these. The wearing rate is considerably affected by the 
change in hardness and surface stiffness. It is therefore important that these changes be studied in order to accurately predict and expedite the life of pot hardware. Microstructure pictures using long distance microscopes as well as Scanning Electron Microscopes are used as tools to look for degradation of surface. The pictures provide valuable information regarding the microstructural changes taking place in the material and also serve as a valuable tool in explaining the wearing rate, hardness change and change in elastic modulus.

The goal of this thesis is to evaluate the surface mechanical properties of selected pot hardware materials by explaining the changes in the material properties with the help of microstructure pictures. 


\section{CHAPTER 2}

\section{BACKGROUND}

\subsection{Friction and Wear Characteristics of Materials in Molten Zinc}

\subsubsection{Continuous Galvanizing Process}

During continuous hot dip galvanizing process, molten zinc is applied onto the surface of steel sheet as it is passed through the molten bath at a predetermined speed. When inside the bath, the steel reacts with the molten zinc to form a coating on the steel surface .The excess coating sticking on the sheet surface is shaved off using gas knives.Figure1 shows the schematic of continuous galvanizing line.

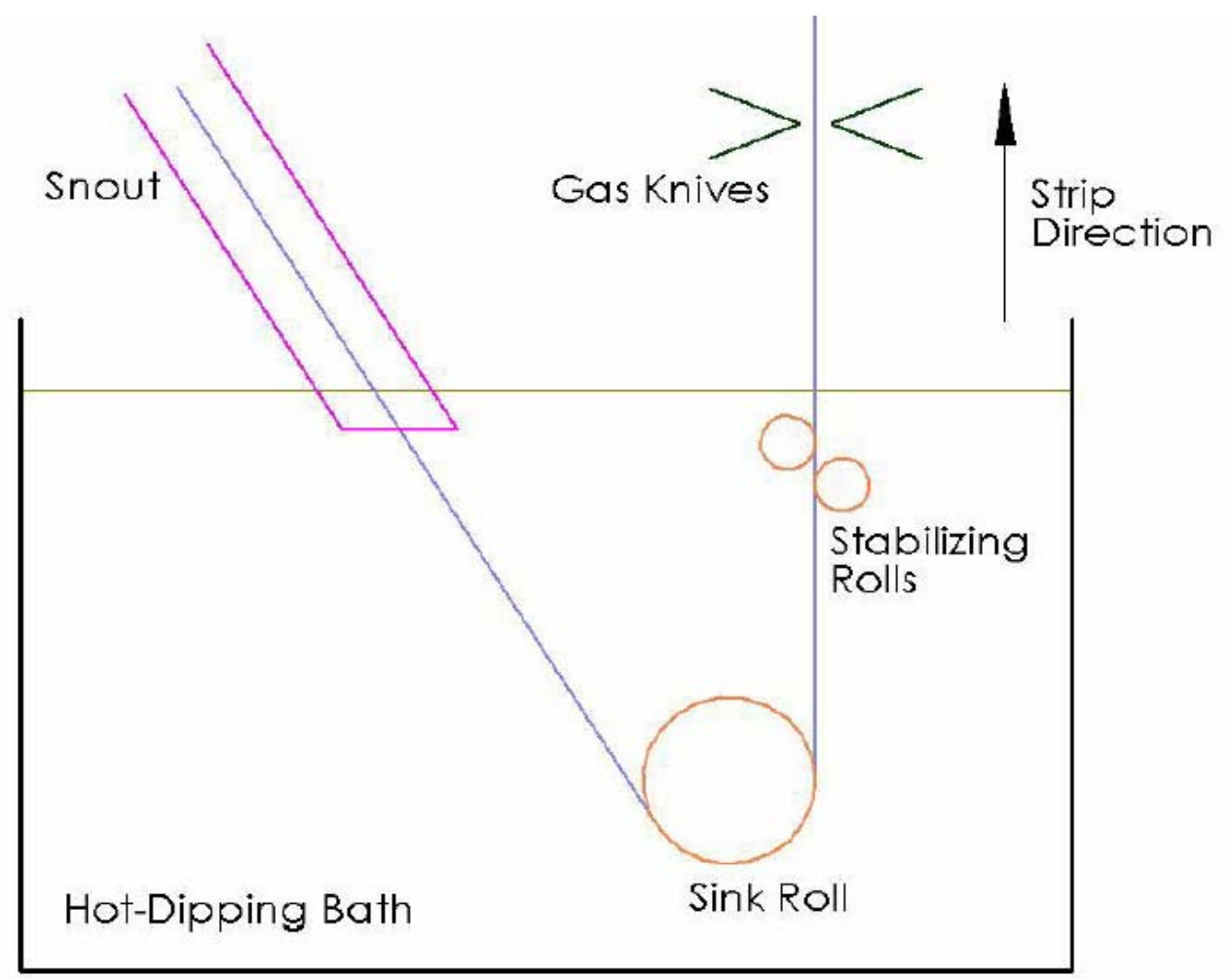

Figure 1 Schematic of Continuous Galvanizing line [1] 
Galvanizing industries are trying to improve the coating quality due to the increased use of galvanized sheet for numerous applications. The degradation of pot hardware materials namely rolls, journals and bearings lead to excessive strip vibration in the coating process and cause poor surface finish [2]. Many studies have been conducted on the pot hardware materials to study factors governing the failure of these materials in molten zinc. Efforts are made to find new materials with good wear resistance, less surface degradation and which are non-wettable in molten zinc.

\subsubsection{Pot Hardware}

\section{Sink Roll}

Sink rolls are employed to guide the steel sheet through the molten zinc bath. Typical material used for sink rolls in production line is CF3M with thermal spray tungsten carbide coating. New materials have been developed for roll bearing such as Oak Ridge National Lab alloy 4-2 (ORNL alloy 4-2).

\section{Bearing Sleeve \& Bushing}

Bearing sleeve at the end of the sink roll rotate inside the sleeve bushing. Typical materials used for the bearing sleeve are Stellite 6, CF3M (cast version of 316 stainless steel) with tungsten carbide laser cladding, Tribaloy T-800, Tribaloy T-400 and Metaullics MSA 2012 and MSA 2020. These sleeves are run against appropriate bushing materials inorder to get maximum efficiency. Typical bearing sleeve and bushing assembly used in production lines are Stellite 6 sleeve against half moon Stellite 6 bushing, CF3M with tungsten carbide laser cladding against Vesuvius ACD ceramic, 
Tribaloy T-800 sleeve against half moon Tribaloy T-800 bushing and Metaullics 2012 sleeve against Metaullics 2012 self aligning bushing.

\subsubsection{Lab scale test setup}

The actual conditions existing in the continuous galvanizing lines were simulated in the lab scale test setup in WVU. A schematic representation of the test setup is shown in figure 2.

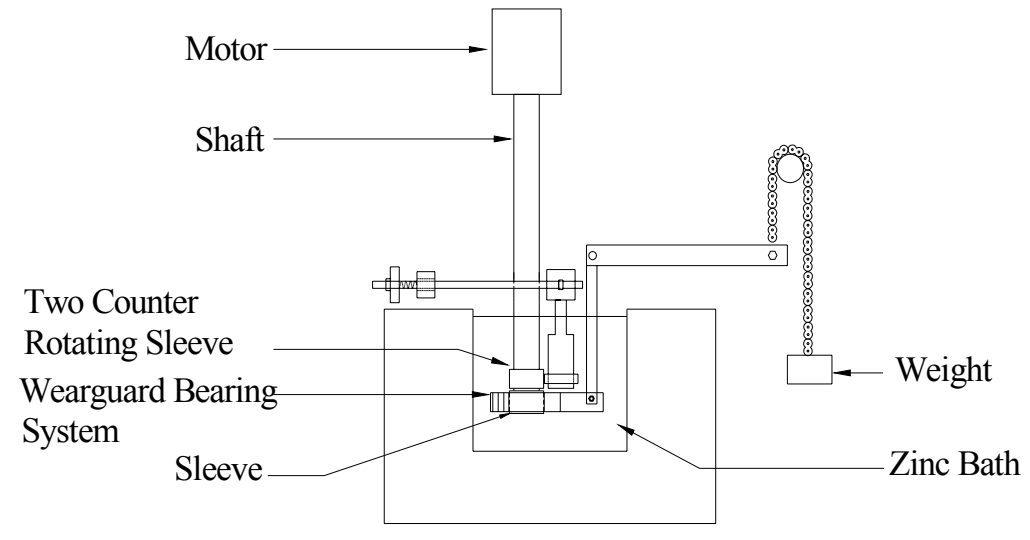

Figure 2 Schematic of WVU lab scale test setup [1]

The setup basically consists of a shaft attached to a motor. Two sleeves are spot welded onto the shaft. The top shaft is the roll sleeve. The roll sleeve rotates against a low carbon steel shaft. The low carbon steel shaft rotates in a high temperature bearing. The tension between the roll and the steel shaft is maintained using springs. The bottom sleeve is the bearing sleeve. The bearing sleeve is run against the appropriate bushing material. A pre calculated load is applied using dead weights attached to a lever arm. The arrangement of roll sleeve and bearing sleeve for the Vesuvius wearguard system is shown in figure 3 . 


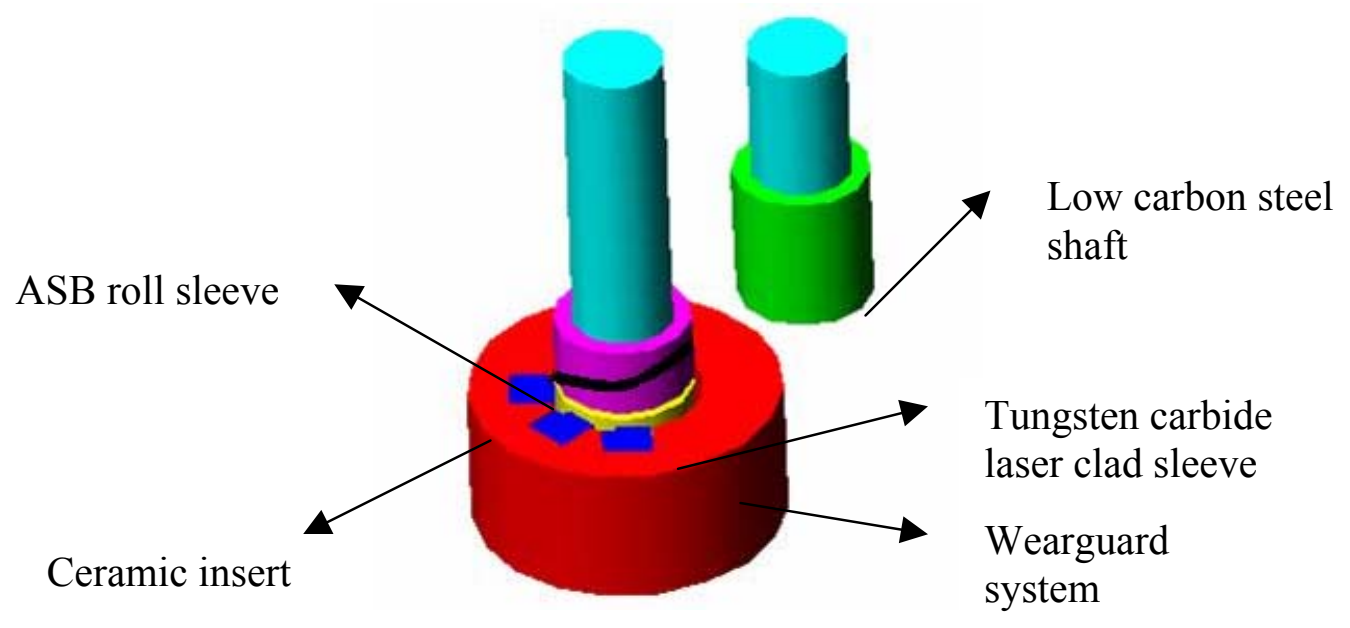

Figure 3 Wearguard test setup [1]

The setup consists of a bushing housing three ceramic inserts. The inserts rub against the laser cladded tungsten carbide sleeve. The initial line contact between the inserts and the sleeve turns into an area contact as the test proceeds.

The arrangement of stellite 6 bearing sleeve and Tribaloy T-400 bushing for is shown in figure 4.

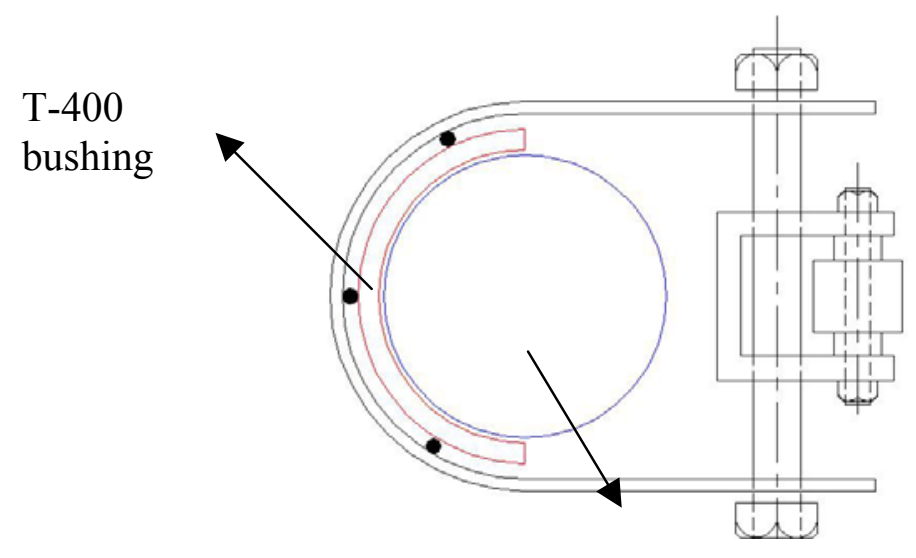

Stellite 6 sleeve

Figure 4 Bearing sleeve setup for stellite 6 sleeve against T-400 bushing [1] 
The complete test setup including the dross built up test setup is shown in figure 5 .

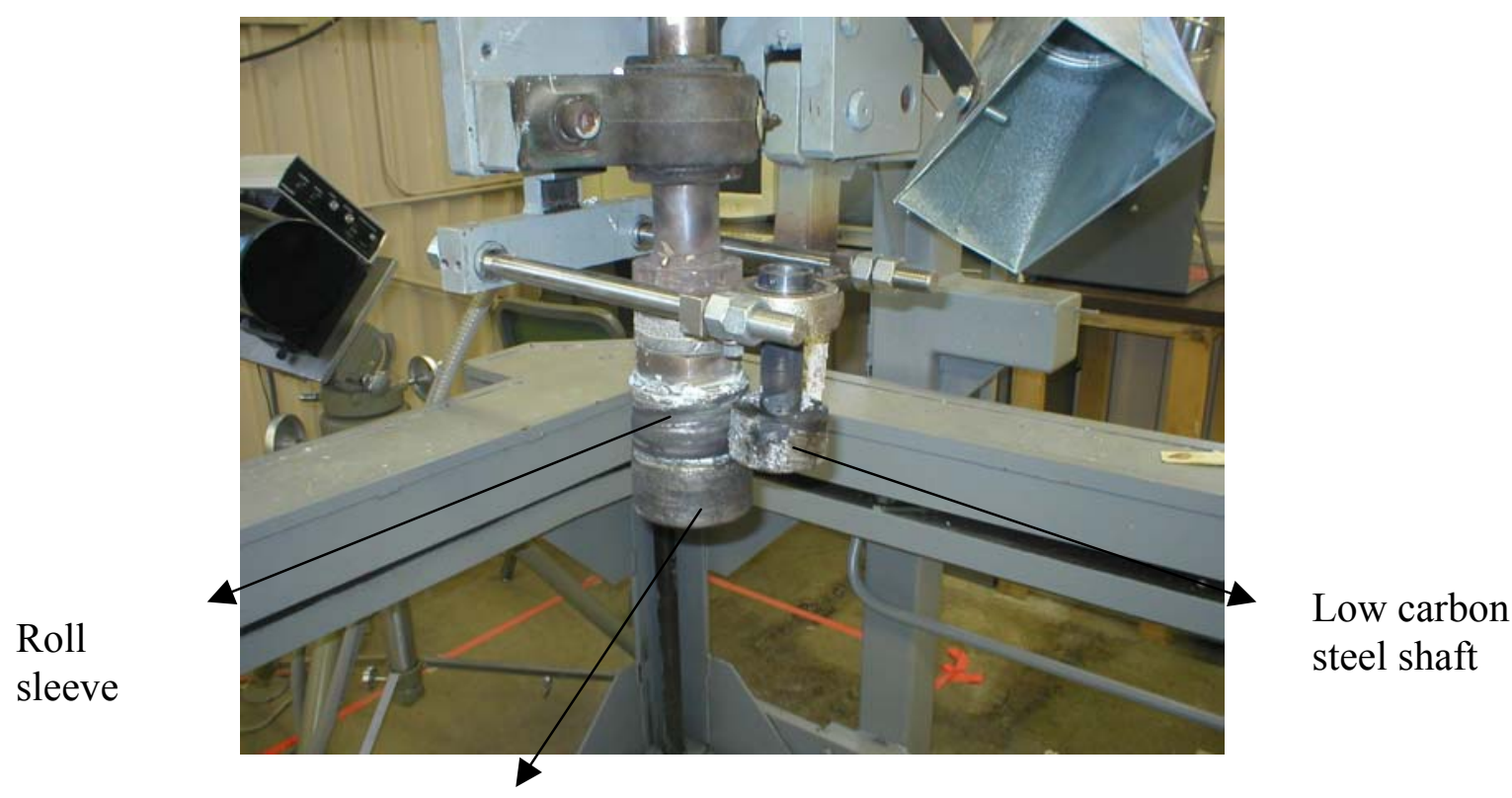

Bearing sleeve

Figure 5 Complete test setup [1]

\subsection{Hardness Measurement}

The definition of hardness is context dependent. The Metals Handbook defines hardness as "Resistance of metal to plastic deformation, mainly by indentation" [3]. But the term hardness can also be defined as stiffness or temper or to resistance to scratching, abrasion, or cutting. Simply put, hardness can be defined as the ability to resist being permanently deformed when a load is applied. The greater the hardness of the metal, the greater resistance it has to deformation.

In metallurgy hardness is defined as the resistance of a material to indentation [3]. In this type of hardness test, a pointed or rounded indenter is pressed into a surface under a substantially static load. 
Hardness measurement can be classified as macrohardness, microhardness or nanohardness scale according to the magnitude of forces applied and the amount of deformation obtained.

Macro-hardness of materials has proved to be a fast and easy method of obtaining mechanical property data for the bulk material from a small sample. However, when we are required to measure the hardness of coatings and surfaces subjected to friction and wear, the macro-indentation depth would be too large relative to the surface-scale features. When hardness of materials with fine microstructure has to be measured, macro hardness measurement fails. This is because the variation in hardness will be high and individual surface features cannot be identified. It is here that micro-hardness measurements become extremely useful.

Microhardness of a material is determined by forcing an indenter such as a Vickers or Knoop indenter into the surface of the material from 15 to 5000 gram force load. The small indentations thus produced are measured using a microscope. Micro hardness can be used to determine hardness of different micro constituents within a structure. Microindenters work by pressing a tip into a sample and continuously measuring applied load, penetration depth and cycle time [4].

Nano-indentation is considered the future of hardness testing [4]. The method is mostly employed for measuring hardness of thin films and coatings. In this, hardness is measured by indentation using very small forces of the order of 1 nano-newton and then measuring the depth of indentation. The indentation forces are precisely controlled using nano movers and the indentation depths are calculated precisely. 


\subsubsection{Conventional Methods of Hardness Measurement}

There are mainly three types of tests used for measuring the hardness of metals; they are the Brinell hardness test, the Rockwell hardness test, and the Vickers hardness test. These hardness tests measure a metal's hardness by determining the metal's resistance to the penetration of a non-deformable ball or cone. The hardness is measured by determining the depth to which such a ball or cone will sink into the metal, under a given load, within a specific period of time. The followings are the most common hardness test methods used today:

\section{Rockwell Hardness Testing}

The principle of Rockwell Hardness test is based on the net increase in depth of impression as a load is applied. In the Rockwell method of hardness testing, the depth of penetration of an indenter under certain arbitrary test conditions is determined. The method uses either a steel ball indenter of some specified diameter or a brale which is a spherical diamond-tipped cone of $120^{\circ}$ angle and $0.2 \mathrm{~mm}$ tip radius. The type of indenter and the test load determine the hardness scale (A, B, C, etc).

A minor load of $10 \mathrm{~kg}$ is first applied, which causes an initial penetration and holds the indenter in place. Then, the dial is set to zero and the major load is applied. The major load causes a permanent deformation. After the load is removed, the depth reading is taken while the minor load is still on. The hardness number is then read directly from the scale [3]. 


\section{Brinell Hardness Testing}

Brinell hardness uses a hard steel or carbide sphere of a specified diameter under a specified load for making an indent on the surface of a material and measuring the diameter of the indentation left after the test. The Brinell hardness number is obtained by dividing the load used, in kilograms, by the actual surface area of the indentation, in square millimeters.

In Brinell hardness tester a desk top machine is used to press a $10 \mathrm{~mm}$ diameter, hardened steel ball into the surface of the test specimen. The machine applies a load of 500 kilograms for soft metals such as copper, brass and thin stock. A 1500 kilogram load is used for aluminum castings, and a 3000 kilogram load is used for harder materials such as iron and steel. The loading time varies from 10 to 15 seconds. After the impression is made, a measurement of the diameter of the resulting round impression is taken. It is measured to plus or minus $.05 \mathrm{~mm}$ using a low-magnification portable microscope. Figure 6 shows the schematic of Brinnel hardness testing.

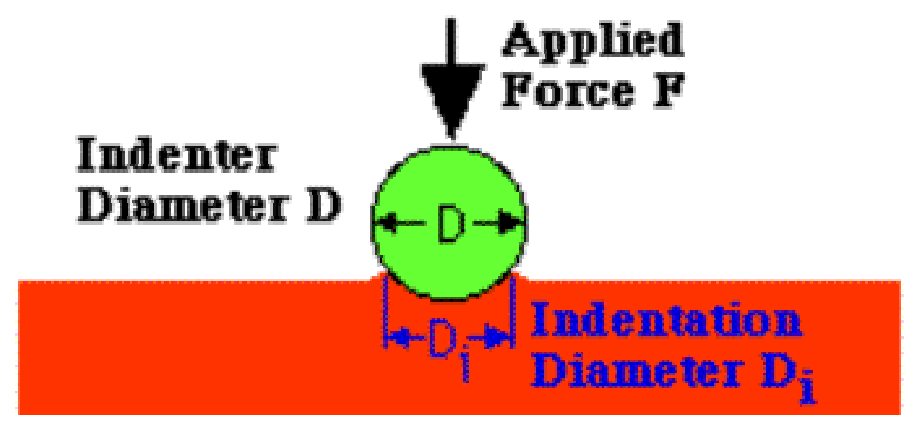

Figure 6 Brinnel hardness testing [3] 


$$
\begin{aligned}
& B H N=\frac{F}{\frac{\pi}{2} D\left(D-\sqrt{D^{2}-D_{i}^{2}}\right)} \ldots . \\
& \mathrm{BHN}=\text { Brinnel hardness number } \\
& \mathrm{F}=\text { Force applied } \\
& \mathrm{D}=\text { diameter of the ball indenter } \\
& \mathrm{Di}=\text { indentation diameter }
\end{aligned}
$$

\section{Vickers Hardness Testing}

Vickers hardness testing is a standard method employed for measuring the hardness of metals with hard surfaces. A pyramid shaped diamond indenter is used to apply a standard pressure for a standard length of time on the surface. The diagonal of the resulting indention is measured under a microscope and the Vickers Hardness value is calculated from an empirical formula.

The Vickers indenter is a square-based pyramid whose opposite sides meet at the apex at an angle of $136^{\circ}$. The diamond is pressed into the surface of the material at loads ranging up to approximately 120 kilograms-force, and the size of the impression is measured with the aid of a calibrated microscope [5]. The Vickers number (HV) is calculated using the following formula:

$\mathrm{HV}=1.854\left(\mathrm{~F} / \mathrm{D}^{2}\right)$ (2.2) where 
$\mathrm{F}$ is the applied load (measured in kilograms-force) and $\mathrm{D}^{2}$ the area of the indentation (measured in square millimeters). Vickers hardness value has a meaning only when the load is specified.

The Vickers test is reliable for measuring the hardness of metals, and can also be used on ceramic materials. Figure 7 shows the schematic of a standard Vickers indentation.

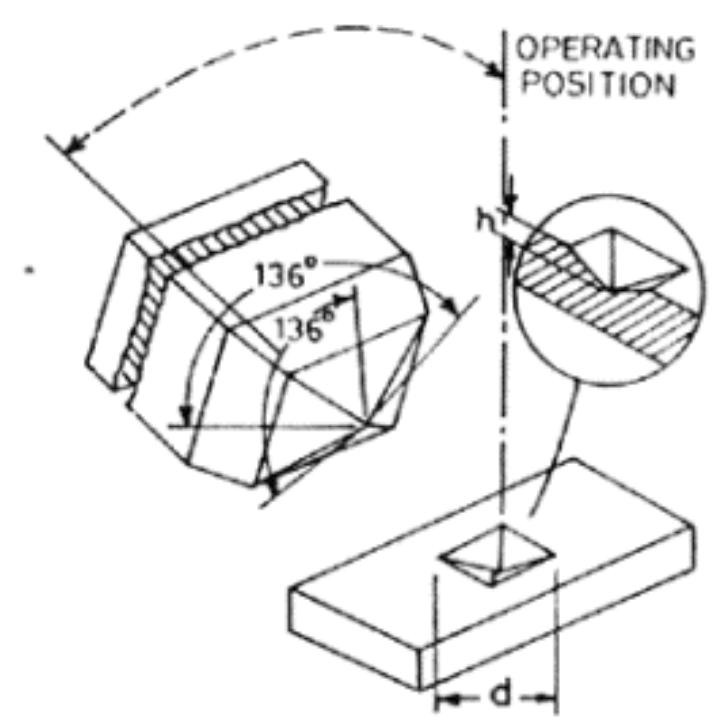

Figure 7 Standard Vickers Indentation [3]

\section{Knoop Hardness}

In a knoop hardness test, a pyramid-shaped diamond indenter with apical angles of $130^{\circ}$ and $172^{\circ} 30^{\prime}$ is pressed against a material. The resulting impression is a thombohedran with one diagonal seven times longer than the other. The hardness of the material is determined by the depth to which the Knoop indenter penetrates [3]. 
The Knoop test allows the hardness testing of brittle materials such as glass and ceramics.

The final Knoop hardness (HK) is derived from the following formula:

$\mathrm{HK}=14.229\left(\mathrm{~F} / \mathrm{D}^{2}\right)$ (2.3) where

$\mathrm{F}$ is the applied load (measured in kilograms-force) and $\mathrm{D}^{2}$ the area of the indentation (measured in square millimeters).

\subsubsection{Portable Hardness Testing}

Mobile hardness testing is the latest trend in hardness measurement. It plays an important role when hardness has to be found out on large geometry parts and positions which are difficult to access. The test piece need not be cut and brought to the hardness tester instead; the hardness can be measured on the site itself [6].

The portable hardness tester measures the frequency shift of a resonating rod having a Vickers-diamond tip. The frequency shift occurs when the diamond penetrates into the test material by applying a specific test load. The frequency shift is evaluated, electronically converted and displayed as a hardness value on an LCD. The principle is called the Ultrasonic Contact Impedance (UCI) principle. Figure 8 shows hardness measurement using portable hardness tester. 


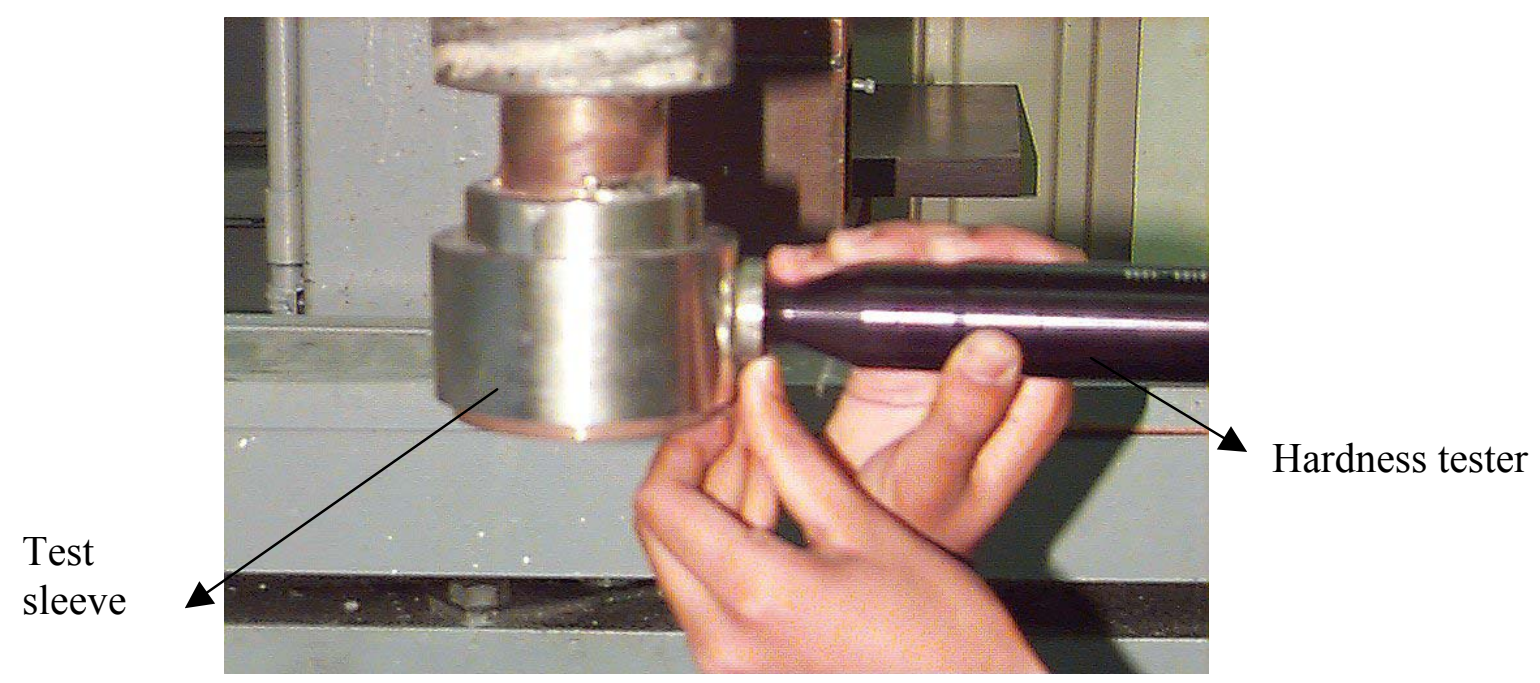

Figure 8 Portable hardness testing using motorized probe

\subsection{Ultrasonics}

Ultrasonics is the branch of physics that deals with the application of high frequency sound waves usually above $20 \mathrm{KHz}$ [7]. Ultrasonic waves are produced by generators which transform alternating current into mechanical vibrations.

Detection and measurement of ultrasonic waves is accomplished mainly through the use of piezoelectric receivers or by optical means. The latter is possible because ultrasonic waves are rendered visible by the diffraction of light.

Application of Ultrasonic waves are numerous and varied. It finds application in cutting, cleaning, nondestructive testing (NDT) to name a few.

\subsubsection{Ultrasonics and Non Destructive Testing}

Nondestructive testing has been practiced for many decades, gaining importance due to rapid developments in instrumentation triggered by the technological advances that occurred during World War II and the subsequent defense effort. Among the techniques that have been developed are eddy currents, x-rays, dye penetrants, magnetic particles 
and ultrasonics.Ultrasonics is particularly attractive among the various techniques because it can be applied to most materials and it can be used to investigate imperfections on the surface as well as on the interior.

Ultrasonic testing uses sound waves to detect imperfections in material and to measure material properties. The pulse echo method is the most commonly used ultrasonic testing technique, wherein sound is introduced into a test object and echoes returned to a receiver from internal imperfections or from the part's geometrical surfaces are analyzed. Defects and other internal irregularities result in changes in the echo pattern from the waves.

In materials science, ultrasonic applications include the determination of such properties of solids as elasticity, compressibility, porosity. Goals can range from the determination of fundamental microstructural characteristics such as grain size, porosity and texture (preferred grain orientation) to material properties related to such failure mechanisms as fatigue, creep, and fracture toughness. Figure 9 shows the schematic of an ultrasonic hardness tester.

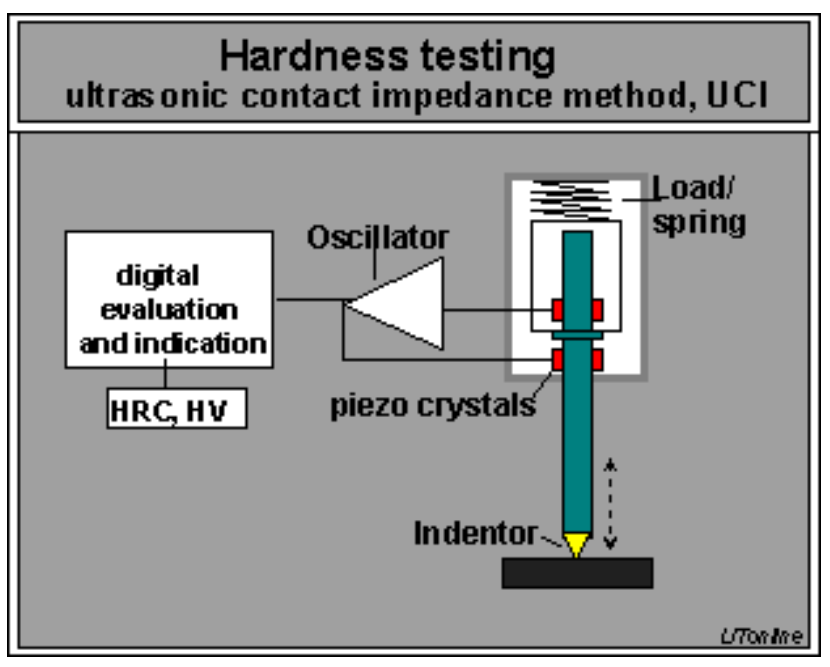

Figure 9 Ultrasonic hardness testing [7] 


\subsubsection{Ultrasonic Wave Attenuation and Material Microstructure}

When sound travels through a medium, its intensity diminishes with distance [7]. This can be due to scattering or absorption. NDT handbook defines attenuation as the loss of acoustic energy when an ultrasonic wave travels from one point to another [7]. This loss may be caused by absorption, scattering or other material characteristics. Basically the sound attenuation increases with an increase in the frequency.

The ultrasonic wave propagation is influenced by the microstructure of the material through which it propagates. The velocity of the ultrasonic wave depends upon the elastic modulus and the density of the material which in turn depends on the surface degradation [8]. Surface degradation influences ultrasonic wave properties and its measurement.

Studies have also shown that an inverse relationship exists between sound velocity and hardness [9].Moreover, attenuation is found to be greater in softer microstructure than in the case of samples having harder microstructure [9].Summing up, the greater the frequency shift more is the attenuation and lesser is the hardness.

\subsection{Operating principle of Krautkramer MIC-10DL Portable Hardness Tester- Ultrasonic Contact Impedance Method}

In the conventional Vickers hardness tester, the indentation area is evaluated optically by means of a microscope. The Krautkramer MIC-10DL portable hardness tester evaluates the area of indentation electronically by measuring the ultrasonic frequency shift.

A UCI probe typically consists of a Vickers diamond attached to the end of a metal rod. Piezoelectric transducers are used to oscillate the rod longitudinally at about $70 \mathrm{kHz}$. To comprehend the UCI principle, the metal rod can be thought of as a large spiral spring held at the end and oscillating at a resonant frequency of $70 \mathrm{kHz}$ at the free end [6]. 
At the very top of this spring (contacting end) there is a contact plate which is the Vickers diamond. The test material, can be imagined as being a system of smaller spiral springs positioned vertically to the surface .This can be imagined like an atomic bonding with two atoms inter connected by means of a "spring". When the probe is used on a hard material, only one of these "atomic springs" is touched by the Vickers diamond and the diamond only slightly penetrates and thus produces a small indentation. For less harder materials, the diamond penetrates deeper and an additional spring is touched. So an additional mass is coupled to the large spiral spring. By doing this, the resonant frequency shifts due to this additional mass or spring.

This frequency shift will become greater when additional "springs" are touched, that means if the diamond penetrates deeper into a material of medium hardness, and the test indentation becomes larger. Analogously, the largest frequency shift is produced by soft test materials; the diamond penetrates deeper into the material and leaves a large indentation. So the frequency shift is proportional to the size of the test indentation produced by the Vickers diamond. Figure 10 shows the working principle of the Krautkramer portable hardness tester. Equation below describes this basic relation in comparison to the definition of the Vickers hardness value.
$\Delta \mathrm{f} \approx \mathrm{E} X \sqrt{\mathrm{A}}$
(2.4) where
$\Delta \mathrm{f}=$ Frequency shift
$\mathrm{E}=$ Elastic modulus of the test specimen
$\mathrm{F}=$ Force applied 
$\mathrm{A}=$ Area of indentation

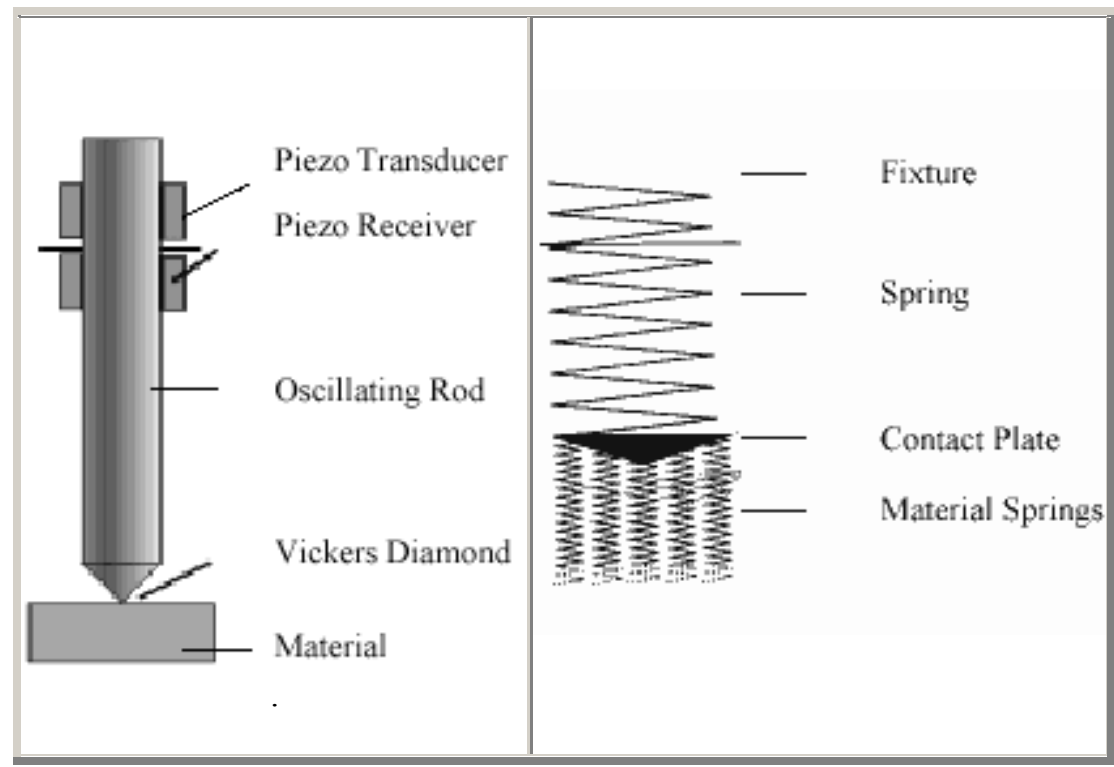

Figure 10 Ultrasonic Contact Impedance principle [6]

To carry out the UCI principle, a probe containing a rod with a Vickers diamond attached to the contact end is resonated by piezoelectric ceramics at an ultrasonic frequency.

A spring applies the load and the frequency of the rod changes in proportion to the contact area of the indentation produced by the Vickers diamond. Therefore the hardness value is not optically determined by measuring the diagonals of the indent, but by an electronic measurement of the frequency shift. The instrument constantly monitors the frequency, relates the shift of frequency to the hardness, performs the calculation and instantaneously displays the hardness value.

The frequency shift nevertheless also depends on the modulus of elasticity, which is a material constant [6]. For the practical application of the UCI method, the elastic modulus therefore has to be considered. The instrument is calibrated when the hardness of different materials with different elastic modulus has to be determined. 


\section{CHAPTER 3}

\section{RESEARCH OBJECTIVE AND PROCEDURE}

The objective of this research is to evaluate the surface mechanical properties of selected pot hardware materials used in continuous galvanizing lines. Hardness and elastic modulus changes are suspected to be related to surface degradation. That is, more the surface degradation, lesser the surface hardness and more is the change in elastic modulus. A completely unique instrument which works on the ultrasonic principle was used to conduct the surface micro hardness measurements. The instrument differed from the conventional hardness testers in two aspects. Firstly, the area of indentation was measured electronically by measuring the shift of ultrasonic frequency as opposed to optically, which is the case in conventional hardness testers. Secondly, the hardness value also depends on the surface stiffness or the surface elastic modulus. So the displayed hardness values are pseudo hardness values which incorporate the effect of change in surface conditions. The frequency shift can be read using a serial cable connected to the computer. The extent of change in surface conditions can be found out if the change in surface stiffness can be found at various depths. It was proposed to use different indenters which applied loads of $0.3 \mathrm{Kgf}, 0.8 \mathrm{Kgf}, 1 \mathrm{Kgf}$ and the $5 \mathrm{Kgf}$. For the same hardness value, the $0.3 \mathrm{Kgf}$ probe gives the least depth of indentation and the $5 \mathrm{Kgf}$ probe gives the highest depth of indentation. The surface conditions can be found out by examining the microstructure pictures taken using an in situ long distance microscope and a Scanning electron microscope. Possible corrosion attacks on the surface of pot hardware materials by the bath elements were also studied. 


\subsection{Hardness Measurement by Portable Hardness Tester (KrautkramerMIC-10 DL)}

Krautkramer MIC-10 DL is a unique instrument that measures the hardness value electronically by measuring the shift of an ultrasonic frequency. The frequency shift is dependent on the area of indentation and the elastic modulus of the material.

The Krautkramer MIC 10 DL hardness tester is calibrated for stainless steels and other alloyed steel. But it has to be calibrated before using it on non ferrous alloys. Calibration was done by doing a series of indentation on the desired test specimen and then adjusting the value to the actual hardness value obtained using standard hardness testers.

Before the start of the test, the hardness of the test sleeve was measured using the standard Vickers hardness tester. A series of indentations were then made on the selected area of the fresh test specimen using the Krautkramer Vickers indenter. After adjusting the average displayed value to the standard hardness value, the instrument can be used to measure the hardness of that particular material of the sleeve. So the instrument has to be calibrated for each test material being tested.

After calibration, the $5 \mathrm{kgf}$ loading indenter was first attached to the instrument and a series of 5 measurements taken. The serial cable attached to the computer reads the frequency shift corresponding to each indentation. The average values of both the readings were noted down. The indenter was then replaced by a $1 \mathrm{kgf}$ loading indenter and the procedure was repeated. Similarly the $0.8 \mathrm{kgf}$ and $0.3 \mathrm{kgf}$ loading indenters were also used. The idea of using different indenters was to detect any surface degradation that may have occurred during the test. Surface degradation is usually characterized by loss of surface stiffness or a change in surface elastic modulus. After the end of first test cycle, the predetermined original area was cleaned using muriatic acid. Once the zinc layer has 
been washed off, the hardness procedure was repeated using the different loading indenters.

\subsection{Hardness Measurement Using Newage Standard Vickers Hardness Tester}

Newage standard hardness tester was useful in doing hardness testing on fresh test specimens for the calibration of Krautkramer portable hardness tester. The instrument also proved extremely useful in comparing the final hardness values of the test specimen with the portable hardness values. The cut specimen was first mounted on a self adjusting table. The self adjusting table ensures the perpendicularity of the specimen with respect to the indenter at all times during the loading period. The $10 \mathrm{X}$ objective lens was then rotated into place above the test specimen by turning a spindle.

In order to view the specimen, the computer system connected to the hardness tester was turned on and the software was run. The load applied, the time of loading and the objective lens used are entered in the software.

The lens was focused to select the desired area of the test specimen free from defects. The desired load of $1 \mathrm{Kgf}$ was then chosen by turning the knob on the machine. The spindle was turned to bring the indenter in place just above the test specimen. The loading button was turned on to make the indentation.

The indenter was now turned away and the $10 \mathrm{X}$ objective lens was placed above the test specimen. Care was taken not to disturb the specimen during loading and when changing the indenter. The 10X objective lens was now focused on the indent formed. If the indent size was small, the $50 \mathrm{X}$ lens was rotated in place instead of the $10 \mathrm{X}$ lens.

The indent size was then measured using the software by placing triangular markers at the end of the indent to specify the lengths of the diagonal. The software then 
automatically calculates the hardness value based on the diagonal length and magnification. The results, if satisfactory are indicated in green. If the difference in the lengths of the measured diagonals exceeds $30 \%$, the value is indicated in red and the corresponding indent is discarded.

Multiple readings are taken at different points and the values averaged. The loading knob is then turned to apply a load of $0.3 \mathrm{Kgf}$ and the above procedure was repeated. Since $1 \mathrm{Kgf}$ and $0.3 \mathrm{Kgf}$ were the only loads that were common to both the krautkramer and the newage hardness tester the other loads were not applied on the specimen.

The objective lens was moved away from the test specimen and the seat was unscrewed to remove the specimen. The loading knob is returned to its normal position and the machine turned off. The computer system is shut down last after closing the software.

\subsection{Microstructure Analysis Using 'Infiniti’ Long Distance Microscope}

Microstructure study reveals important information regarding the changes that takes place in a material after exposure to different test conditions. In the case of pot hardware materials, the wearing along with the temperature and chemical attack by the bath constituents alters the material surface physically and chemically. It is therefore important to study these microstructure changes and correlate them to the change of physical properties like hardness, elastic modulus and wear. 


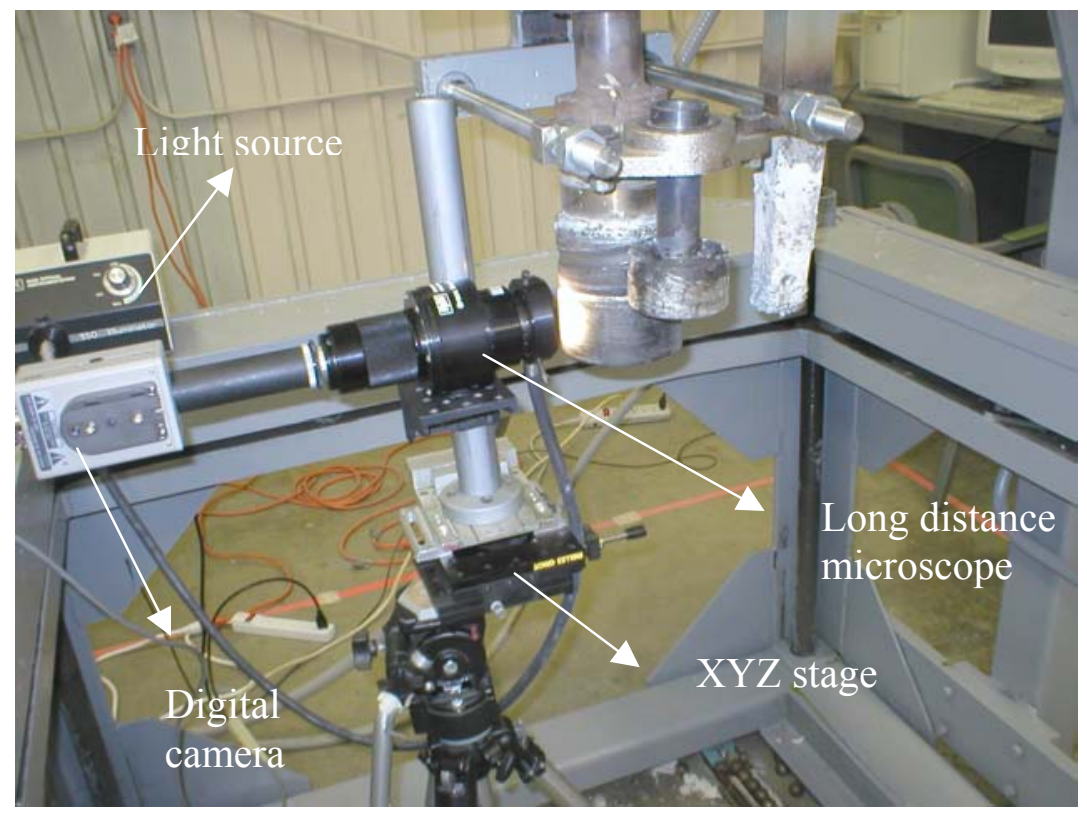

\section{Figure 11 Microstructure analysis using long distance microscope}

The infinity long distance microscope was used to perform microstructure analysis after each test cycle. The microstructure pictures provided explanations to the hardness change and wearing rate after each test cycle. Figure 11 shows the arrangement of long distance microscope for microstructure analysis.

The infinity microscope was first fixed to the motorized stage which rests on the $\mathrm{Y}$ and $\mathrm{Z}$ stages. The 10X objective was then mounted to the 'Infinity' system. The digital camera was attached to the microscope through an adapter. The motorized probe was connected to the controller. Finally the optical fiber lighting was connected to the 'Infiniti' microscope. An internal lighting for the infinity system was used to give the best possible results in terms of clarity of details. The internal lighting causes a uniform lighting of the viewed area and also helps to eliminate unwanted shadows. Now the camera was connected to the monitor to get the focused image. 
After adjusting the $\mathrm{Y}$ and $\mathrm{Z}$ stages to the proper location (the area of interest), the $\mathrm{X}$ stage was moved using the controller in relatively large steps. Once a good focus is achieved, a smaller step in the controller was used to get to the best focused image. Care was taken to ensure that the microscope is perpendicular to the surface of the specimen. A remote control was used to capture the picture, and to avoid shaking. Then the objective lens was changed to 20X for more detailed views. Microscopic details can also be captured using the 50X objective.

Once the entire test was completed, the bearing sleeve was removed from the shaft and was cut using the electrical discharge machine (EDM) for a detailed microstructure study using SEM.

\subsection{Wearing rate measurement}

Wearing on the sleeve was calculated by measuring the change in diameter after each test cycle. After each test cycle, the sleeve was cleaned using a dilute solution of hydrochloric acid. A high precision digital indicator attached to a diametric measurement unit was used to measure the diameter of the sleeve. The resolution of the indicator was $1 \mu \mathrm{m}$. The indicators are attached to an arm as shown in figure 12. Measurement was first taken on a standard calibration block and the values were adjusted to zero. The indicators were then aligned with the mark made on the top of the bearing sleeve. By controlling the precision $\mathrm{XYZ}$ stage, the indicators were moved closer to the diametric point. The diametric point was identified when the indicator reaches a maximum value and then decreased. The procedure is repeated three times for precision measurement. The difference between the initial diameter and the measured diameter gives the wearing in millimeters after each test cycle. 


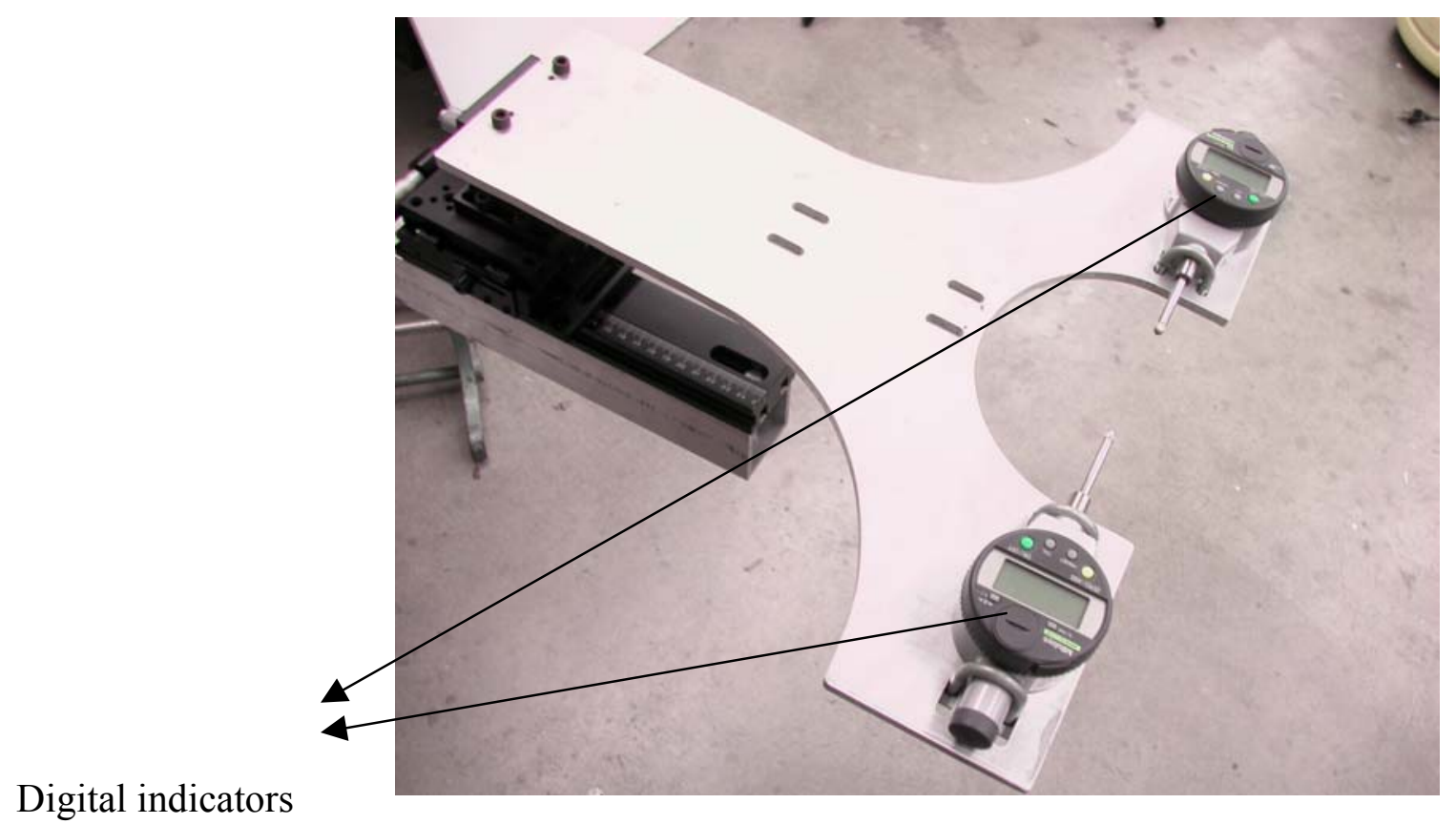

Figure 12 Diametric measurement unit

\section{5 Procedure for Examining the Degradation of Surface}

The bearing sleeve and the ASB roll suffer degradation of material property. This degradation can be due to the wearing of the sleeve, the corrosion attack due to molten zinc or a combination of both. Degradation in material property includes the reduction in the microhardness value and change in elastic modulus of the material. It is therefore imperative that these changes be studied in order to determine the life of pot hardware in continuous galvanizing lines.

A portable hardness tester (Krautkramer MIC 10-DL) was employed to measure the surface hardness on site. The instrument works on the principle of Ultrasonic Contact Impedance (UCI). According to this method, the area of indentation is measured electronically by measuring the shift of an ultrasonic frequency.

The basic equation governing the operation of Krautkramer is 
$\Delta \mathrm{f} \approx \mathrm{EX} \sqrt{\mathrm{A}}$

$\Delta \mathrm{f}=$ frequency shift in $\mathrm{KHz}$

$\mathrm{E}=$ Elastic modulus of the material

$\mathrm{A}=$ Area of indentation

The instrument has four probes which can be interchanged. These are the $5 \mathrm{Kgf}, 1 \mathrm{Kgf}, 0.8$ Kgf and the $0.3 \mathrm{Kgf}$ probes. The frequency shift of the instrument can be measured using a serial cable connected to the computer. The $5 \mathrm{Kgf}$ probe is connected initially to make the indent. The hardness and frequency shift readings are noted down. The probe is then replaced by a $1 \mathrm{Kgf}$ probe and the readings are taken. Similarly the $0.8 \mathrm{Kgf}$ and $0.3 \mathrm{Kgf}$ probes are used. The $0.8 \mathrm{Kgf}$ and $0.3 \mathrm{Kgf}$ probes are motor driven, i.e. the load is applied by a motor thereby negating the inaccuracies of applying the load using hand, which is the case for the $5 \mathrm{Kgf}$ and $1 \mathrm{Kgf}$ probes.

The purpose of using the smaller load of 0.8 and $0.3 \mathrm{Kgf}$ is that, the penetration depth of these probes are very small. So any layer that is formed on the surface of the bearing sleeve or the ASB roll can be easily identified.

During the test cycle, we change the load from the high load of $5 \mathrm{Kgf}$ to the lowest load of $0.3 \mathrm{Kgf}$ thereby changing the depth of indentation. The $5 \mathrm{Kgf}$ load may penetrate any layer that's being formed and hit the substrate. The $0.3 \mathrm{Kgf}$ load may not penetrate the layer. So the two probes will actually be measuring two different things. So we can conclude that there is a surface degradation.

Before the start of the test,

$\Delta \mathrm{f} \approx \mathrm{E} X \sqrt{\mathrm{A}}$

After the test, 


$$
\Delta \mathrm{f}^{*} \approx \mathrm{E}^{*} \mathrm{X} \sqrt{ } \mathrm{A}^{*}
$$

From equations 3.1 and 3.2,

The change in elastic modulus $E^{*} / E=(\sqrt{ } \mathrm{A} \times \Delta f) /\left(\sqrt{ } A^{*} \times \Delta f^{*}\right)$

$\mathrm{E}^{*}=$ Elastic modulus after the test

$\mathrm{E}=$ Elastic modulus before the test

$\mathrm{A}^{*}=$ Area of indentation after the test

$\mathrm{A}=$ Area of indentation before the test

$\Delta \mathrm{f}^{*}=$ Frequency shift after the test

$\Delta \mathrm{f}=$ Frequency shift before the test 


\section{CHAPTER 4}

\section{RESULTS}

\subsection{CF3M with Tungsten Carbide Coating against Vesuvius ACD Ceramics}

\subsubsection{Correlation between Surface Hardness and Elastic Modulus}

Microstructure study demands a proper understanding of the chemical composition and fabrication techniques of the original test material. Any deviation from this composition which can be observed using the microstructure analysis tools like Scanning Electron Microscope and long distance microscopes can prove useful in correlating to the change in physical properties of the material like hardness and surface stiffness.

Tungsten Carbide Composite is metallurgically bonded by a Laser Process to a 316L Stainless Steel Sleeve [10]. Table 1 shows the chemical composition of a laser clad Tungsten carbide deposited on a 316 LS substrate.

\begin{tabular}{|l|l|l|l|l|}
\hline Elements & Tungsten & Co & Cr & Mn \\
& Carbide & & & \\
\hline$\%$ composition & $20-80$ & $1-15$ & $1-25$ & $0-1.5$ \\
\hline
\end{tabular}

Table 1 Chemical composition of tungsten carbide laser clad coating 
Table 2 shows the conditions in which the test was run.

\begin{tabular}{|l|l|}
\hline Bearing Wearing test & WC-laser clad coating on 316 LS against Vesuvius ACD ceramics in \\
wearguard bearing set up
\end{tabular}

Table 2 Lab scale test conditions for WC laser clad coating against Vesuvius ACD ceramics

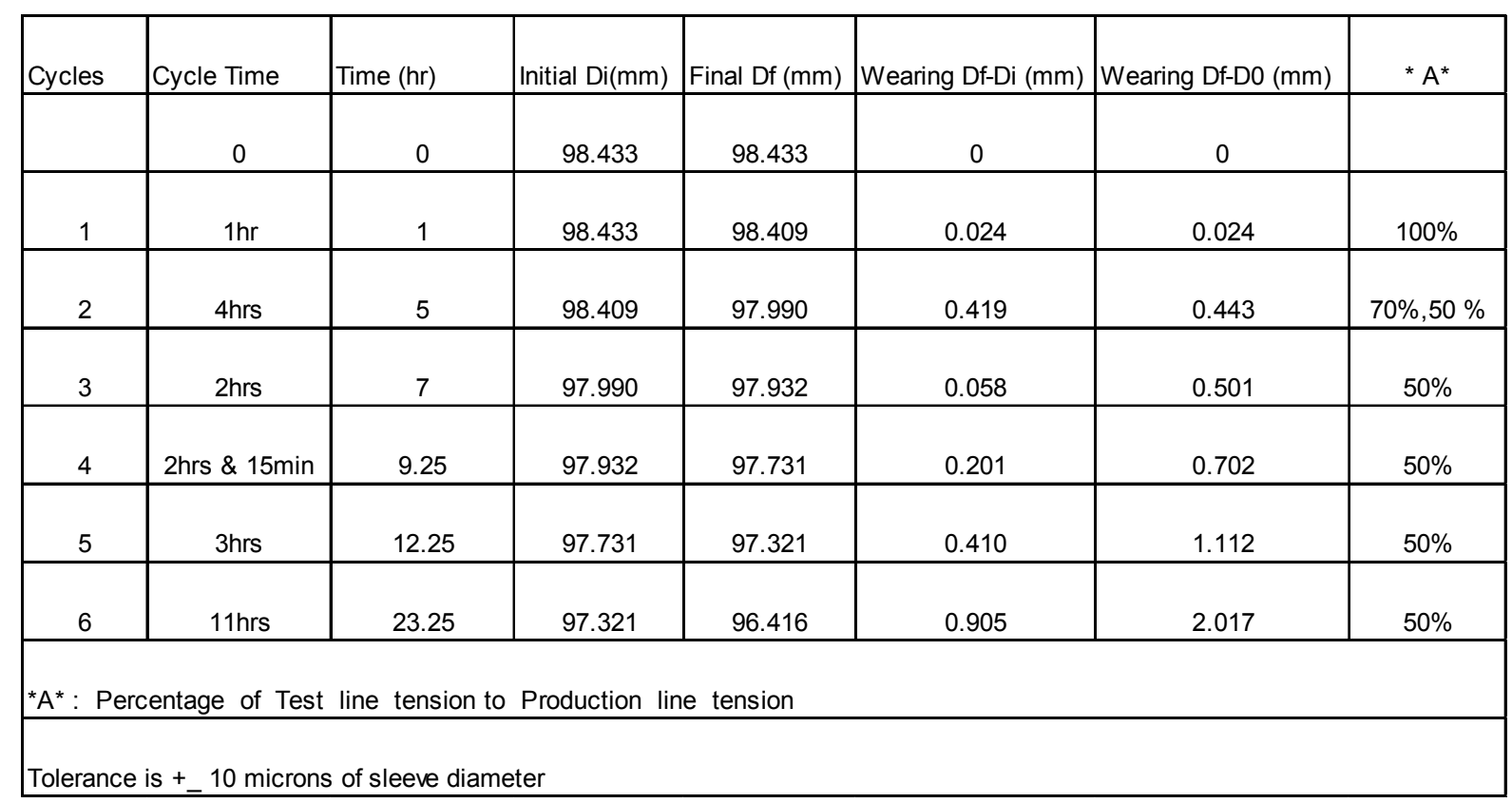

Table 3 Wearing rate on the tungsten carbide laser clad sleeve

Table 3 shows the wearing rate on the tungsten carbide laser clad sleeve calculated from the diameter change. 
The WC sleeve was run against the wearguard bearing setup having three Vesuvius ACD ceramic pieces as inserts. The WC-Co laser clad sleeve had an initial hardness of 1360 HV when measured using the portable Vickers hardness tester under a load of $1 \mathrm{Kgf.The}$ initial microstructure picture before the test revealed a smooth and unrugged surface as seen in figure 14.. The change in hardness value of the sleeve after each test cycle was measured using the portable hardness tester. Figure 13 shows the plot of hardness value against time. The $\mathrm{X}$ axis shows the time of running of the test and the $\mathrm{Y}$ axis shows the hardness value. The curve showed a decrease in hardness value of the WC sleeve for about $13 \mathrm{hrs}$ of running. The hardness value then remained constant till the end of the test.

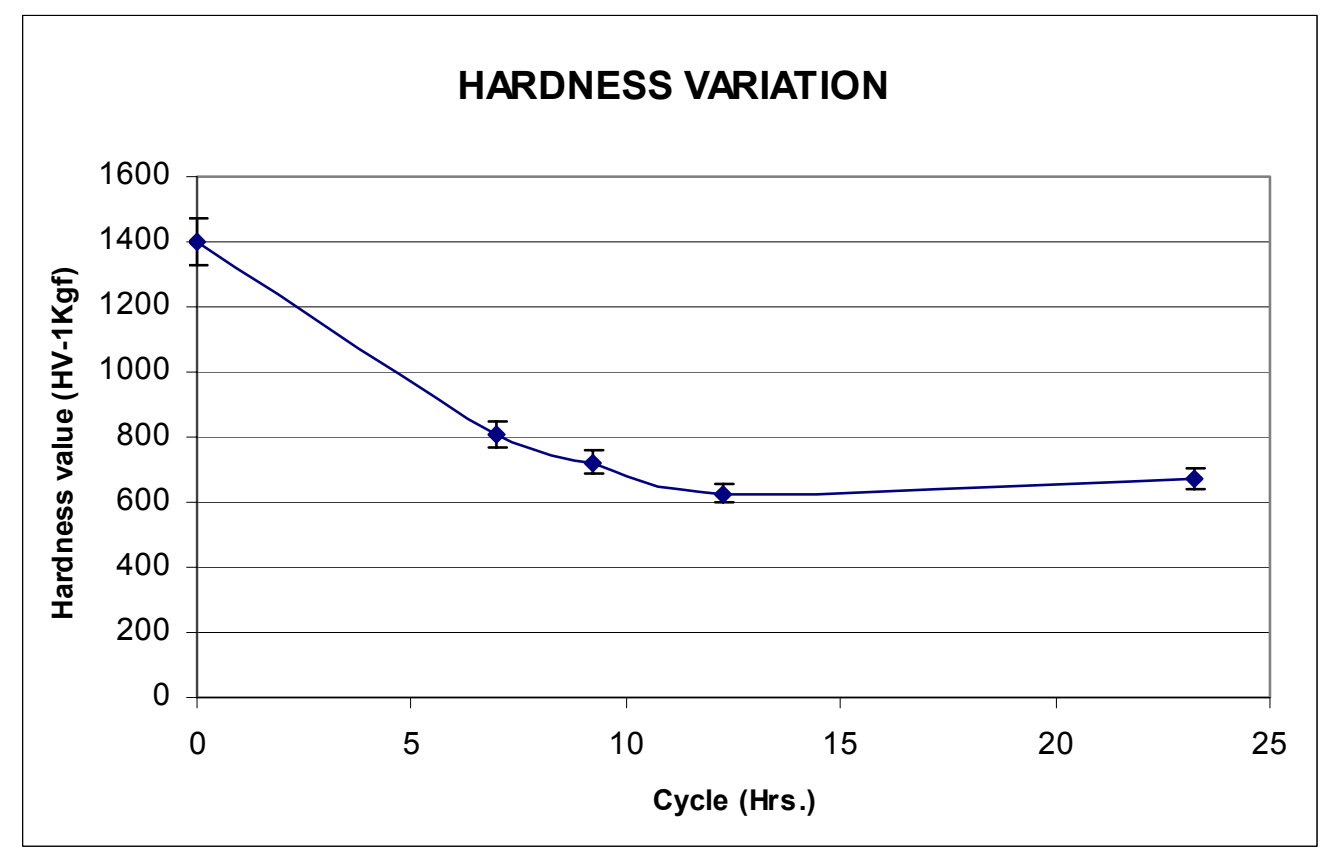

Figure 13 Hardness variation on the wearing sleeve surface 


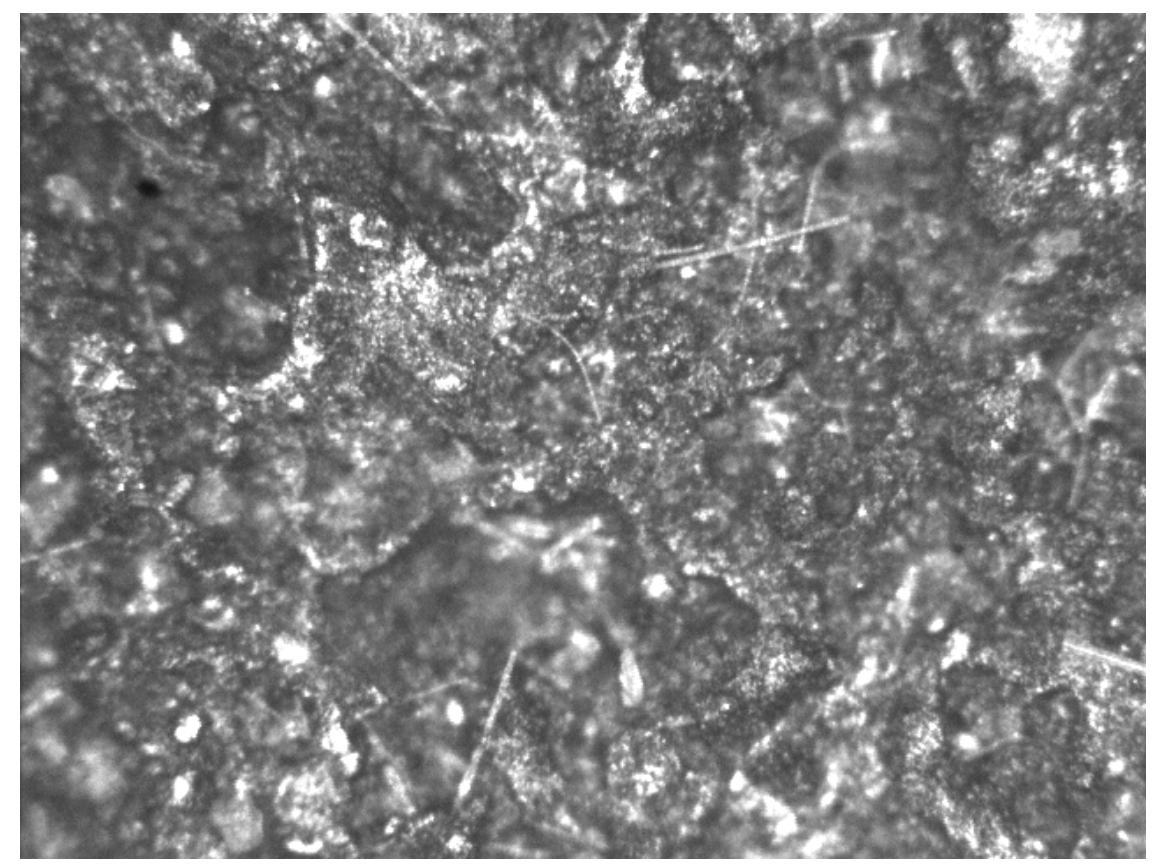

Figure 14 Microstructure of Tungsten carbide laser clad sleeve before the test

Hardness was measured on the wearing and non wearing region of the bearing sleeve surface.

An explanation for the decrease in hardness value in the wearing region can be given on the basis of the depletion of WC particles from the cobalt matrix. Initial loading condition caused the WC carbide particles to crack and form wears debris. The loss of tungsten carbide particles can be due to the initial vibration of the bearing sleeve system. The vibration caused transverse surface cracks on the surface as seen on figure 15 . The weak matrix prevents the propagation of the cracks. SEM analysis of the wearing and nonwearing surface of the sleeve showed corrosion attack on both the surface, possibly initiated by the surface cracks. Figure 16 shows the presence of corrosion attack in the sleeve surface. The corrosion attack might have weakened the matrix and caused the dissolution of WC particles into the bath. 


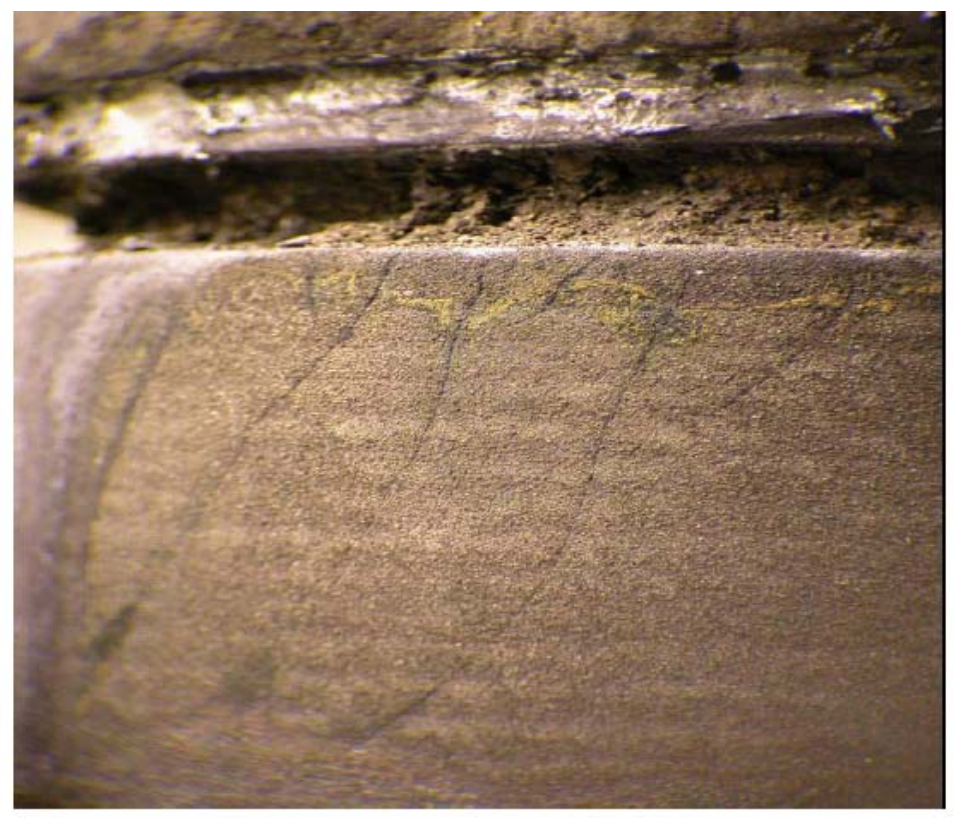

Figure 15 Cracks on the wearing sleeve surface [1]

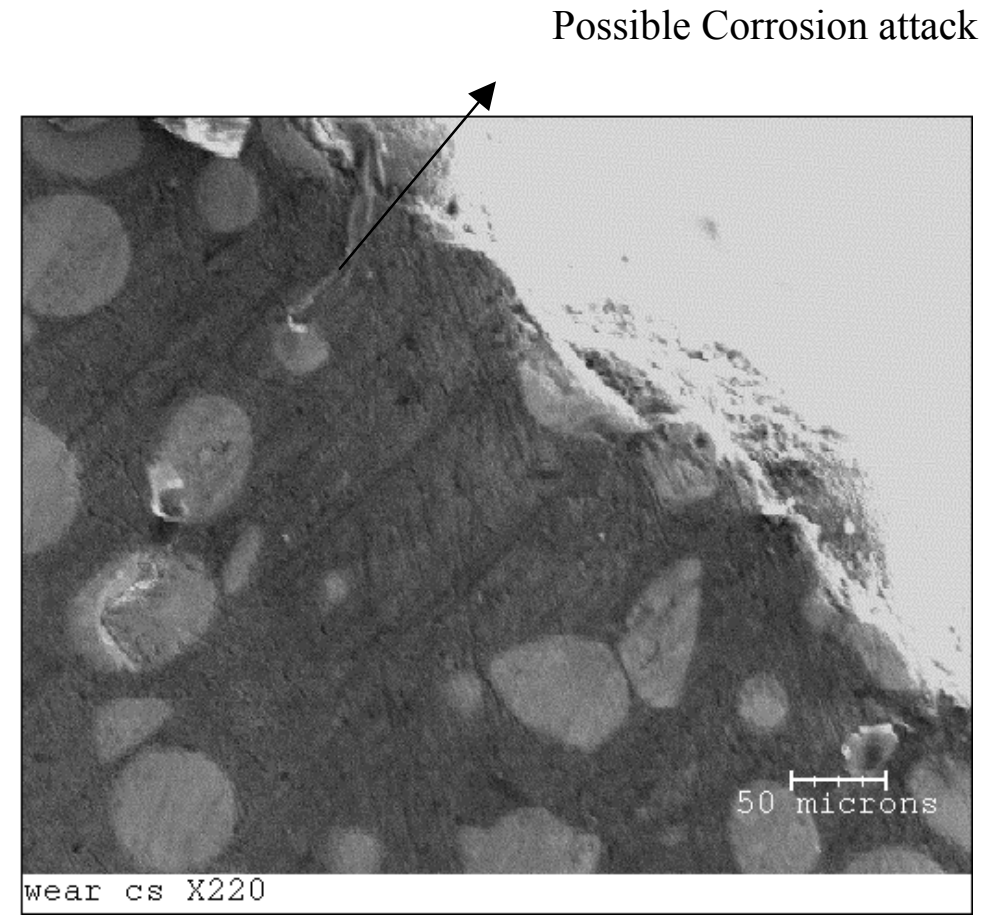

Figure 16 Corrosion crack on the wearing sleeve cross section [1]

Figure 17 shows the voids left behind from the loss of WC particles. 


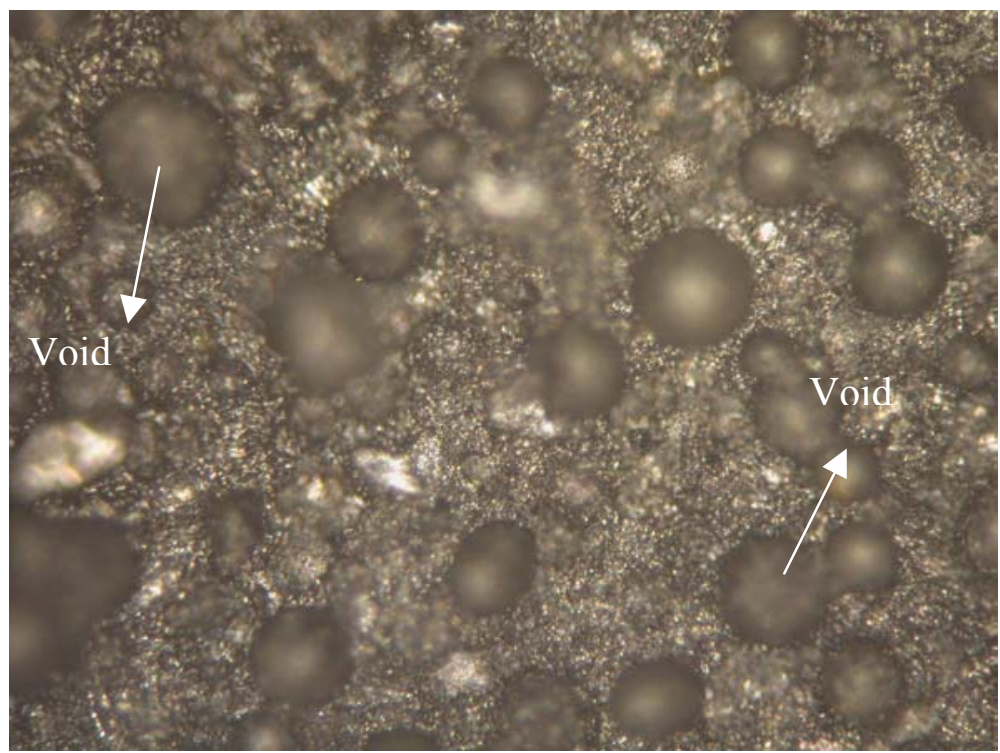

\section{Figure 17 Microstructure of wearing sleeve surface showing voids left behind by WC particles}

The Krautkramer ultrasonic portable hardness tester measures the hardness value based on the size of indentation measured electronically by correlating to the frequency shift. Ultrasonic wave properties are affected by change of particle density in the matrix [17]. The change in frequency shift is a function of the surface stiffness or in other terms the surface density. The depletion of WC particles caused an overall decrease in the surface density as seen from figure 17. The voids left behind increased the wave attenuation. In other words, the energy lost due to beam spread increased. This causes the ultrasonic frequency shift to increase and subsequently displaying a lower hardness value which is in relation to the surface condition or stiffness. After most of the WC particles get dissoluted into the bath, the indenter senses only the cobalt matrix and therefore displays a constant value thereafter.

There was a non wearing region on the wear surface due to the absence of contact with the ACD ceramic pieces. After the test this region was lightly polished. After the polishing, the density of WC particles in the region showed an appreciable increase. The 
comparison between the unpolished and polished surface is shown in figure18 and 19.This shows that wearing phenomenon causes the loss of matrix material thereby exposing the WC particles.

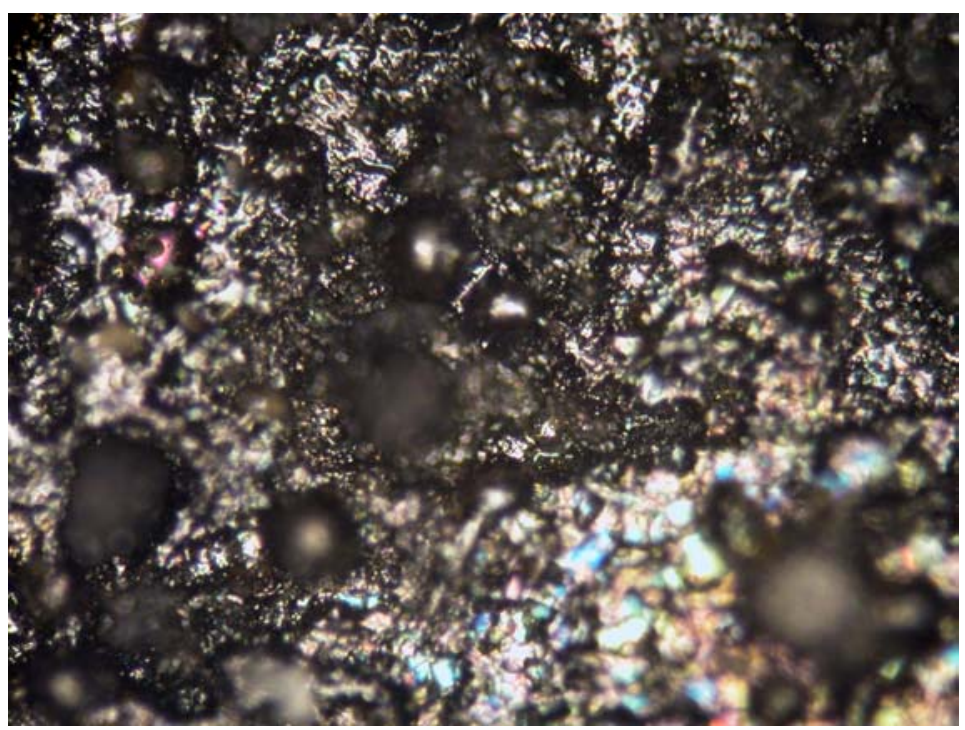

Figure 18 Density of tungsten carbide particles before polishing

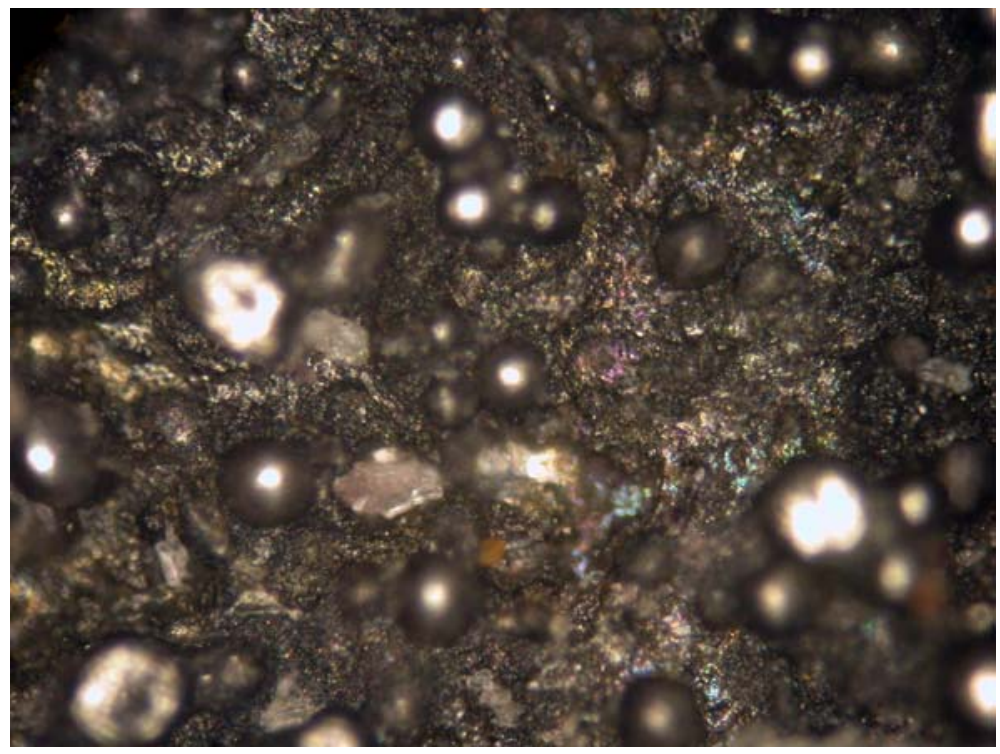

Figure 19 Density of WC particles after polishing 


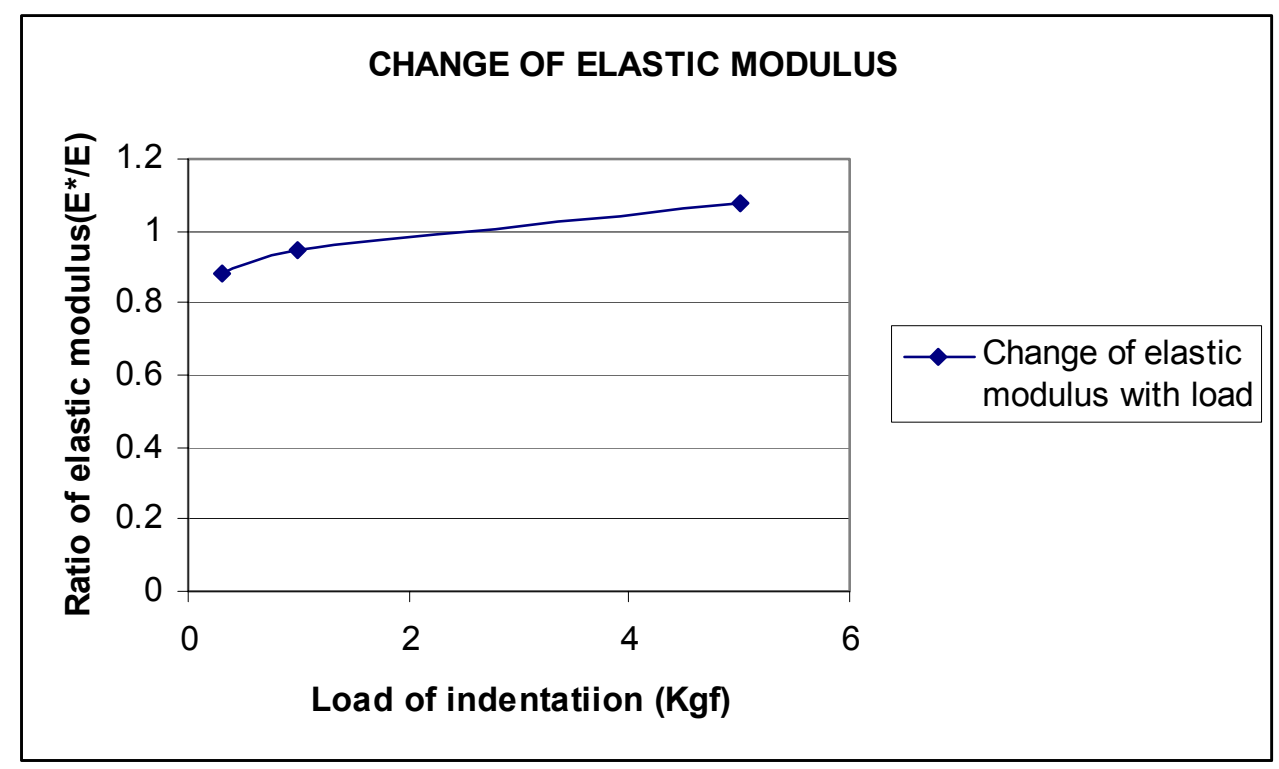

\section{Figure 20 Ratio of elastic modulus after the test to the elastic modulus before the test as a function of load of indentation}

The degradation of surface property for WC-Laser clad sleeve was found by calculating the ratio of the final elastic modulus to the initial elastic modulus as a function of the applied load of indentation using the Krautkramer hardness tester. This was accomplished by using the governing equation of the Krautkramer hardness tester. The plot of elastic modulus change is shown in figure 20.

The ratio of elastic modulus was found to increase and tended to go towards a value of 1 with increasing load. This can be explained as follows. There was an appreciable decrease in the density of tungsten carbide particles as seen from figure 17. The loss of WC particles caused voids in the matrix. Krautkramer MIC 10DL hardness tester works on the ultrasonic principle. The wave properties are affected by changes in material properties like density [17]. When the density decreases, the ultrasonic wave attenuation is increased. This is because waves are transmitted with higher loss of energy. 


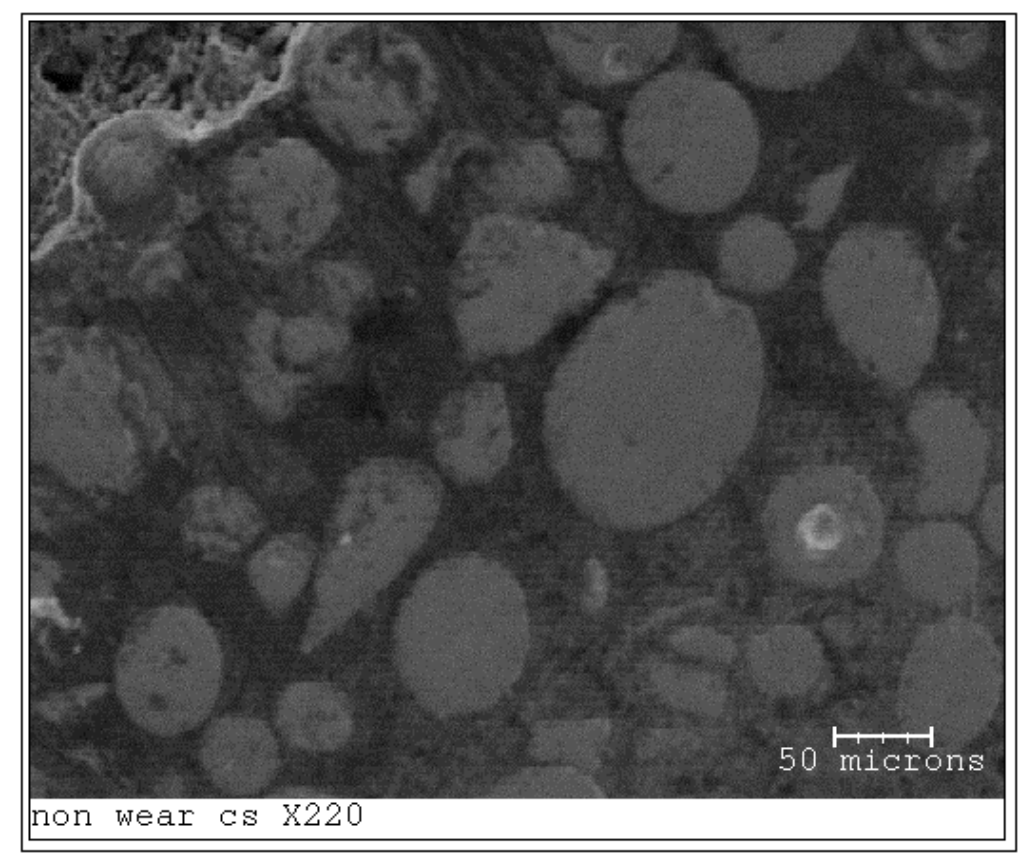

\section{Figure 21 Density of tungsten carbide particles in the non wearing region}

At low load of $0.3 \mathrm{Kgf}$, the depth of penetration is less and the tip of the indenter is still within the low density region. As the loading increases, the indenter penetrates the surface more and senses the higher density regions, there by increasing the elastic modulus.

Krautkramer MIC hardness tester measures hardness as a function of surface density. Therefore the effect of depletion of WC particles and the effect of weakening of the matrix is reflected in the hardness readings. The conventional hardness tester does not incorporate this effect. The indentation made on the WC particle and the matrix show two distinctive hardness readings.

When the hardness was measured on the wearing and non wearing regions of the tungsten carbide test sleeve using the Newage hardness tester, the indentation made on the WC particle showed similar value but the indentation made on the matrix region differed. It can therefore be concluded that the tungsten carbide particles are not affected by 
corrosion. The hardness in the non wearing region showed a higher value compared to the wearing side. This is due to the effect of the matrix corrosion by bath constituents as seen from figure 24 . Figures 22 to 25 show the hardness measurement using Newage standard hardness tester on the WC particle and the matrix regions of the wearing and non wearing regions of the test sleeve.

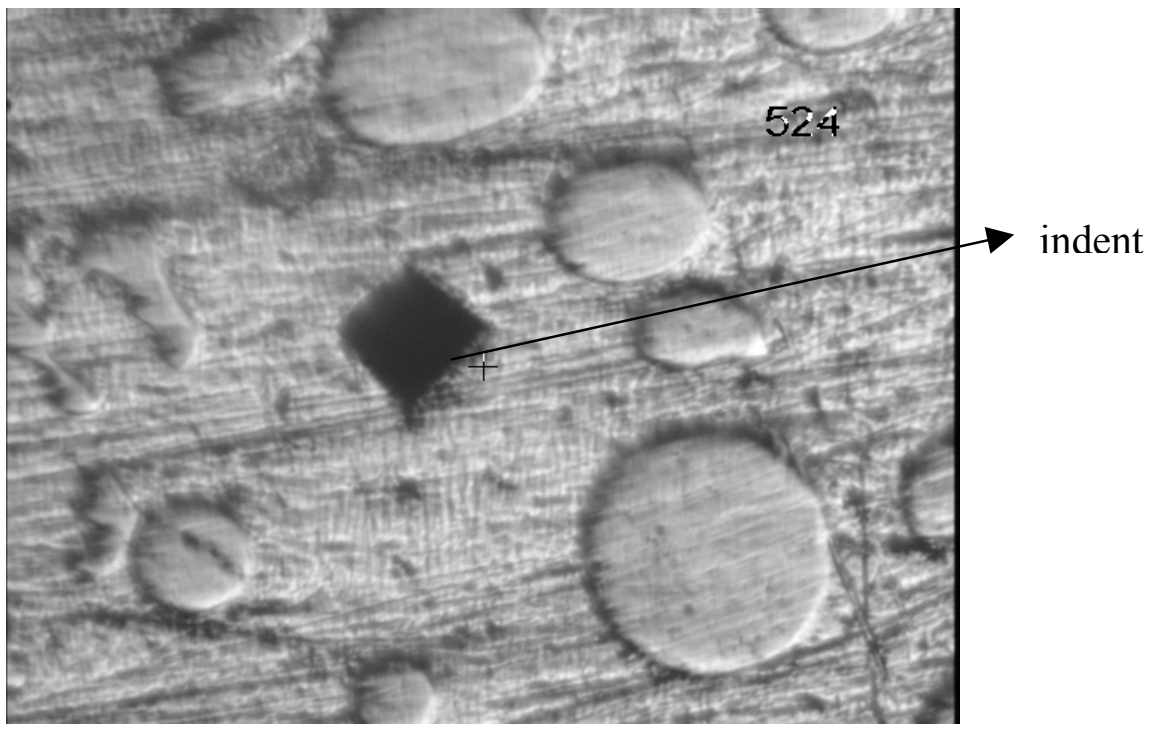

Figure 22 Indentation in the matrix region of the non wearing part of the sleeve

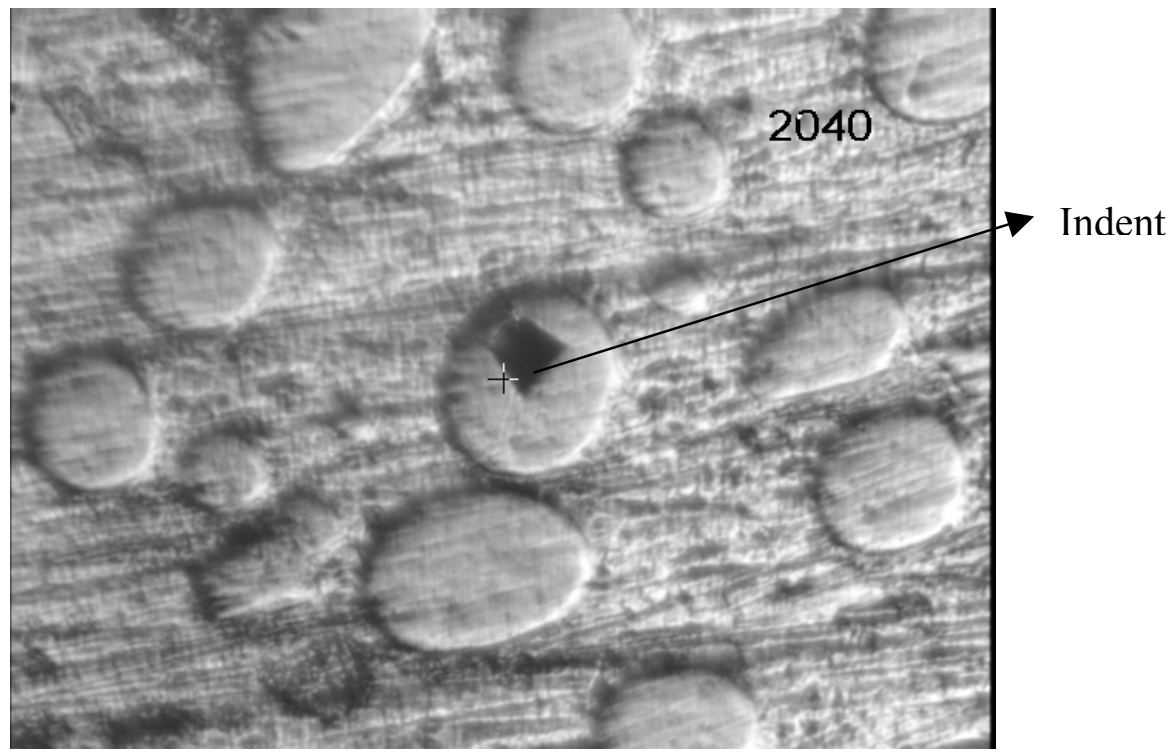

Figure 23 Indentation on WC particle in the non wearing region 


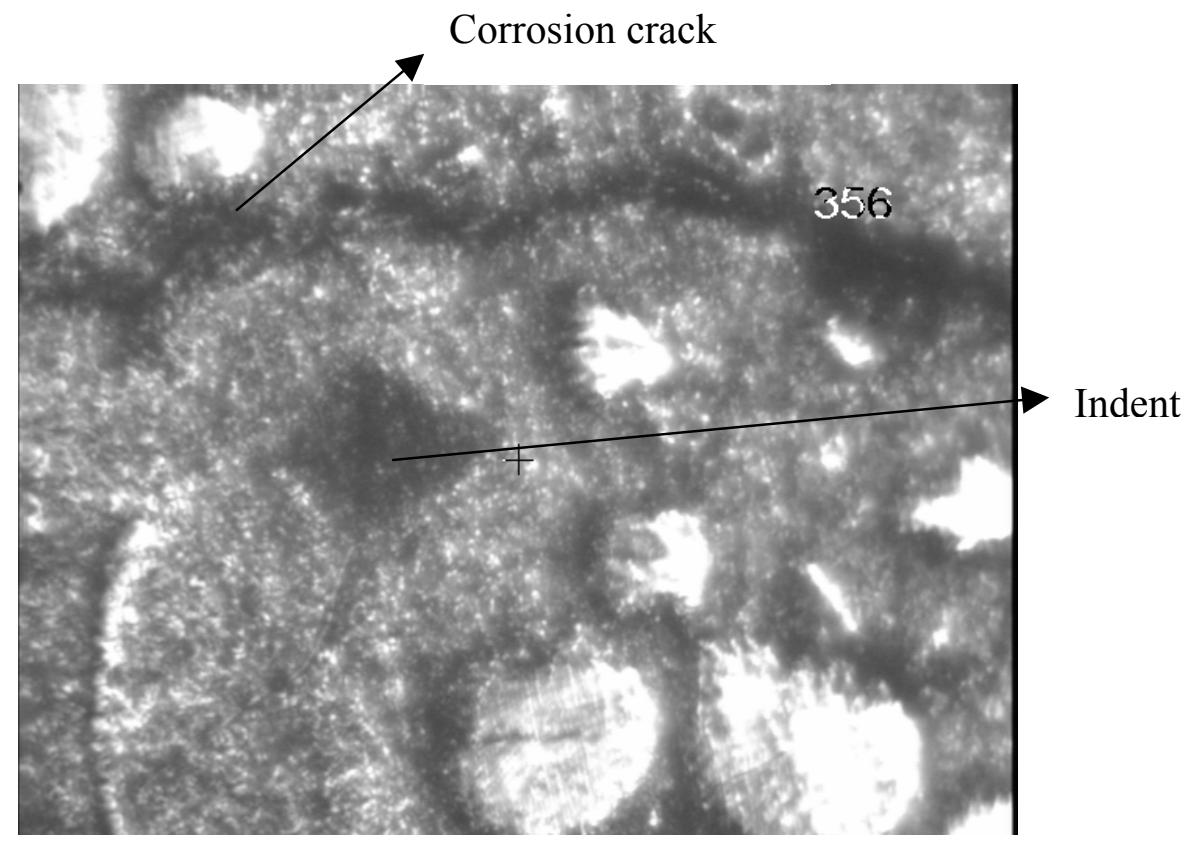

Figure 24 Indentation in the matrix region of the wearing part of the sleeve

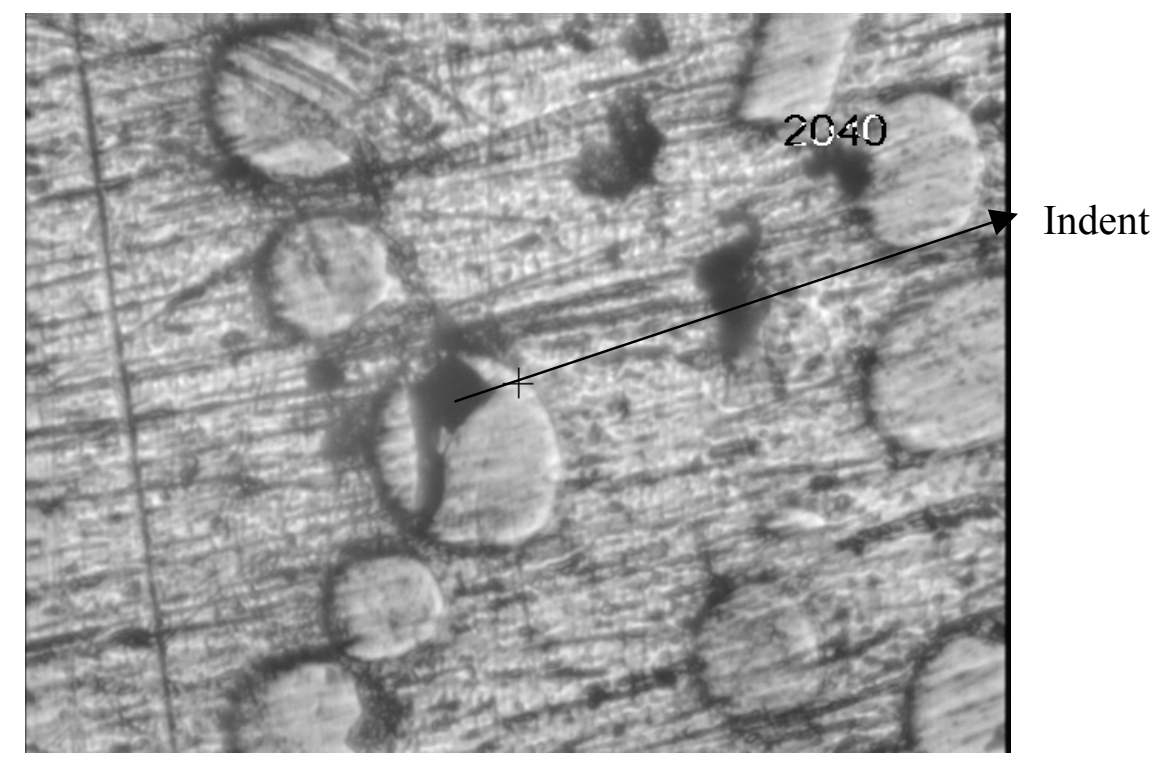

Figure 25 Indentation on WC particle in the wearing region

The non wearing region of the sleeve had a hardness of $1025 \mathrm{HV}$ and the wearing region had a hardness of $624 \mathrm{HV}$. Both these hardness values are representative of their respective surface conditions. The hardness value displayed by the Krautkramer MIC 10 DL is an overall value which takes the surface conditions into account. Therefore it is 
advantageous to use the Krautkramer MIC 10 DL for such conditions where the test material is of heterogeneous nature.

From the hardness value of the wearing region, the depth of indentation for a $1 \mathrm{Kgf}$ probe was about $10.3 \mu \mathrm{m}$.

\subsection{Stellite 6 against Tribaloy T-400}

\subsubsection{Correlation between Surface Hardness and Elastic Modulus}

Compared to WC laser clad coating, Stellite 6 and T-400 alloys are homogeneous materials. Stellite 6 was the bearing sleeve material and T-400 was used as the bushing material. Table 3 shows the typical composition of Stellite 6[14].

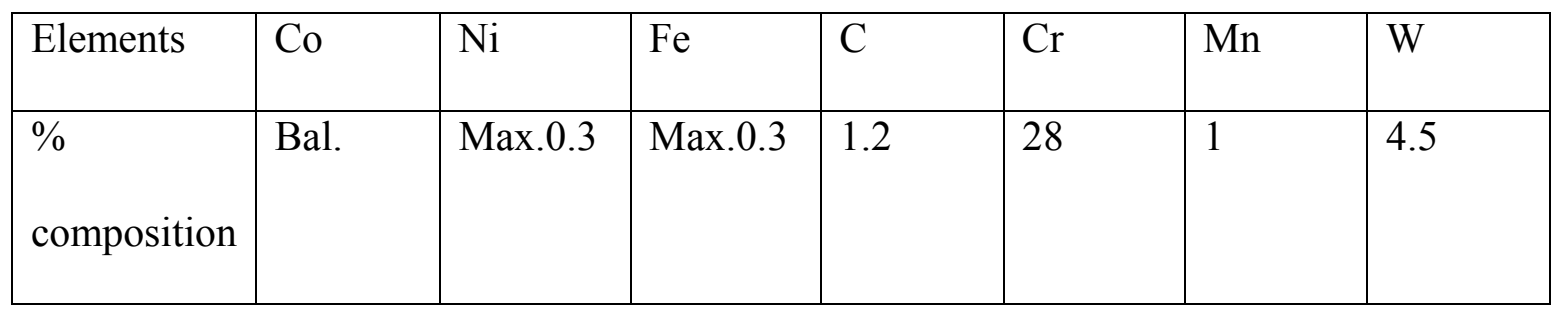

Table 4 Typical chemical composition of Stellite 6 alloy

Table 4 shows the typical composition of Tribaloy T-400 alloy [16].

\begin{tabular}{|c|c|c|c|c|c|c|c|}
\hline Elements & Co & Ni & Fe & C & Cr & Mo & Si \\
\hline$\%$ & Bal & Max. & Max.1.5 & 0.08 & 8.5 & 29 & 2.6 \\
composition & & 1.5 & & & & & \\
\hline
\end{tabular}

Table 5 Typical chemical composition of Tribaloy T-400 alloy 


\begin{tabular}{|l|l|}
\hline Bearing wearing test & Stellite 6 against Tribaloy T 400 \\
\hline Dross built up test & $\begin{array}{l}\text { WC-ASB coating on 316 LS against low } \\
\text { carbon steel }\end{array}$ \\
\hline Bearing load & $5401 \mathrm{~b}$ \\
\hline RPM & 108 \\
\hline Bath temperature & $850-870$ deg.F \\
\hline
\end{tabular}

Table 6 Lab scale test conditions for Stellite 6 against Tribaloy T-400

\begin{tabular}{|c|c|c|c|c|c|c|c|c|}
\hline \multirow[t]{2}{*}{ Cycle \# } & \multirow[t]{2}{*}{ Cycle Time } & \multicolumn{2}{|c|}{ Total Time } & \multirow{2}{*}{$\begin{array}{l}\text { Initial Di } \\
(\mathrm{mm})\end{array}$} & \multirow{2}{*}{$\begin{array}{l}\text { Final Df } \\
(\mathrm{mm})\end{array}$} & \multirow{2}{*}{$\begin{array}{c}\text { Wearing Each Cycle Df-Di } \\
(\mathrm{mm})\end{array}$} & \multirow{2}{*}{$\begin{array}{c}\text { Total Wearing Df-D0 } \\
(\mathrm{mm})\end{array}$} & \multirow[t]{2}{*}{${ }^{*} A^{*}$} \\
\hline & & (hours) & (days) & & & & & \\
\hline & 0 & 0 & 0.00 & 98.417 & 98.417 & 0 & 0 & 34.94 \\
\hline 1 & $6 \mathrm{hr} 45 \mathrm{~min}$ & 6.75 & 0.28 & 98.417 & 98.39 & 0.027 & 0.027 & 34.94 \\
\hline 2 & $6 \mathrm{hr} 30 \mathrm{~min}$ & 13.25 & 0.55 & 98.39 & 98.304 & 0.086 & 0.113 & 34.94 \\
\hline 3 & $7 \mathrm{hrs}$ & 20.25 & 0.84 & 98.304 & 98.249 & 0.055 & 0.141 & 34.94 \\
\hline 4 & $15 \mathrm{hrs} 45 \mathrm{~min}$ & 36 & 1.50 & 98.249 & 98.047 & 0.202 & 0.257 & 34.94 \\
\hline
\end{tabular}

\section{Table 7 Wearing rate on the stellite 6 sleeve}

Table 5 shows the test conditions for Stellite 6 against T-400. After each cycle, the bearing sleeve was cleaned with muriatic acid and hardness measurements were taken. The change in surface hardness is shown in figure 26. Table 6 shows the wearing rate on the stellite 6 sleeve calculated from the diameter change. 


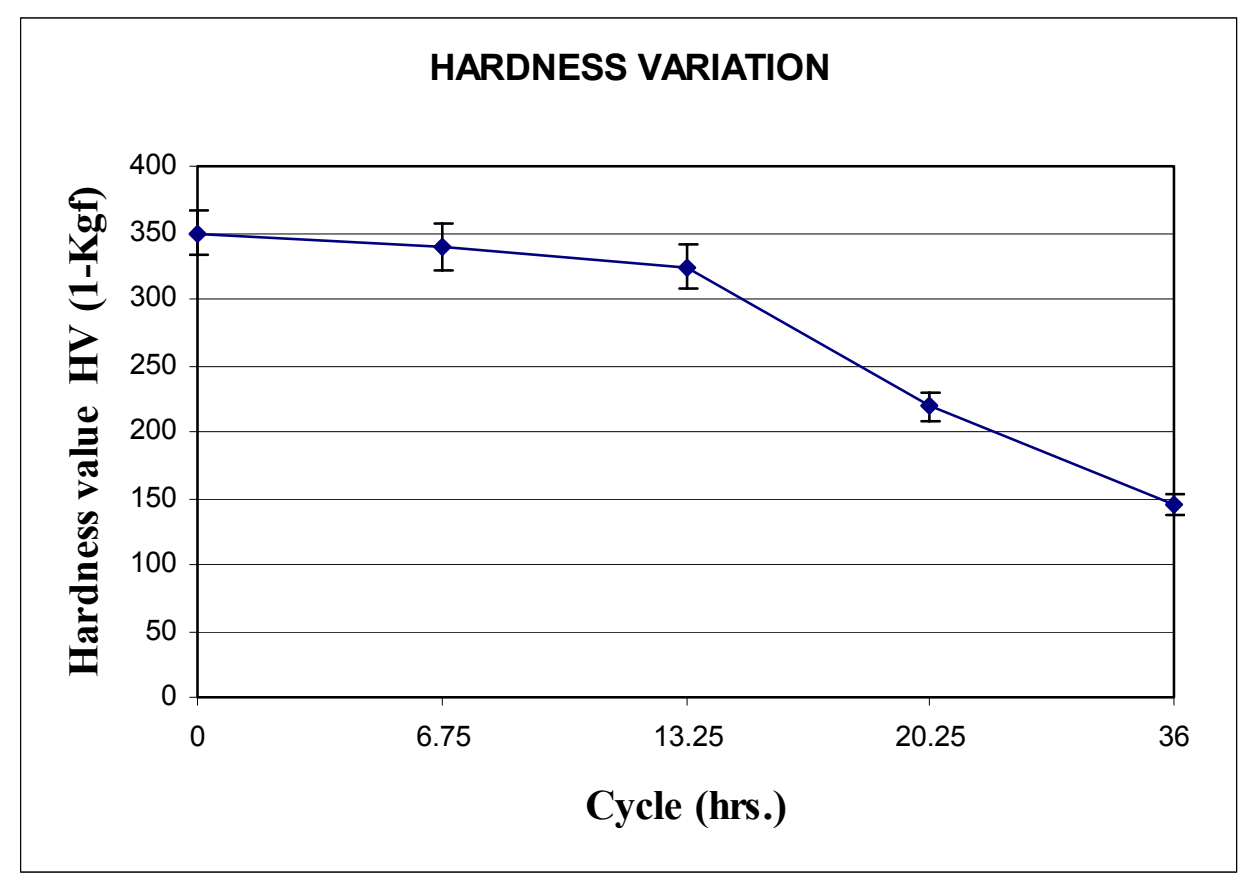

Figure 26 Hardness variation on the wearing sleeve surface

The curve showed a continuous decrease in the hardness value of the Stellite 6 sleeve.

The microstructure picture revealed deep grooves on the test sleeve after cycle 2 as seen on figures 27 and 28.

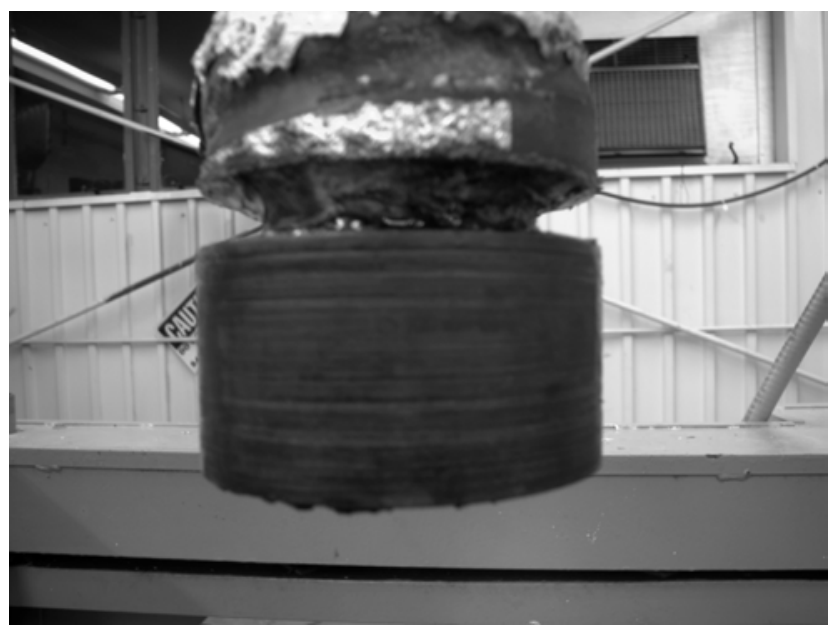

Figure 27 Grooves seen on Stellite 6 surface due to plowing by intermetallic particles 


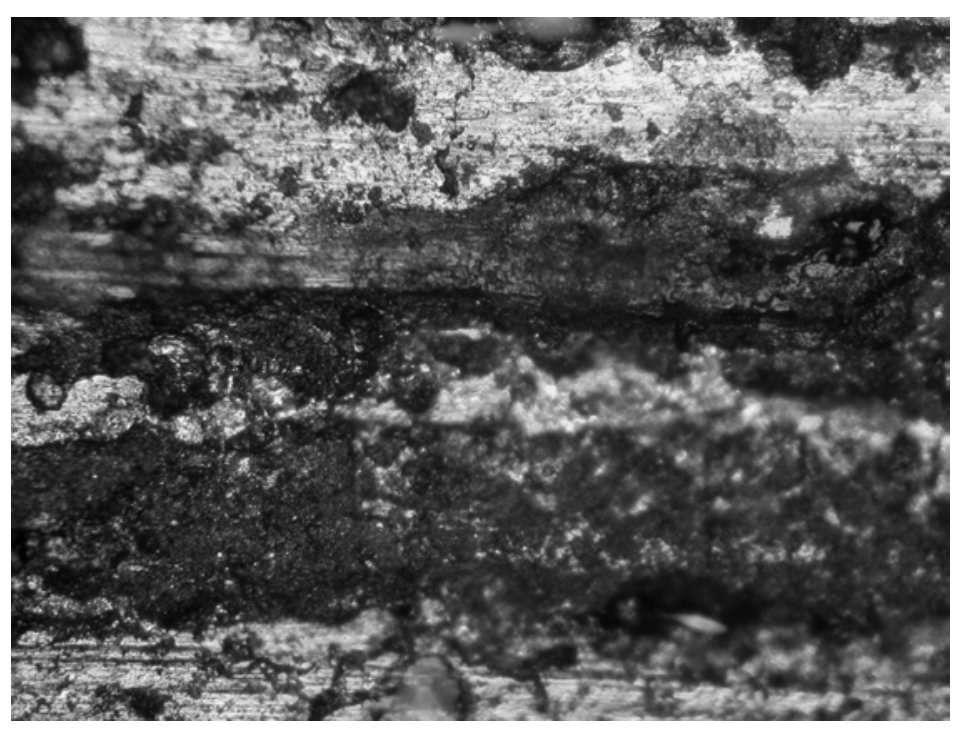

Figure 28 Grooves seen on Stellite 6 surface due to plowing by intermetallic particles

The reaction of molten metal with Stellite 6 is evident by the presence of CoAl intermetallic compounds. These intermetallic particles may detach and reattach to the contact surface after reacting with molten zinc [16]. The formation of groves is due to the presence of intermetallic particles [16]. Figure 29 and 30 shows the presence of CoAl intermetallic particles within the sleeve surface [15].

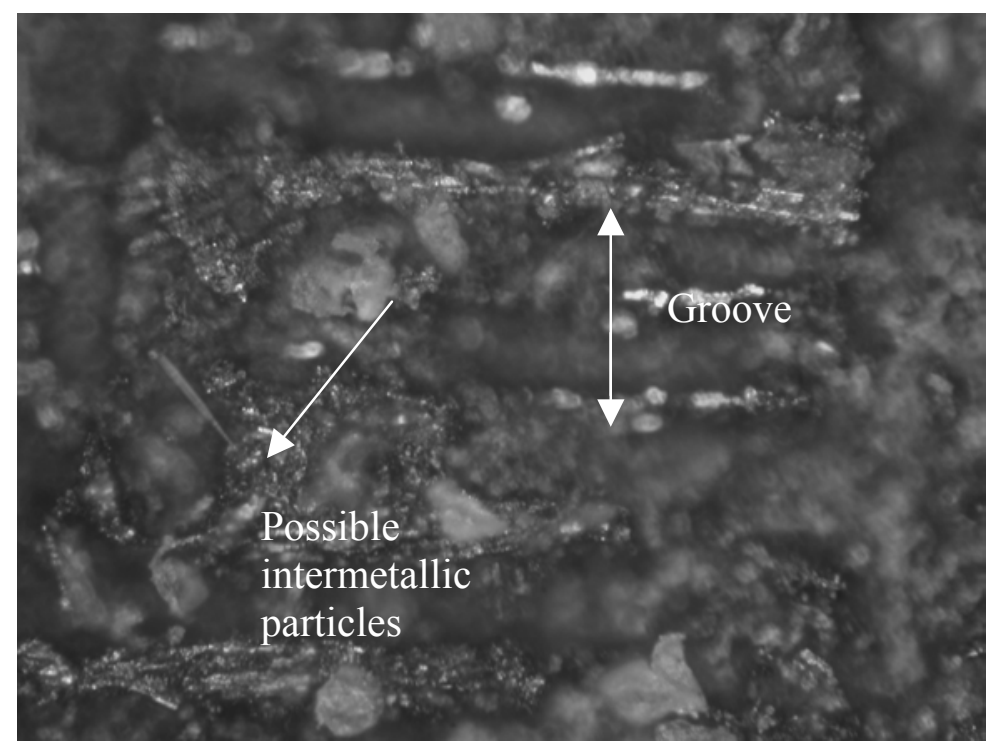

Figure 29 Intermetallic particles inside the groove 


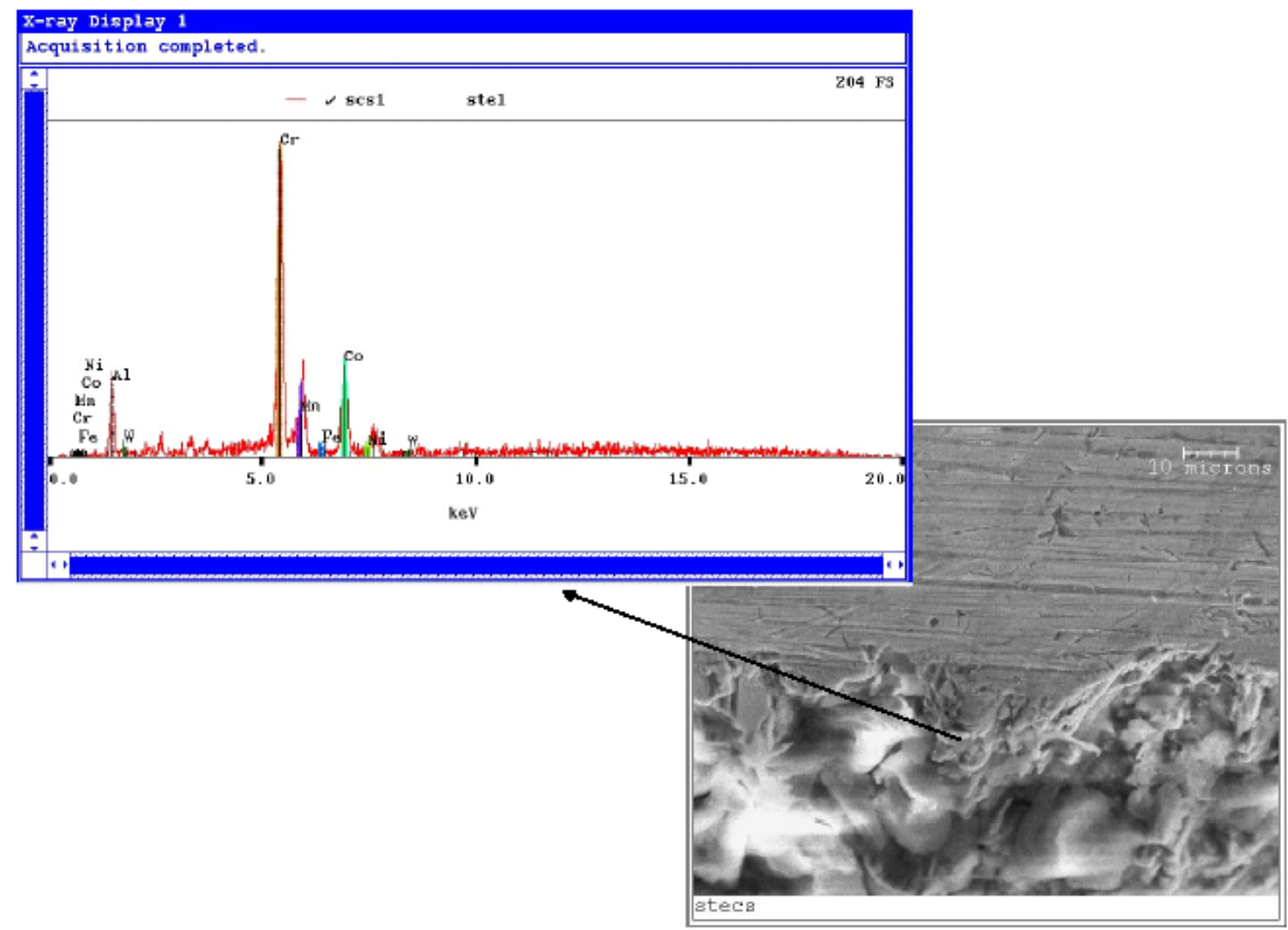

Figure $30 \mathrm{CoAl}$ intermetallic particle in Stellite 6 [1]

Small specimens were cut from the bearing sleeve surface and prepared for microstructure analysis. Analysis showed the diffusion of Co from the matrix into the bath [15]. Presence of intermetallic particle inside the groove region is shown in figure 30. The spectrum analysis was done starting from the edge of wear surface cross section until the actual Stellite 6 composition was reached as shown in Figures 31 to 33. The analysis was repeated on different locations of the wearing cross section. Thickness of the Co depletion diffusion zone was not uniform and typical thickness ranged from $5 \mu \mathrm{m}$ to $20 \mu \mathrm{m}$. The formation of the diffusion zone leads to the drop in hardness value of the material, as the inherent Stellite 6 composition is absent in the cobalt depletion zone. 


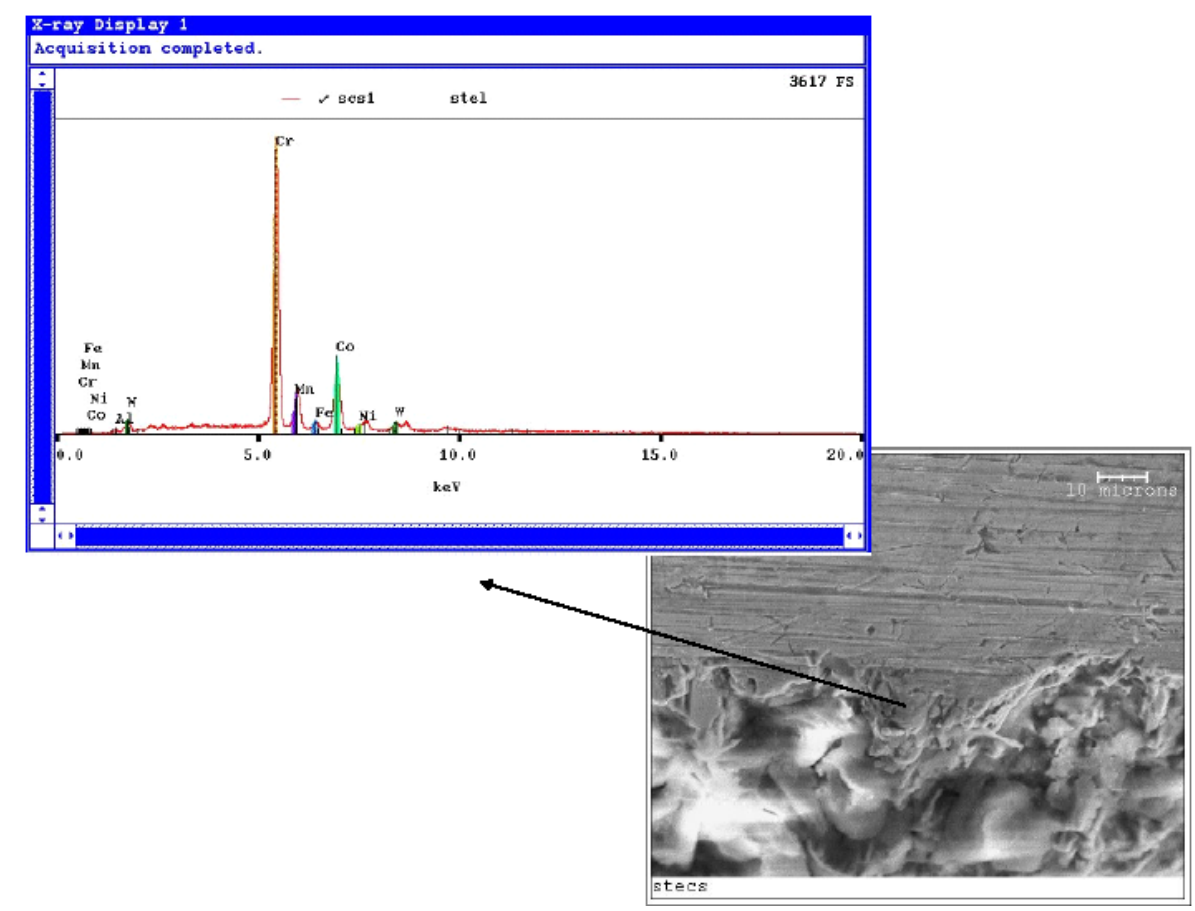

Figure 31 Cross sectional view showing depletion of cobalt near the wear surface [1]

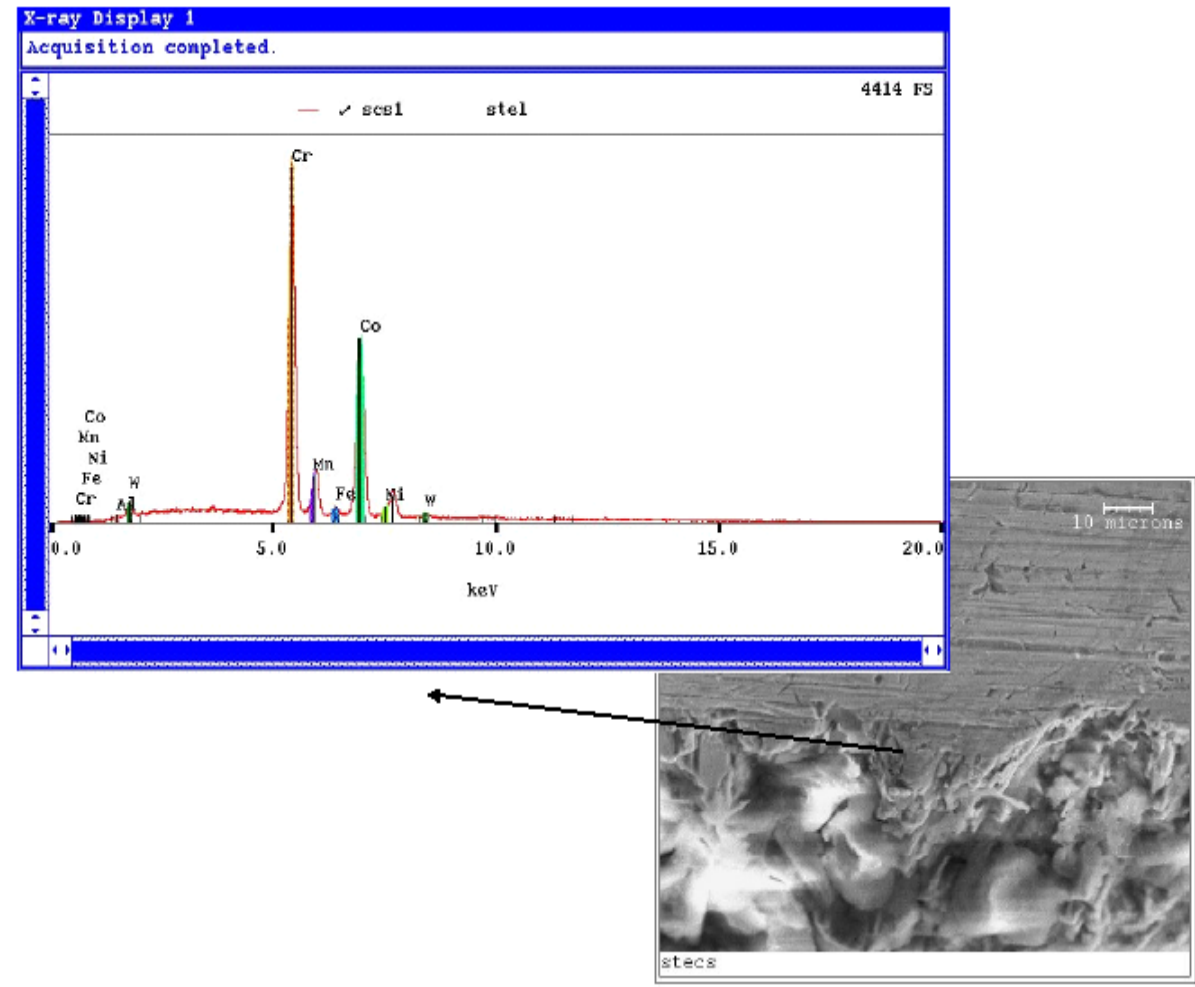

Figure 32 Cross sectional view showing an increase of cobalt further away from the surface [1] 


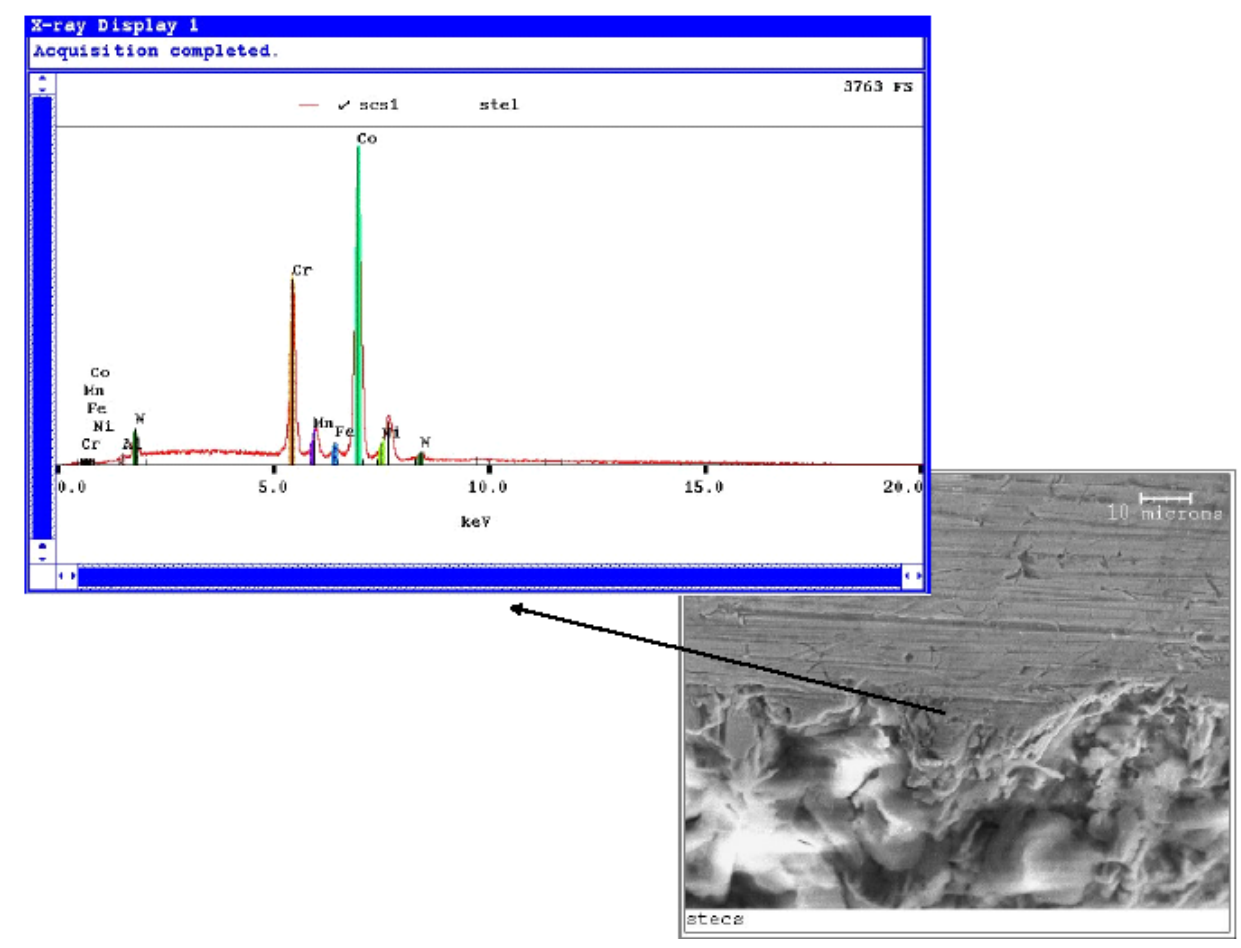

Figure 33 Cross sectional view showing actual Stellite 6 composition away from the surface [1]

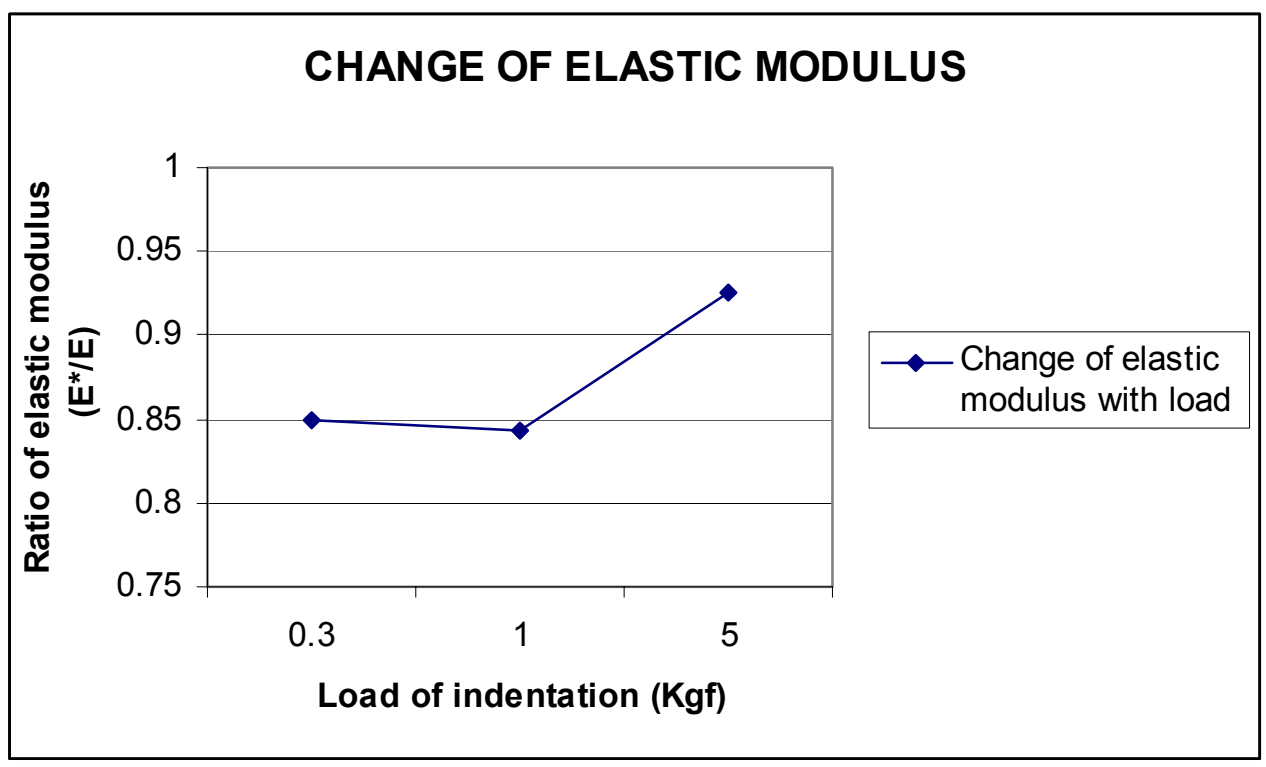

Figure 34 Ratio of elastic modulus after the test to the elastic modulus before the test as a function of load of indentation 
The change in surface elastic modulus of the bearing sleeve surface is shown in figure 34 . The plot shows a lower elastic modulus of 0.85 when indented with probes of $0.3 \mathrm{Kgf}$ and $1 \mathrm{Kgf}$. The elastic modulus shoots up to 0.925 when a higher load of $5 \mathrm{Kgf}$ is used. This increase in elastic modulus can be due to the combined effect of the presence of a cobalt depletion layer and surface grooves. The lower loads of 0.3 and $1 \mathrm{Kgf}$ have indentation depths well within the depletion zone. When the higher load of $5 \mathrm{Kgf}$ is used, the indenter senses the actual Stellite 6 composition, thereby giving a higher elastic modulus.

A bushing specimen from AK steel was analyzed for hardness change. A comparison of the hardness change for the stellite 6 bushing from AK steel and a specimen from the lab scale test is compared in the table below.

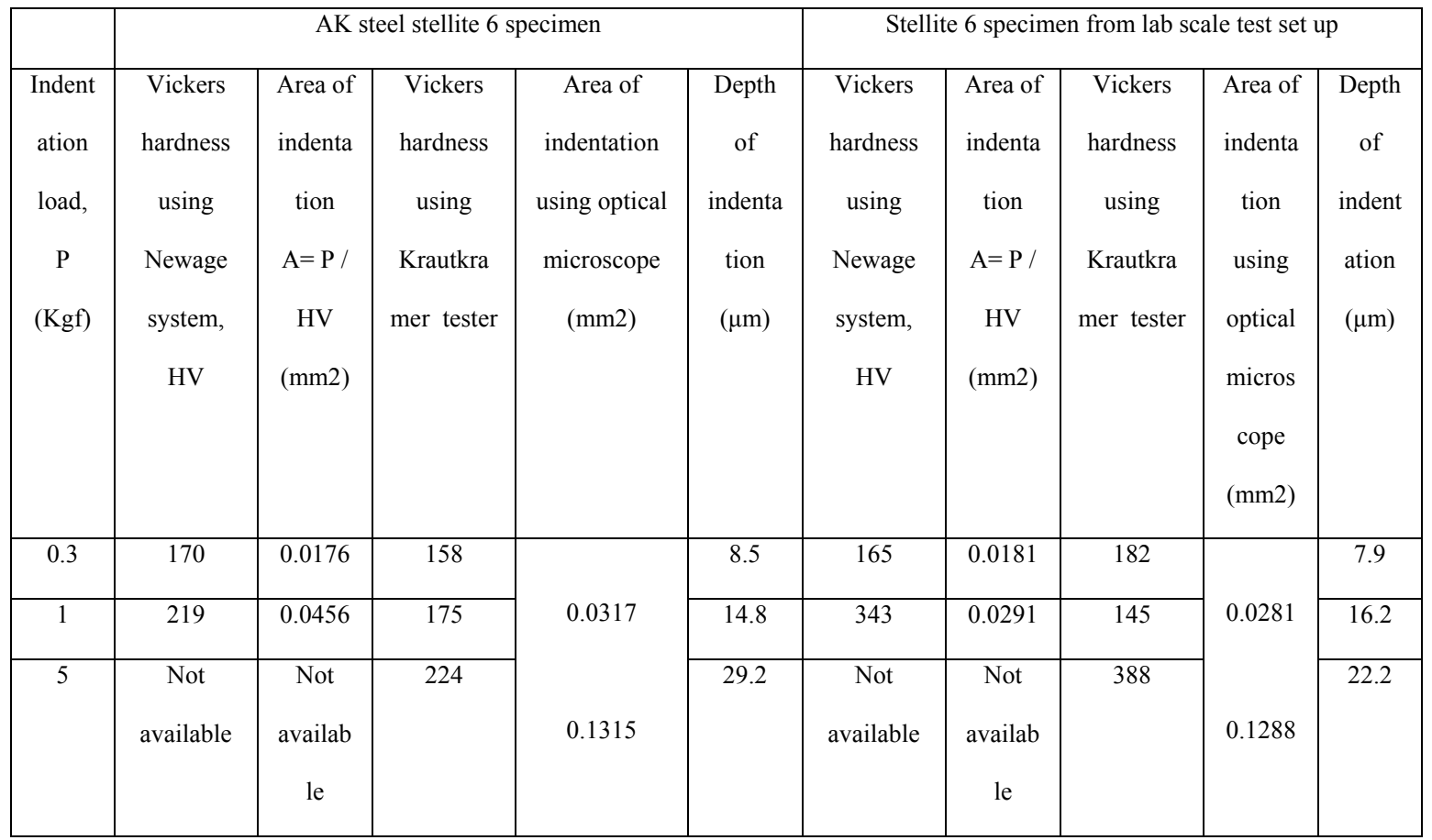

Table 8 Hardness value comparison of stellite 6 from AK steel and lab scale test

The table shows that the hardness value using Krautkramer hardness tester is nearly same for both the specimens for a load of 0.3 and $1 \mathrm{Kgf}$. For a load of $5 \mathrm{Kgf}$, the specimen 
from AK steel showed a lower hardness value compared to the specimen from lab scale test. The cobalt depletion zone appears to be above 29 microns as compared to the 22 microns in the case of the stellite 6 sleeve used in the lab scale test. This could probably mean that the depletion zone is thicker in the specimen form AK steel as compared to the specimen from the lab scale test. The thicker zone can be due to the varying amount of time these test specimens are immersed in the zinc bath. Typically the AK steel bushing is used for 2 weeks before it is replaced. The stellite 6 specimen from the lab scale test was tested for only 36 hours. It is recommended that an elemental analysis on the specimen cross section be performed to verify the thickness of the depletion zone. Moreover, the stellite 6 bushing from AK steel was run against a stellite 6 sleeve. The stellite 6 sleeve in the lab scale test was run against a T-400 bushing. All these differences in test conditions are the reason for the difference in hardness value.

\subsection{Metaullics MSA 2012 against MSA 2012}

\subsubsection{Correlation between surface hardness and elastic modulus}

\begin{tabular}{|l|l|l|l|l|l|l|l|l|l|}
\hline Elements & $\mathrm{Mo}$ & $\mathrm{W}$ & $\mathrm{Cr}$ & $\mathrm{Co}$ & $\mathrm{V}$ & $\mathrm{Nb}$ & $\mathrm{C}$ & $\mathrm{Mn}, \mathrm{Si}$ & $\mathrm{Fe}$ \\
\hline \% composition & $5-10$ & $5-10$ & $5-10$ & $2-5$ & $2-5$ & $2-5$ & 1.25 & casting & $>50$ \\
\hline
\end{tabular}

Table 9 Typical chemical composition of MSA 2012 alloy

MSA 2012 is predominantly a Fe based alloy. The elements W and Mo impart the necessary hardness to the alloy. These elements are present in the form of carbides in the softer Fe matrix. These dendrite phases act as the alloy strengthening phase [13].

The test running conditions are tabulated below. 


\begin{tabular}{|l|l|}
\hline Bearing wearing test & Metaullics 2012 against Metaullics 2012 \\
\hline Dross built up test & $\begin{array}{l}\text { WC-ASB coating on 316 LS against low } \\
\text { carbon steel }\end{array}$ \\
\hline Bearing load & $3001 \mathrm{~b}$ \\
\hline RPM & 108 \\
\hline Bath temperature & $850-870$ deg.F \\
\hline
\end{tabular}

Table 10 Lab scale test conditions for Metaullics 2012 against MSA 2012

\begin{tabular}{|c|c|c|c|c|c|c|c|c|}
\hline Cycle \# & Cycle Time & & iime & Initial Di & Final Df & Wearing Each Cycle Df-Di & Total Wearing Df-D0 & ${ }^{*} \mathrm{~A}^{*}$ \\
\hline & & (hours) & (days) & $(\mathrm{mm})$ & $(\mathrm{mm})$ & $(\mathrm{mm})$ & $(\mathrm{mm})$ & \\
\hline 0 & 0 & 0 & 0.00 & 76.2 & 76.2 & 0 & 0 & 26.69 \\
\hline 1 & $2 \mathrm{hr} 45 \mathrm{~min}$ & 2.75 & 0.11 & 76.2 & 75.898 & 0.302 & 0.302 & 26.69 \\
\hline 2 & $4 \mathrm{~h}$ & 6.75 & 0.28 & 75.898 & 75.346 & 0.552 & 0.854 & 26.69 \\
\hline 3 & $12 \mathrm{hr} 15 \mathrm{~min}$ & 21.65 & 0.90 & 75.346 & 72.002 & 3.344 & 4.198 & 26.69 \\
\hline
\end{tabular}

Table 11 Wearing rate on the Metaullics MSA 2012 sleeve

Table 11 shows the wearing rate on the MSA 2012 sleeve calculated from the diameter change. 


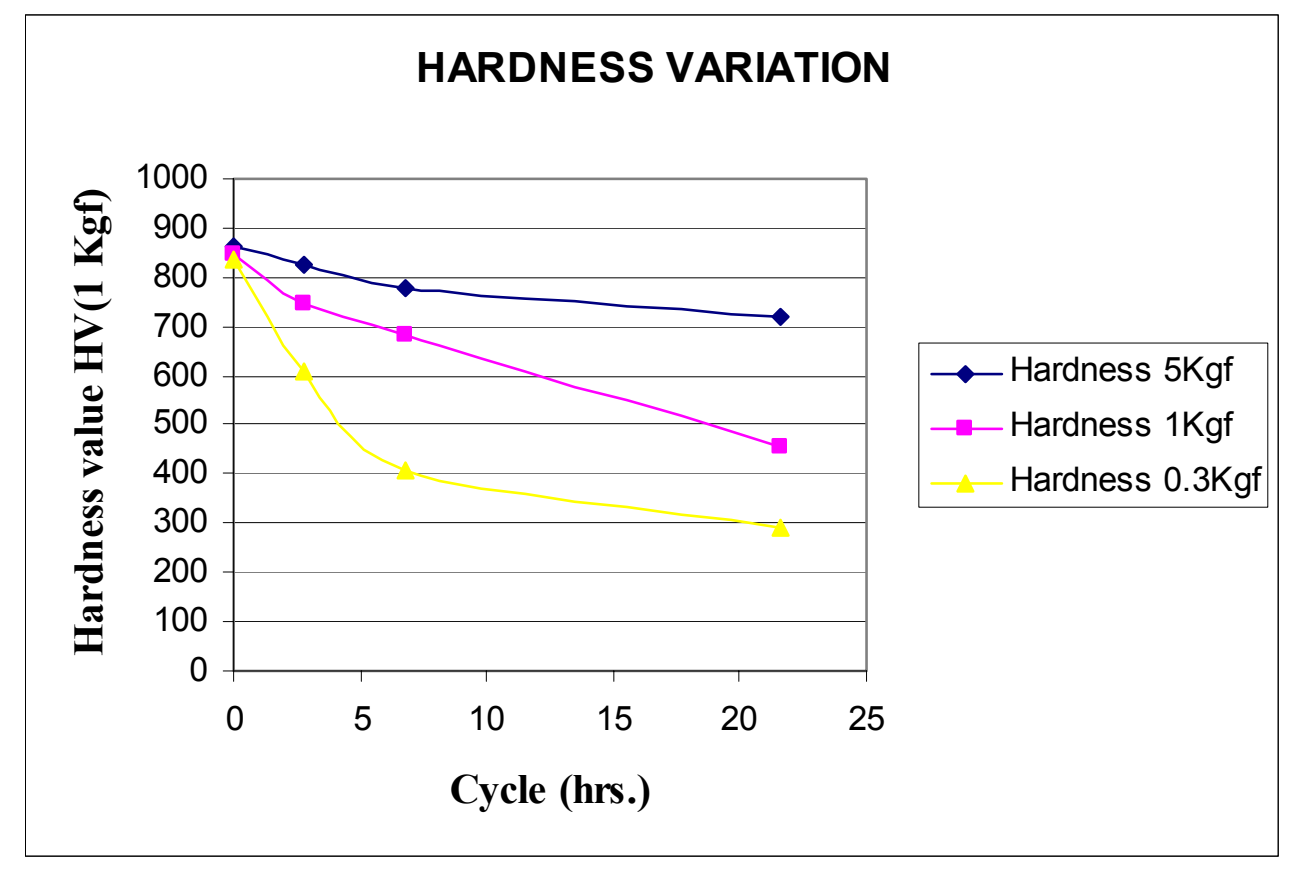

Figure 35 Hardness variation on the wearing sleeve surface

Hardness was measured on the sleeve surface using the Krautkramer MIC-10DL ultrasonic hardness tester. Three different loads were used to investigate the effect of surface degradation on the hardness change. The change of surface hardness on the MSA 2012 wearing sleeve for different probe loads after each test cycle is shown in figure 35 . The plot shows a decrease in surface hardness as the cycle progresses. The drop in hardness is highest for the $0.3 \mathrm{Kgf}$ probe followed by the $1 \mathrm{Kgf}$ and $5 \mathrm{Kgf}$ probes. The 0.3 Kgf probe produces the shallowest indentation and the $5 \mathrm{Kgf}$ produces the deepest. This shows that the MSA 2012 surface has undergone some degradation. The hardness value using newage tester for the $0.3 \mathrm{Kgf}$ load is lower compared to the corresponding Krautkramer reading. This could be because of the effect of the carbide phase on the frequency shift readings. The presence of the carbide phase decreases the attenuation, thereby slightly increasing the hardness value. 
Sub surface cracks

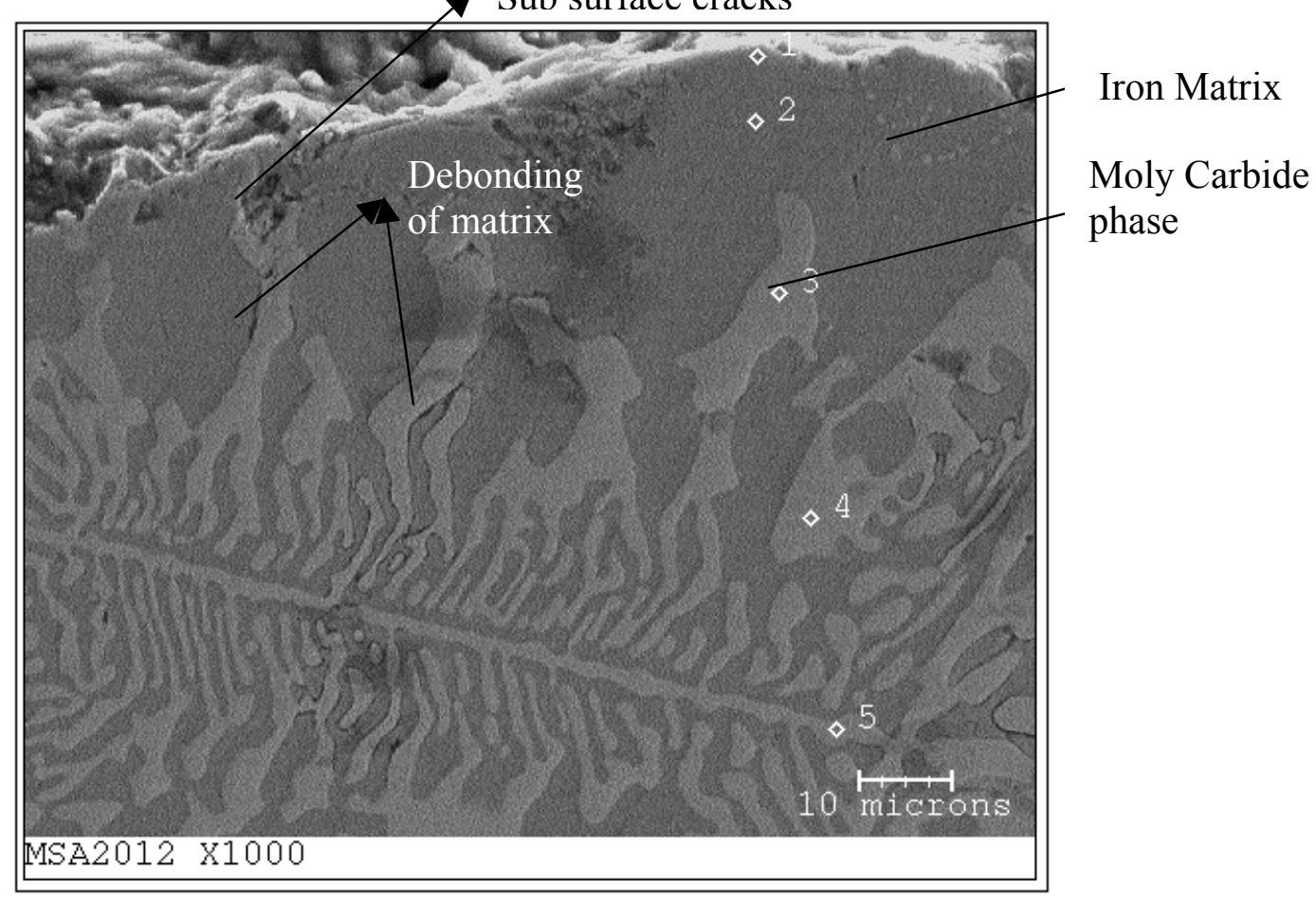

Figure 36 SEM cross section view of MSA 2012 sleeve

Figure 36 shows the cross section SEM picture of the MSA 2012 sleeve. The material removal phenomenon in MSA 2012 is purely due to wear and no dissolution of the matrix elements take place. Stationary tests conducted on the sleeve surface have confirmed the presence of a reaction layer [13]. But this layer was most likely removed by the wearing phenomena. The rate of wear could have been much higher than the rate of formation of the reaction layer [13]. The cross section of the wear surface revealed a relatively smooth surface with the presence of sub surface cracks. These cracks act as vacancy channels for the molten zinc to penetrate the surface and corrode the iron matrix [13] as seen from figure 36 and figure 37 . The corroded matrix might have caused the debonding of the carbide phase thereby forming voids in the interface between the matrix and carbide phase. Figure 37 shows the elemental mapping of the MSA 2012 wearing surface cross section. The picture shows the presence of zinc inside the matrix. 


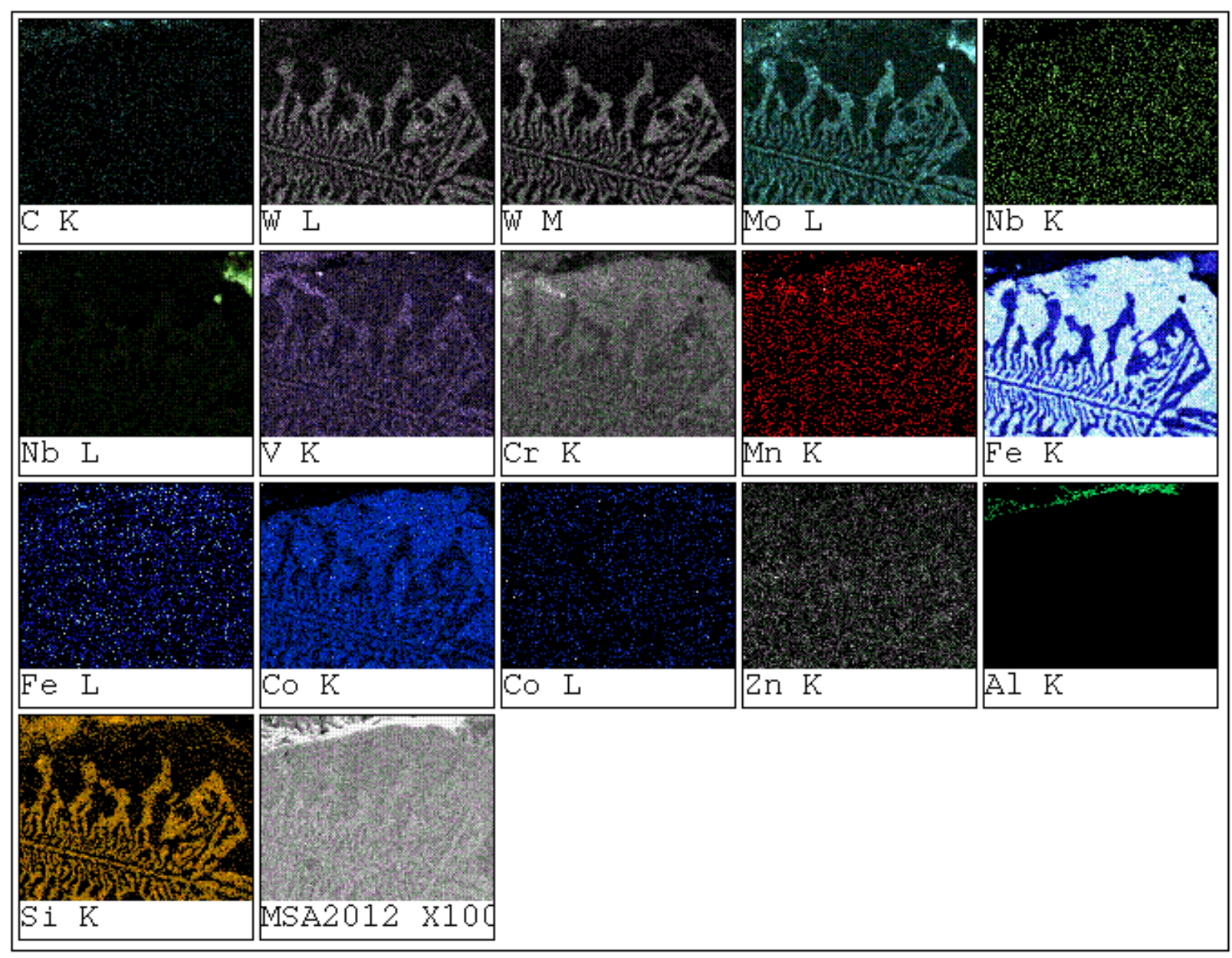

Figure 37 Elemental mapping of MSA 2012 sleeve cross section

The corrosion of the matrix by the molten zinc is the reason for the drop in surface hardness of the MSA 2012 sleeve surface as seen from figure 37. The Iron matrix is weakened by the corrosion. The softer matrix and the presence of interface voids cause an increase in ultrasonic wave attenuation [8]. This increases the frequency shift and subsequently displaying a lesser hardness value. 


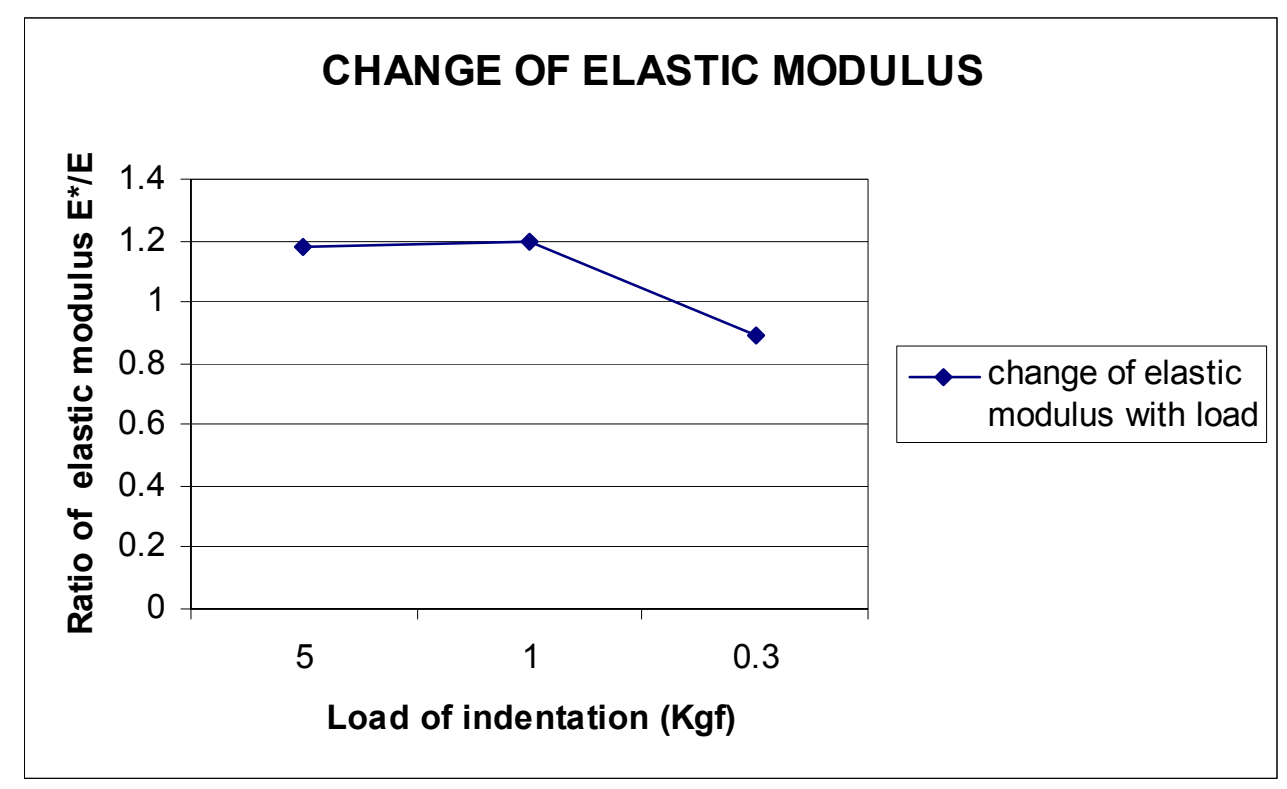

Figure 38 Ratio of elastic modulus after the test to the elastic modulus before the test as a function of load of indentation

The change of elastic modulus of the MSA 2012 sleeve was calculated by measuring the ultrasonic frequency shift and using the basic equation of the Krautkramer hardness tester. The plot of the ratio of elastic modulus $\left(\mathrm{E}^{*} / \mathrm{E}\right)$ after the test to the elastic modulus before the test as a function of load of indentation is shown in figure 38. The plot shows a higher ratio for a higher load of $5 \mathrm{Kgf}$. The ratio does not change much when the surface is probed using a $1 \mathrm{Kgf}$ probe. The ratio drops when a load of $0.3 \mathrm{Kgf}$ is used. From the SEM picture shown in figure 36, there appears to be a region close to the wearing surface which is free from the carbide phases. This region is around $10-15 \mu \mathrm{m}$ in width. The lower load probes do not penetrate the surface enough to reach the carbide phase and the indentation formed is with in the zinc corroded Fe matrix zone. The higher load probes of $1 \mathrm{Kgf}$ and $5 \mathrm{Kgf}$ successfully penetrate the Fe matrix zone and hit the carbide zone. So the higher probes indicate a higher elastic modulus compared to the lower load probes. 


\subsection{CF3M with Tungsten Carbide ASB coating against low carbon steel}

\subsubsection{Correlation between surface hardness and elastic modulus}

CF3M coated with Tungsten carbide ASB coating is run against the low carbon steel sleeve to simulate the roll and steel sheet in the actual galvanizing line. The change in hardness was measured on the WC ASB sleeve after each test cycle by using the Krautkramer MIC 10 DL portable hardness tester. Figure 39 shows the change in surface hardness after each test cycle.

\begin{tabular}{|l|l|l|l|}
\hline Elements & WC & Co & $\mathrm{Cr}$ \\
\hline$\%$ & 86 & 10 & 4 \\
composition & & & \\
\hline
\end{tabular}

Table 12 Typical chemical composition of tungsten carbide coated ASB roll

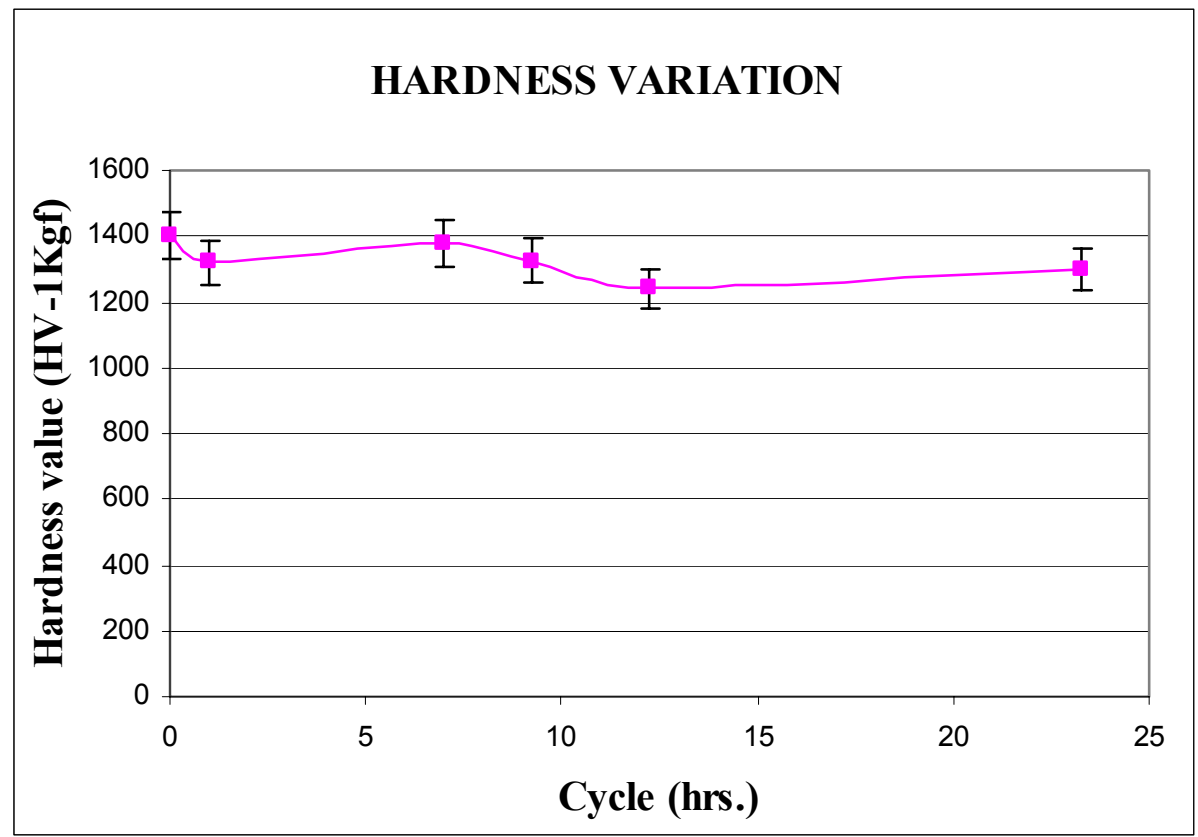

Figure 39 Hardness variation on the roll sleeve surface 
There appeared to be no significant drop in the hardness value for the WC coated ASB sleeve. From the microstructure pictures shown in figure 40 and figure 41 , there appeared to be no significant wear on the surface. The surface therefore was not degraded to cause a drop in hardness.

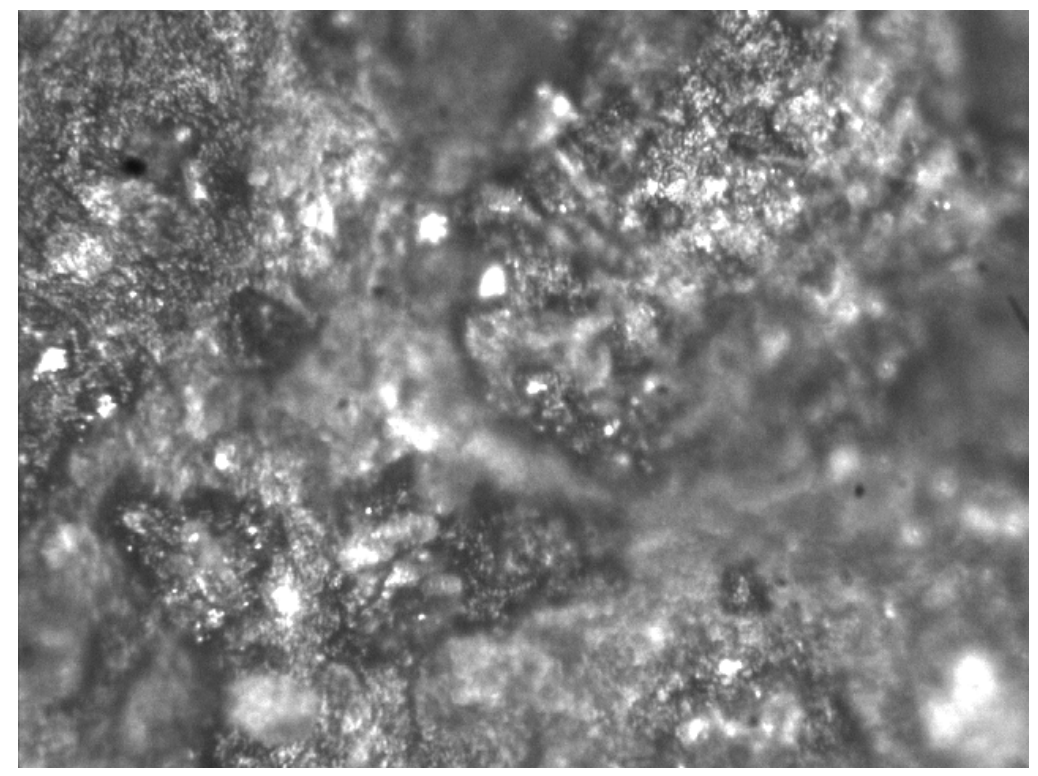

Figure 40 Surface microstructure of the WC coated ASB roll surface before the test

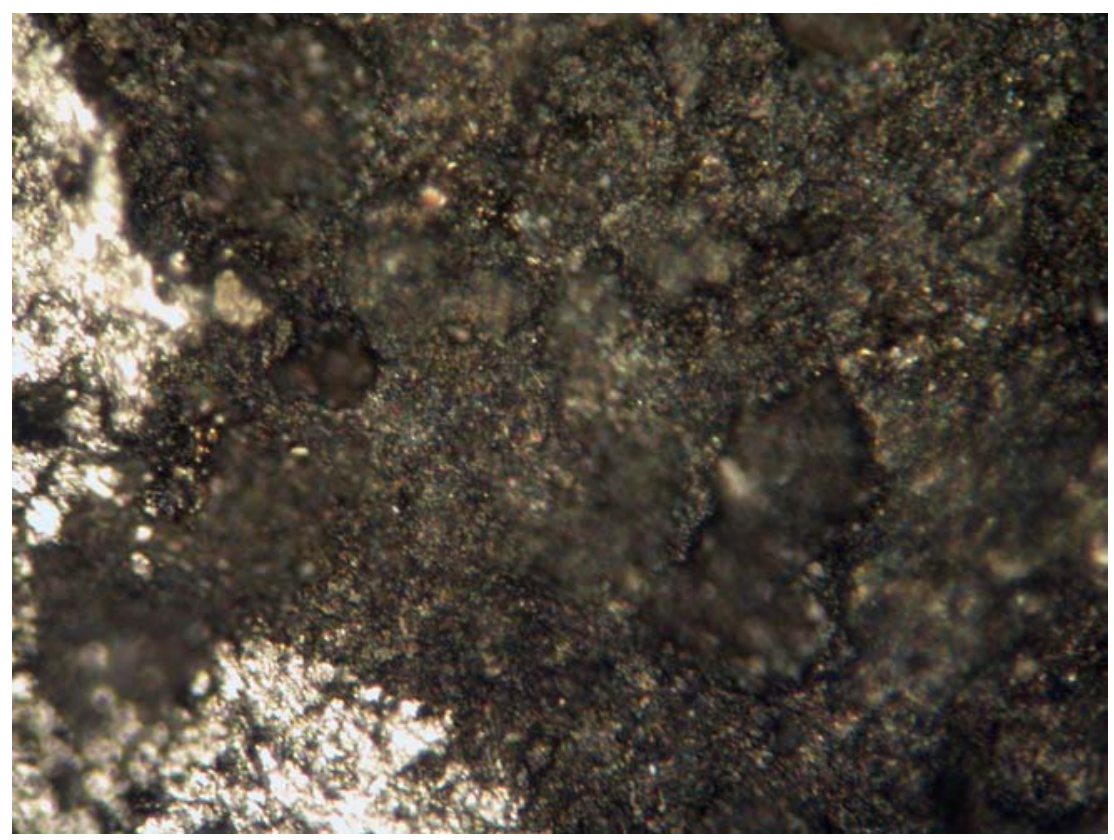

Figure 41 Surface microstructure of WC coated ASB roll surface after the 6th cycle 


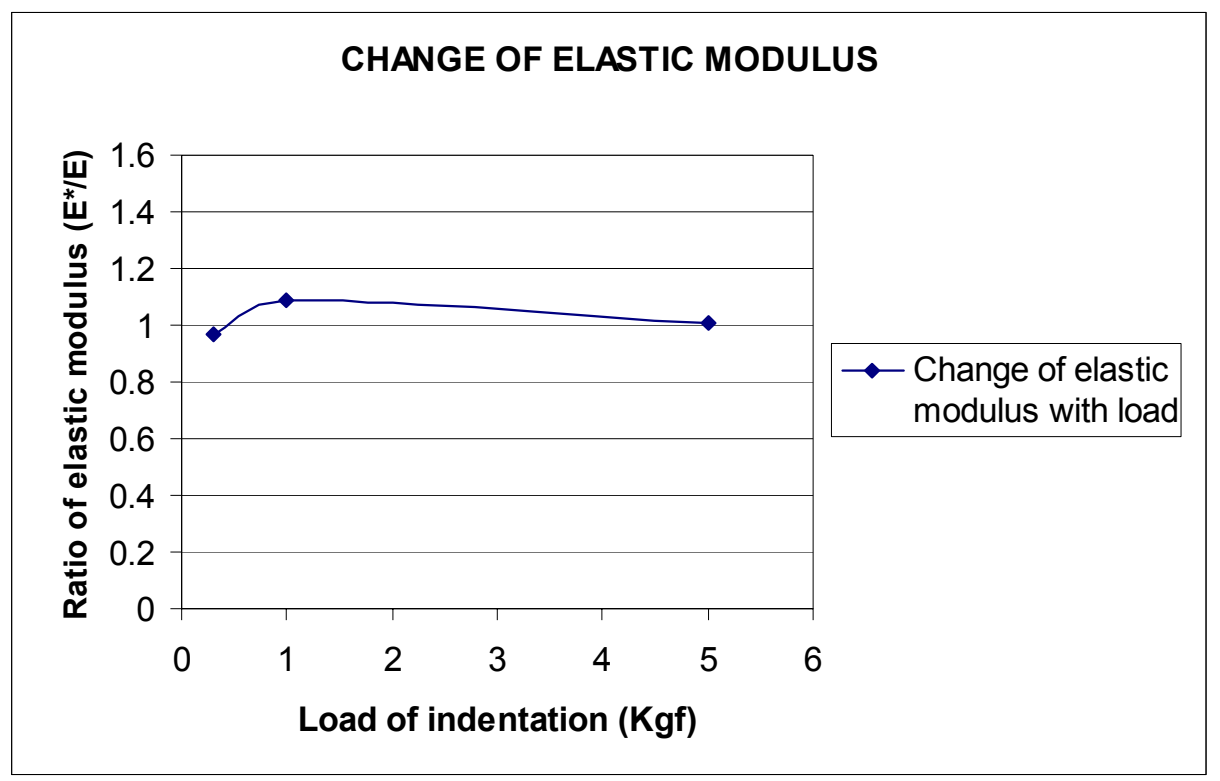

Figure 42 Ratio of elastic modulus after the test to the elastic modulus before the test as a function of load of indentation

The change in elastic modulus was calculated by plugging in the frequency shift values into the basic equation of Krautkramer hardness tester. The plot is shown in figure 42.There was no appreciable change in the elastic modulus as the elastic modulus ratios before and after the test was nearly same. Therefore there was no appreciable degradation of the WC coated ASB roll surface. 


\section{CHAPTER 5}

\section{CONCLUSION AND RECOMMENDATIONS}

The measurement of hardness and elastic modulus change in pot hardware materials has provided valuable insight into the issue of surface degradation.

A consistent drop in hardness and elastic modulus was observed in all the test materials.

In CF3M coated with tungsten carbide laser clad coating, the drop in hardness is due to the decrease in the density of WC particles caused due to the wearing and corrosion effect.This is evident from figures 17, 22 and 24 . The density decrease affects the ultrasonic wave properties and causes the instrument to show a decreased hardness value. From figures 17, 22 and 24, it can be inferred that the decrease in WC particles and the corrosion effect are the reasons for the decrease in surface elastic modulus.

The drop in hardness in the Stellite 6 sleeve can be attributed to the formation of a cobalt depletion zone due to cobalt dissolution into the bath. This is evident from figures 30

through 33. Grooves are formed on the Stellite 6 sleeve due to the abrasive action of CoAl intermetallic particles as seen from figures 28,29 and 30. This brings about a decrease in surface density. The combined effect of the depletion zone and the grooves could be the reason for the drop in hardness and elastic modulus.

Hardness tests conducted on an actual specimen of stellite 6 from AK steel indicated similar hardness values for a load of $0.3 \mathrm{Kgf}$ and $1 \mathrm{Kgf}$. The $5 \mathrm{Kgf}$ probe however indicated a higher value for the lab scale test specimen compared to the actual specimen. A thicker depletion zone could be a possible reason for this change in hardness value. It is therefore recommended to perform elemental composition analysis on the cross section of the actual test specimen to determine the depth of the depletion zone. 
Metaullics MSA 2012 alloy is predominantly an iron based matrix with molybdenum and tungsten present as the alloy strengthening phase. No reaction layer could be found on the wearing surface.

From figure 37 it can be inferred that the drop in hardness and elastic modulus in Metaullics MSA 2012 alloy is due to the corrosion of zinc. The vacancy channels formed due to the wearing could have initiated the corrosion of the matrix as seen from figure 36 . CF3M coated with Tungsten carbide spray coating was run against the low carbon steel. The surface degradation was considerably less as seen from figures 40 and 41 . Due to this there was no appreciable change in hardness or elastic modulus of the sleeve.

It can be concluded from the results that the surface degradation could affect the hardness and elastic modulus considerably and could be a factor affecting the life of pot hardware. The Krautkramer hardness tester is highly suitable for measuring hardness of materials that undergo surface degradation due to exposure to harsh environment. This is made possible by the unique working principle of the instrument coupled with the ability to interchangeable loads thereby facilitating the measurement of surface conditions at various depths.

It is recommended to device a procedure to conduct hardness tests on the pot hardware materials in the actual galvanizing lines after short runs. The results can then be compared with the short term testing done using the lab scale test set up. 


\section{REFERENCES}

1. V. Parthasarathy "Long Term Performance of Pot Hardware in Continuous Galvanizing Lines," Master's Thesis, West Virginia University, WV, USA, 2003.

2. K. Zhang, N.Y Tang, and F.E. Goodwin, "Effects of bearing design on the wear of a journal bearing sliding in molten zinc," Teck Cominco Metals Ltd, $44^{\text {th }}$ MWSP Conference Proceedings, Vol.XL, pp 1285-1297, 2002.

3. "Material Hardness", CALCE Test Services and Failure Analysis (TSFA) Laboratory, University of Maryland, College Park, MD. See Internet Posting: http://www.calce.umd.edu/general/Facilities/Hardness_ad_htm

4. "Nanoindentation Hardness Testing”, Handbook of Analytical Methods, Materials Evaluation and Engineering, Inc., Plymouth, MN. See Internet Posting: http://www.mee-inc.com/nano.html

5. "Vickers Hardness (Test)", Dictionary of Metallurgy, Renimex Inc., Ontario, Canada. See internet Posting: http://www.steelmill.com/Dictionary/dictionaryofmetallurgySZ.html

6. F. Stefan, "Portable Hardness Testing- Application Guide".

7. “Attenuation: Ultrasonic Testing", Nondestructive Testing Encyclopedia, The eJournal of Nondestructive Testing. See Internet Posting: http://www.ndt.net/article/az/ut_idx.htm

8. A. Kumar, V. Shankar, T.Jayakumar, K.Bhanu Sankara Rao and B. Raj, "Effect of precipitates on the correlation of ultrasonic velocity with mechanical properties in Ni based super alloy INCONEL 625”. $8^{\text {th }}$ ECNDT, v 8, n 6 
Barcelona, Spain, June 2002. See Internet Posting: http://www.ndt.net/article/ecndt02/116/116.htm

9. A. E. Brown, "Rationale and summary of methods for determining ultrasonic properties of materials at Lawrence Livermore National Laboratory", Report Submitted to US Department of Energy, Report Number: UCRL-ID-119958. See Internet Posting: http://www.ndt.net/article/brown/us_prop4.htm

10. Laser clad pot roll sleeves and bushings for galvanizing baths, US Patent Number 6,037,287 issued November-26-1997.

11. D.S Forsyth, R.D Leblanc, A. Fahr, A. Maslauhi, A. Moreau, " Practical ultrasonic techniques for assessment of heat damages in 7050 aluminum alloy", The e-Journal of Nondestructive Testing, v 2, n 11, Nov 1997. See Internet Posting: http://www.ndt.net/article/aero1197/forsyth/forsyth.htm

12. K. Zhang, L. Battiston, "Friction and wear characteristics of some cobalt and iron based super alloys in zinc alloy bath”. Wear, v.252, n.3-4, 332-344, Feb 2002.

13. J.M. Snider II, "Zinc Pot Bearing Material Wear and Corrosion Characterization," Ph.D. Dissertation, West Virginia University, WV, USA, 2004.

14. X. Liu, S. Rangarajan, E. Barbero and M.Yao, "Corrosion of Several alloys in Industrial Hot dipping baths,".Galvatech conference proceedings, Chicago ,USA pp 629-636,2004.

15. V.Parthasarathy, B.S.J. Kang, A. Krishnaswamy, K. Huat, E. Barbero, K.M. Chang, C. Irwin, F. Goodwin, “ Long time performance of pot hardware in continuous galvanizing line,’Galvatech conference proceedings, Chicago, USA, pp 637-648, 2004. 
16. K.Zhang, N-Y-Tang and A.B.File "A Practical approach to Enhance Wear Resistance of Bearing in molten Zinc", Galvanizer's Association Proceedings, 2002.

17. C.H.Gur "Investigation of microstructure-ultrasonic velocity relationship in SiCparticle reinforced aluminum matrix composites", Materials science and Engineering A, v 361, n1-2, Nov 25, 2003, pp 29-35. 


\section{APPENDIX A}

\section{ELASTIC MODULUS CALCULATIONS}

\section{A.1 Introduction}

Basic equation for the operating principle of Krautkramer MIC 10 DL hardness tester

$$
\Delta \mathbf{f} \approx \mathbf{E} \times \sqrt{ } \mathbf{A}
$$

Where

$\Delta \mathrm{f}=$ Ultrasonic frequency shift

$\mathrm{E}=$ Elastic modulus of the material

$\mathrm{A}=$ Area of indentation

$\mathrm{A}=\mathrm{P} / \mathrm{HV}$

Where

$\mathrm{P}=$ Applied probe load

$\mathrm{HV}=$ Vickers hardness

Affected zone can be calculated using the equation

$$
\mathbf{D}=\mathbf{0 . 0 6 2} \sqrt{ }(\mathbf{P} / \mathrm{HV})
$$




\section{A.2 Material: 316 LS Coated with WC Laser Clad Coating}

Before the test

\begin{tabular}{|c|c|c|c|c|c|}
\hline Indentation & Frequency & Vickers & Area of & Vickers & Area of \\
load, & shift, & hardness & indentation, & hardness & indentation \\
P & $\Delta \mathrm{f}$ & using & $\mathrm{A}=\mathrm{P} / \mathrm{HV}$ & using & using optical \\
& $(\mathrm{KHz})$ & Newage & $(\mathrm{mm} 2)$ & Krautkramer & microscope \\
& & system, & & tester & (mm2) \\
\hline 0.3 & 0.005226 & 1312 & 0.0022 & 1232 & 0.006 \\
\hline 1 & 0.0211 & 1264 & 0.007911 & 1360 & 0.0407 \\
\hline 5 & 0.03228 & Not & Not available & 1227 & \\
\hline
\end{tabular}

Table 13 Hardness and frequency shift values for WC laser clad coating before the test 
After the test

\begin{tabular}{|c|c|c|c|c|c|}
\hline Indentation & Frequency & Vickers & Area of & Vickers & Area of \\
\hline load, & shift, & hardness & indentation & hardness & indentation \\
\hline $\mathrm{P}$ & $\Delta \mathrm{f}$ & using & $\mathrm{A}=\mathrm{P} / \mathrm{HV}$ & using & using optical \\
\hline \multirow[t]{3}{*}{ (Kgf) } & (KHz.) & Newage & $(\mathrm{mm} 2)$ & Krautkramer & microscope \\
\hline & & system, & & tester & $(\mathrm{mm} 2)$ \\
\hline & & HV & & & \\
\hline 0.3 & 0.007009 & 568 & 0.00528 & 280 & \multirow{3}{*}{0.01212} \\
\hline 1 & 0.03154 & 513 & 0.01949 & 650 & \\
\hline 5 & 0.03326 & $\begin{array}{c}\text { Not } \\
\text { available }\end{array}$ & Not available & 1349 & \\
\hline
\end{tabular}

Table 14 Hardness and frequency shift values for WC laser clad coating after the test

\section{Calculation}

From the basic krautkramer equation,

$E^{*} / E=(\sqrt{ } \mathrm{A} \times \Delta f) /\left(\sqrt{ } A^{*} \times \Delta f^{*}\right)$ where

$\mathrm{E}^{*}=$ Elastic modulus after the test

$\mathrm{E}=$ Elastic modulus before the test

$\mathrm{A}^{*}=$ Area of indentation after the test

$\mathrm{A}=$ Area of indentation before the test

$\Delta \mathrm{f}^{*}=$ Frequency shift after the test

$\Delta \mathrm{f}=$ Frequency shift before the test 
Substituting the values from the table,

\begin{tabular}{|c|c|}
\hline Indentation load, P ( Kgf) & Ratio of elastic modulus ( $\left.\mathrm{E}^{*} / \mathrm{E}\right)$ \\
\hline 0.3 & 0.88 \\
\hline 1 & 0.95 \\
\hline 5 & 1.08 \\
\hline
\end{tabular}

Table 15 Change of elastic modulus for WC laser clad sleeve

Affected zone $=11.9 \mu \mathrm{m}$

\section{A.2 Material: Stellite 6}

Before the test

\begin{tabular}{|c|c|c|c|c|c|}
\hline Indentation & Frequency & Vickers & Area of & Vickers & Area of \\
\hline load, & shift, & hardness & indentation, & hardness using & indentation using \\
\hline $\mathrm{P}$ & $\Delta \mathrm{f}$ & using & $\mathrm{A}=\mathrm{P} / \mathrm{HV}$ & Krautkramer & optical \\
\hline \multirow[t]{3}{*}{ (Kgf) } & (KHz.) & Newage & $(\mathrm{mm} 2)$ & tester & microscope \\
\hline & & system, & & & $(\mathrm{mm} 2)$ \\
\hline & & HV & & & \\
\hline 0.3 & 0.00566 & 291 & 0.0103 & 416 & 0.00634 \\
\hline 1 & 0.02198 & 350 & 0.0285 & 350 & 0.018 \\
\hline 5 & 0.0359 & $\begin{array}{c}\text { Not } \\
\text { available }\end{array}$ & $\begin{array}{c}\text { Not } \\
\text { available }\end{array}$ & 590 & 0.0847 \\
\hline
\end{tabular}

Table 16 Hardness and frequency shift values for Stellite 6 sleeve before the test 
After the test

\begin{tabular}{|c|c|c|c|c|c|c|}
\hline Indentation & Frequency & Vickers & Area of & Vickers & Area of & Depth of \\
\hline load, & shift, & hardness & indentation, & hardness & indentation & indentation \\
\hline $\mathrm{P}$ & $\Delta \mathrm{f}$ & using & $\mathrm{A}=\mathrm{P} / \mathrm{HV}$ & using & using optical & $(\mu \mathrm{m})$ \\
\hline (Kgf) & (KHz.) & Newage & $(\mathrm{mm} 2)$ & Krautkramer & microscope & \\
\hline & & system, & & tester & $(\mathrm{mm} 2)$ & \\
\hline & & HV & & & & \\
\hline 0.3 & 0.00832 & 165 & 0.01817 & 182 & \multirow{3}{*}{$\begin{array}{l}0.0281 \\
0.1288\end{array}$} & 7.9 \\
\hline 1 & 0.040514 & 343 & 0.02915 & 145 & & 16.2 \\
\hline 5 & 0.0478 & $\begin{array}{c}\text { Not } \\
\text { available }\end{array}$ & Not available & 388 & & 22.2 \\
\hline
\end{tabular}

Table 17 Hardness and frequency shift values for Stellite 6 sleeve after the test

\section{Calculation}

From the basic krautkramer equation,

$E^{*} / E=(\sqrt{ } \mathrm{A} \times \Delta f) /\left(\sqrt{ } A^{*} \times \Delta f^{*}\right)$ where

$\mathrm{E}^{*}=$ Elastic modulus after the test

$\mathrm{E}=$ Elastic modulus before the test

$\mathrm{A}^{*}=$ Area of indentation after the test

$\mathrm{A}=$ Area of indentation before the test

$\Delta \mathrm{f}^{*}=$ Frequency shift after the test

$\Delta \mathrm{f}=$ Frequency shift before the test

Substituting the values from the table, 


\begin{tabular}{|c|c|}
\hline Indentation load, P ( Kgf) & Ratio of elastic modulus ( E*/E) \\
\hline 0.3 & 0.85 \\
\hline 1 & 0.843 \\
\hline 5 & 0.925 \\
\hline
\end{tabular}

Table 18 Change of elastic modulus for Stellite 6 sleeve

Affected zone (Cobalt depletion zone $)=20 \mu \mathrm{m}$

\section{A.3 Material: Metaullics MSA 2012}

Before the test

\begin{tabular}{|c|c|c|c|c|c|}
\hline Indentation & Frequency & Vickers & Area of & Vickers & Area of \\
\hline load, & shift, & hardness & indentation, & hardness & indentation \\
\hline $\mathrm{P}$ & $\Delta \mathrm{f}$ & using & $\mathrm{A}=\mathrm{P} / \mathrm{HV}$ & using & using optical \\
\hline \multirow[t]{3}{*}{ (Kgf) } & (KHz.) & Newage & $(\mathrm{mm} 2)$ & Krautkramer & microscope \\
\hline & & system, & & tester & $(\mathrm{mm} 2)$ \\
\hline & & HV & & & \\
\hline 0.3 & 0.00429 & 838 & 0.00358 & 838 & 0.00447 \\
\hline 1 & 0.0169 & 845 & 0.0118 & 845 & 0.009 \\
\hline 5 & 0.0346 & $\begin{array}{c}\text { Not } \\
\text { available }\end{array}$ & Not available & 865 & 0.0578 \\
\hline
\end{tabular}

Table 19 Hardness and frequency shift values for MSA 2012 sleeve before the test 
After the test

\begin{tabular}{|c|c|c|c|c|c|}
\hline Indentation & Frequency & Vickers & Area of & Vickers & Area of \\
load, & shift, & hardness & indentation, & hardness & indentation \\
P & $\Delta \mathrm{f}$ & using & $\mathrm{A}=\mathrm{P} / \mathrm{HV}$ & using & using optical \\
& $(\mathrm{KHz})$ & Newage & $(\mathrm{mm} 2)$ & Krautkramer & microscope \\
& & system, & & tester & $(\mathrm{mm} 2)$ \\
\hline 0.3 & 0.011 & 102 & 0.0294 & 291 & 0.042 \\
\hline 1 & 0.0455 & 170 & 0.0588 & 454 & 0.0697 \\
\hline 5 & 0.0624 & Not & Not available & 717 & \\
\hline
\end{tabular}

Table 20 Hardness and frequency shift values for MSA 2012 sleeve after the test

\section{Calculation}

From the basic krautkramer equation,

$E^{*} / E=(\sqrt{ } \mathrm{A} \times \Delta f) /\left(\sqrt{ } A^{*} \times \Delta f^{*}\right)$ where

$\mathrm{E}^{*}=$ Elastic modulus after the test

$\mathrm{E}=$ Elastic modulus before the test

$\mathrm{A}^{*}=$ Area of indentation after the test

$\mathrm{A}=$ Area of indentation before the test

$\Delta \mathrm{f}^{*}=$ Frequency shift after the test

$\Delta \mathrm{f}=$ Frequency shift before the test

Substituting the values from the table, 


\begin{tabular}{|c|c|}
\hline Indentation load, P ( Kgf) & Ratio of elastic modulus ( E*/E) \\
\hline 0.3 & 0.89 \\
\hline 1 & 1.2 \\
\hline 5 & 1.18 \\
\hline
\end{tabular}

Table 21 Change of elastic modulus for Metaullics MSA 2012 sleeve

Affected zone $=16.3 \mu \mathrm{m}$

\section{A.4 Material: CF3M with Tungsten Carbide ASB Coating}

Before the test

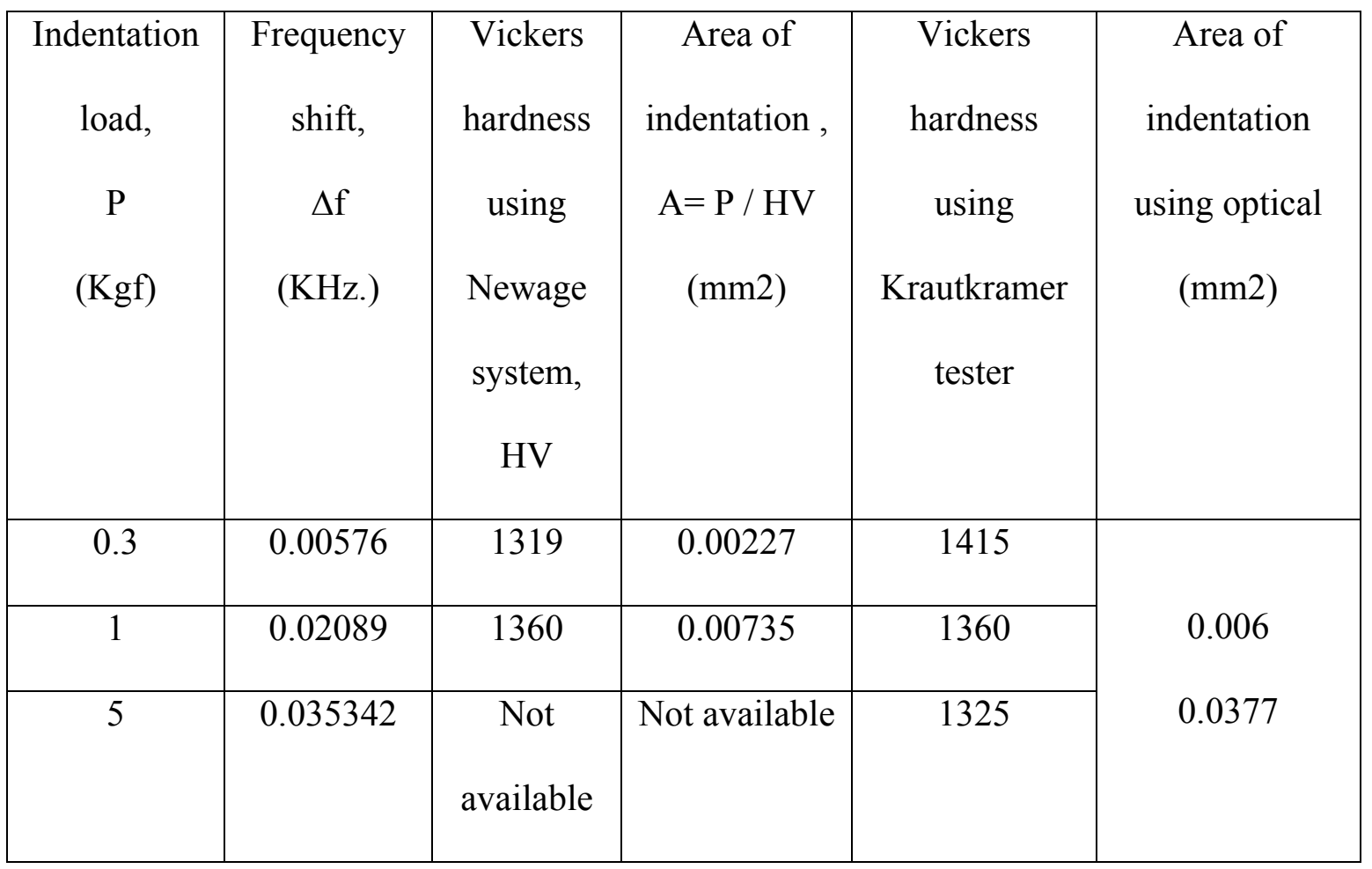

Table 22 Hardness and frequency shift values for WC ASB coating before the test 
After the test

\begin{tabular}{|c|c|c|c|c|c|}
\hline Indentation & Freauency & Vickers & Area of & Vickers & A rea of \\
\hline load, & shift, & hardness & indentation & hardness using & indentation using \\
\hline $\mathrm{P}$ & $\Delta \mathrm{f}$ & using & $\mathrm{A}=\mathrm{P} / \mathrm{HV}$ & Krautkramer & optical microscope \\
\hline \multirow[t]{3}{*}{ (Kgf) } & (KHz.) & Newage & $(\mathrm{mm} 2)$ & tester & $(\mathrm{mm} 2)$ \\
\hline & & system, & & & \\
\hline & & HV & & & \\
\hline 0.3 & 0.005425 & 1394 & 0.00215 & 1335 & \multirow{3}{*}{0.00869} \\
\hline 1 & 0.02421 & 1220 & 0.00819 & 1300 & \\
\hline 5 & 0.03873 & $\begin{array}{c}\text { Not } \\
\text { available }\end{array}$ & $\begin{array}{c}\text { Not } \\
\text { available }\end{array}$ & 1136 & \\
\hline
\end{tabular}

Table 23 Hardness and frequency shift values for WC ASB coating after the test

\section{Calculation}

From the basic krautkramer equation,

$\mathrm{E}^{*} / \mathrm{E}=(\sqrt{\mathrm{A}} \mathrm{x} \Delta \mathrm{f}) /\left(\sqrt{ } \mathrm{A}^{*} \mathrm{x} \Delta \mathrm{f}^{*}\right)$ where

$\mathrm{E}^{*}=$ Elastic modulus after the test

$\mathrm{E}=$ Elastic modulus before the test

$\mathrm{A}^{*}=$ Area of indentation after the test

$\mathrm{A}=$ Area of indentation before the test

$\Delta \mathrm{f}^{*}=$ Frequency shift after the test

$\Delta \mathrm{f}=$ Frequency shift before the test 
Substituting the values from the table,

\begin{tabular}{|c|c|}
\hline Indentation load, P ( Kgf) & Ratio of elastic modulus ( E*/E) \\
\hline 0.3 & 0.97 \\
\hline 1 & 1.09 \\
\hline 5 & 1.01 \\
\hline
\end{tabular}

Table 24 Change of elastic modulus for ASB roll surface 